UNIVERSIDAD POLITÉCNICA DE MADRID

Facultad de Ciencias de la Actividad Física y del Deporte (INEF)

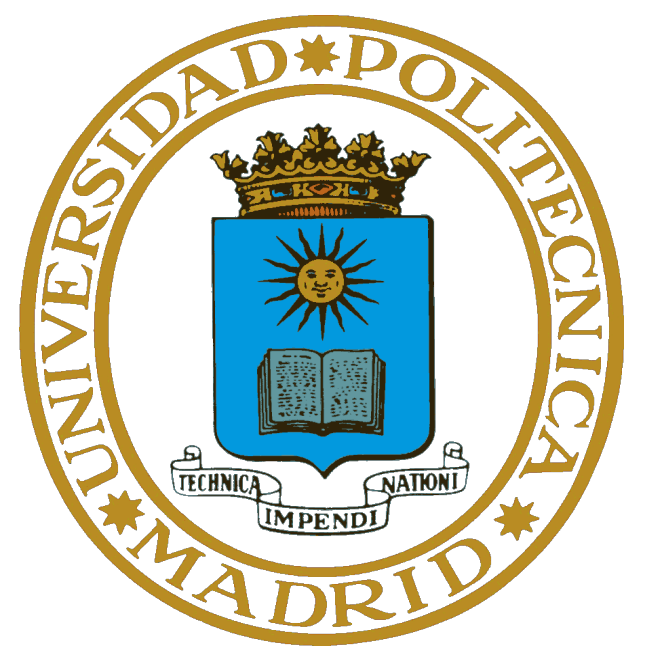

\title{
EVOLUTION OF TECHNICAL AND PHYSICAL MATCH PERFORMANCES IN THE CHINESE SOCCER SUPER LEAGUE
}

\author{
Tesis Doctoral \\ D. Changiing Zhou \\ 周长敬
}





\section{POLITÉCNICA}

\section{UNIVERSIDAD POLITÉCNICA DE MADRID}

Facultad de Ciencias de la Actividad Física y del Deporte (INEF)

\section{EVOLUTION OF TECHNICAL AND PHYSICAL MATCH PERFORMANCES IN THE CHINESE SOCCER SUPER LEAGUE}

TESIS DOCTORAL

D. Changjing Zhou

Madrid, 2020 

DEPARTAMENTO DE CIENCIAS DE LA ACTIVIDAD FÍSICA, DEL DEPORTE Y DEL OCIO

Facultad de Ciencias de la Actividad Física y del Deporte (INEF)

\title{
EVOLUTION OF TECHNICAL AND PHYSICAL MATCH PERFORMANCES IN THE CHINESE SOCCER SUPER LEAGUE
}

\author{
AUTOR: \\ D. Changjing Zhou \\ Master's Degree in Sports Training \\ Beijing Sport University \\ DIRECTORES:
}

Dr. Alberto Lorenzo Calvo, Doctor en Ciencias de la Actividad Física y del Deporte, Universidad Politécnica de Madrid.

Dr. Miguel Ángel Gómez Ruano, Doctor en Ciencias de la Actividad Física y del Deporte, Universidad Politécnica de Madrid. 

Tribunal nombrado por el Magfco. y Excmo. Sr. Rector de la Universidad Politécnica de Madrid, el día......de. de 2020 .

Presidente: D................................................................ Vocal:

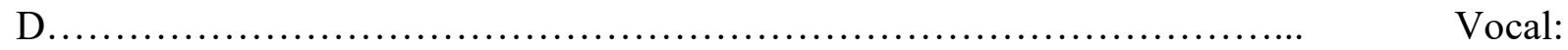

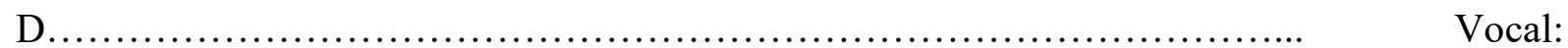

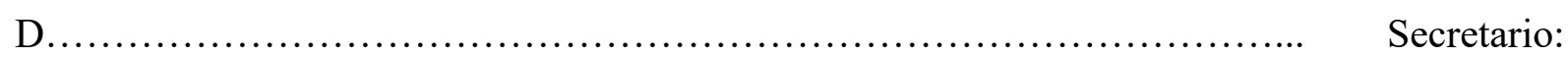

D..............................................................

Realizando el acto de defensa y lectura de la Tesis el día......de.................. de 2020. En.

Calificación.

EL PRESIDENTE

LOS VOCALES

EL SECRETARIO 



\begin{abstract}
As the most popular sport in the world, soccer is complex and unpredictable. The performance analysis in soccer has a relatively long history, but it is still very young when compared to other disciplines. Soccer has evolved across time because of changes of rules, match tactics and strategies, increases in professionalism, the use of new technologies, global exposure, and transformations in training and player selection process. Understanding these evolutionary tendencies can provide valuable information to estimate, for example, future match and training demands, to assist in the player selection and talent identification, or to predict the impact of rule changes. In practice, for the coach staff, they are not only required to be familiar with the demands of modern players in technical-tactical and physical aspects and potential impact of situational, environmental variables, even the influence of players' age on these match parameters, but also expected to understand the key performance indicators and their impact along the seasons when determining the match outcome.
\end{abstract}

Purpose: The general aim of the current $\mathrm{PhD}$. thesis is to analyse the modern trends in Chinese soccer performance, with specific reference to the physical and technical performance of matches played in the Chinese Soccer Super League (CSL) between 2012 and 2017. To achieve the aims of this research, this $\mathrm{PhD}$. thesis can be summarized in five chapters and separated into the following three sections. Firstly, identifying the match-related statistics which discriminate between winning, drawing and losing teams in the CSL (Chapter 2); secondly, modelling the effects of situational factors (match location, strength of team and opponent) and environmental-related factors (relative air humidity, temperature and air quality index) on the technical and physical match performance of the CSL (Chapter 3); then, exploring the evolution of physical and technical performance parameters in the CSL (Chapter 4) and determining whether the role of every performance indicator has varied from a long-term perspective (from 2012 season to 2017 season) (Chapter 5); finally, identifying the evolution and influence of 
players' age on the technical and physical match performances according to different playing positions in the CSL (Chapter 6).

Methods: Data of this PhD. thesis was collected from 1,429 CSL matches from the 2012 season to the 2017 season (six seasons) using a validated live football statistics system-Amisco Pro (Amisco, Nice, France). In Chapter 2, 1,056 balance matches (identified via clustering analysis) of six seasons were selected. Sixteen technical, eleven physical and two situational variables were analysed using one-way analysis of variance and discriminant analysis. While in the next study, the generalised mixed modelling was employed to determine the effects of situational factors (match location, strength of team and opponent) and environmental-related factors (relative air humidity, temperature and air quality index) on the technical and physical match performance, based on the data of all 240 matches in the season 2015 (Chapter 3). Fourteen technical performance-related indicators and 11 physical performance-related indicators were analysed using a mixed linear model for repeated measures, significant main effects of season on teams' performance were followed up using the Bonferroni correction (multiple comparisons) (Chapter 4). Seventeen technical performance-related indicators, eleven physical performance-related indicators and two situational variables (match location and quality of opposition) were analysed using the Binary logistic regression models to measure the level of association between these factors and match outcome (Win/Lose-draw) over the six seasons studied (Chapter 5). A total of 28,547 matches participation from 923 players (Five playing positions and four age groups) were collected during six seasons, 14 technical performancerelated parameters and six physical performance-related parameters were analysed using oneway analysis of variance to determine the difference between four age groups according to their playing position (Chapter 6).

Results: Study 1: The results showed that winning teams performed significantly better than losing-drawing teams in the following match-statistics: shots, shots on target, 50-50 challenge 
won, off-sides, sprinting distance, sprinting effort, sprinting distance in ball possession, highspeed-running distance in ball possession. Losing teams had significantly higher averages in crosses, passes, forward passes, sprinting distance out of ball possession, high-speed-running distance out of ball possession. Discriminant analysis showed that the variables that best discriminated between winning, drawing and losing teams were shots on target, sprinting distance in ball possession, quality of opposition, passes and forward passes.

Study 2: Increase in the rank difference would increase the number of goal-scoring related, passing and organising related actions to a small-to-moderate extent (Effect size (ES): 0.370.99). Match location had small positive effects on goal-scoring related, passing and organising related variables (ES: $0.27-0.51)$, while a small negative effect on yellow card $(\mathrm{ES}=-0.35)$. Increments in relative air humidity and air quality index would only bring trivial or small effects on all the technical performance (ES: -0.06-0.23). Increases in humidity would decrease the physical performance at a small magnitude (ES: -0.55--0.38). Teams achieved the highest number in the physical performance-related parameters at the temperature between 11.6 and $15.1{ }^{\circ} \mathrm{C}$.

Study 3: Although there were some irregularities, performance variables generally showed significant upward trends across the six seasons $(\mathrm{p}<0.05)$, resulting in significant increases from 2012 season to 2017 season in the total sprint distance $(2,069.7 \pm 509.3 \mathrm{~m}$ vs. $2,272 \pm 493.6 \mathrm{~m}$; $\mathrm{p}<0.001$; effect size [ES]: 0.40), number of sprints (100.1 \pm 22.8 vs. $104.8 \pm 20.8, \mathrm{p}<0.001$; ES: $0.22)$, high-speed distance $(2,568.4 \pm 503.5 \mathrm{~m}$ vs. $2,823.1 \pm 479.2 \mathrm{~m}$; $(\mathrm{p}<0.001$; ES: 0.52$)$, and high-speed effort $(187.5 \pm 36.1$ to $204.7 \pm 33.7$; $<<0.001$; ES: 0.49$)$. Furthermore, there were $\sim 23 \%$ more crosses $(\mathrm{p}<0.001$; ES: 0.45$), \sim 12 \%$ more shots on target $(\mathrm{p}<0.001$; ES: 0.22$)$, and $\sim 11 \%$ more opponent penalty area entries ( $<<0.001$; ES: 0.20$)$ in the 2017 season than in the 2012 season.

Study 4: The results revealed that shots on target, possession, total distance in possession of the 
ball, total distance out of ball possession, and match location exerted a decreased influence on winning the matches from 2012 to 2014 seasons. However, these indicators play a more important role in winning matches from 2014 to 2017 seasons. Additionally, the quality of opposition has a continuously increaseded negative effect on the match outcome.

Study 5: The running performance of players decreased as their ages increased, especially for high-intensity running. However, older wide midfielders and attackers (beyond 30 years) who are still playing in the league presented similar physical efforts. Full-backs and attackers performed more passes and forward passes as older the players are. Midfielders take more passes and crosses when they are near 30 years old. Midfielders and attackers have a higher shot ability (number of shots, shots accuracy) when they are older.

Conclusions: In the CSL, shots on target, sprinting distance in possession of the ball, quality of opposition, passes and forward passes had more power in discriminating match outcome in balance games. Situational variables had major effects on the technical performance and environmental-related factors affected mainly the physical performance. Besides, physical performance, especially high-intensity running distance, together with technical performance parameters, such as crosses, shots on target, and opponent penalty area entries, have increased over six seasons in the CSL. There are significant trends of factors influencing the match outcome: shots on target, possession, total distance out of ball possession; and match location exerted a decreased influence on winning from 2012 to 2014 season, while its impact increased after the 2014 season. The quality of opposition had an increasing negative influence on the match outcome over the seasons. Lastly, high-intensity running distance decreased as their ages increased. However, older wide midfielders and attackers (beyond 30 years) who are still playing in the league presented higher physical efforts. Midfielders take more passes and crosses when they are near 30 years old. Midfielders and attackers have a higher shot ability when they are older. 
Key words: Match analysis, Chinese soccer, longitudinal, evolution, physical fitness, match performance, soccer players, age, development, reference values/normative profile, performance indicator, situational variable, performance profile, environmental variable. 


\section{Resumen}

Siendo el deporte más popular del mundo, el fútbol es complejo e impredecible. El análisis del rendimiento en el fútbol tiene una historia relativamente larga, pero todavía es muy joven en comparación con otras disciplinas. El fútbol ha evolucionado a lo largo del tiempo debido a los cambios de las reglas, las tácticas y estrategias de los partidos, el aumento del profesionalismo, el uso de nuevas tecnologías, la exposición mundial y las transformaciones en el proceso de entrenamiento y selección de jugadores. La comprensión de estas tendencias evolutivas puede proporcionar información valiosa para estimar, por ejemplo, las futuras demandas de los partidos y los entrenamientos; ayudar en la selección de jugadores y la identificación de talentos, o predecir el impacto de los cambios de las reglas. En la práctica, el grupo técnico del equipo necesitan tanto estar familiarizados con las exigencias de los jugadores modernos en función de los aspectos técnico-tácticos y físicos, el posible impacto de las variables situacionales y ambientales, incluso la influencia de la edad sobre estos parámetros del partido, como comprender los indicadores clave del rendimiento y sus impactos a lo largo de las temporadas sobre el resultado del partido.

Propósito: El objetivo general de esta tesis es analizar la tendencia reciente del rendimiento del fútbol chino, con referencia específica al aspecto físico y técnico de los partidos que se jugaron en la Superliga de Fútbol China (CSL) entre 2012 y 2017. Para lograr los objetivos de esta investigación, esta tesis doctoral puede resumirse en cinco capítulos y separarse en las siguientes tres secciones. En el primer lugar, identificar los indicadores del rendimiento que discriminan entre los equipos ganadores, empatados y perdedores en la CSL (Capítulo 2). En el segundo lugar, modelar los efectos de los factores situacionales (lugar del partido, calidad del equipo y del oponente) y los factores ambientales (humedad relativa del aire, temperatura e índice de calidad del aire) sobre el rendimiento técnico-táctico y físico del partido en la CSL (Capítulo 3). Por el último, explorar la evolución de los parámetros de rendimiento técnico- 
táctico y físico en la CSL (Capítulo 4) y determinar si el papel de cada indicador de rendimiento se ha variado en función de largo plazo (desde la temporada 2012 hasta la temporada 2017) (Capítulo 5). Luego, identificar la evolución e influencia de la edad de los jugadores en el rendimiento técnico y físico de los partidos según las diferentes posiciones de juego en la CSL (Capítulo 6).

Métodos: Se recogieron los datos de 1.429 partidos de la CSL durante las temporadas 20122017 (seis temporadas) a través del sistema de estadística en fútbol—Amisco Pro (Amisco, Niza, Francia). En el Capítulo 2, 1.056 partidos equilibrados durante seis temporadas fueron identificado por el análisis de agrupación. Después, se compararon la diferencia en 16 variables técnicas, 11 físicas afectados por dos variables situacionales mediante un análisis unidireccional de la varianza y un análisis discriminante. En el siguiente Capítulo 3, se empleó el modelo mixto generalizado para determinar los efectos de factores situacionales (ubicación del partido, calidad del equipo y del oponente) y ambientales (humedad relativa del aire, temperatura e índice de calidad del aire) sobre el rendimiento técnico-táctico y físico de los partidos, utilizando datos de los 240 partidos de la temporada 2015. En el Capítulo 4, se analizaron 14 indicadores del rendimiento técnico-táctico y 11 indicadores físicos utilizando un modelo lineal mixto para medidas repetidas, y se hizo un seguimiento de los principales efectos significativos de la temporada utilizando la corrección de Bonferroni (comparaciones múltiples). En el Capítulo 5, las relaciones entre 17 indicadores del rendimiento técnico-táctico, 11 indicadores físicos y dos variables situacionales (lugar del partido y calidad del oponente) y el resultado del partido (ganar, perder y empatar) durante las 6 temporadas fueron analizado por el modelo de regresión logística binaria. En el Capítulo 6, se realizó un total de 28.547 participaciones en partidos de 923 jugadores (cinco posiciones de juego y cuatro grupos de edad) durante seis temporadas, se analizaron 14 parámetros relacionados con el rendimiento técnico y seis parámetros relacionados con el rendimiento físico mediante un análisis unidireccional de la 
varianza para determinar la diferencia entre cuatro grupos de edad según su posición de juego.

Los resultados: Estudio 1: Los resultados mostraron que los equipos ganadores rindieron significativamente mejor que los equipos empatados y perdedores en las siguientes variables: tiros, tiros a la puerta, desafío 50-50 ganado, fuera de juego, distancia de sprint, esfuerzo de sprint, distancia de sprint en posesión del balón, distancia de carrera a alta velocidad en posesión del balón. Los equipos perdedores tuvieron significativamente promedios más altos en cruces, pases, pases hacia adelante, distancia de sprint fuera de posesión, distancia de carrera a alta velocidad fuera de posesión. El análisis discriminante mostró que las variables que mejor discriminaban entre los equipos ganadores, empatados y perdedores fueron disparos a la portería, distancia de carrera corta en posesión, calidad del oponente, pases y pases hacia adelante.

Estudio 2: El aumento de la diferencia de rango aumentaría el número de acciones relacionadas con los goles, los pases y la organización con una medida de pequeña a moderada (Tamaño del efecto (ES): 0,37-0,99). El lugar del partido presentó pequeños efectos positivos sobre las variables relacionadas con los goles, los pases y la organización (ES: 0.27-0.51), mientras tuvo un pequeño efecto negativo sobre la tarjeta amarilla $(\mathrm{ES}=-0.35)$. Los incrementos en la humedad relativa del aire y el índice de calidad del aire sólo trajeron efectos triviales o pequeños sobre todo el rendimiento técnico (ES: -0.06-0.23). Los incrementos en la humedad reducieron el rendimiento físico con una pequeña magnitud (ES: -0.55--0.38). Los equipos alcanzaron el número más alto en los parámetros relacionados con el rendimiento físico a una temperatura entre 11,6 y $15,1^{\circ} \mathrm{C}$.

Estudio 3: Aunque hubo algunas irregularidades, las variables de rendimiento mostraron en general tendencias ascendentes significativas a lo largo de las seis temporadas $(\mathrm{p}<0,05)$ : la distancia total de sprint $(2.069,7 \pm 509,3 \mathrm{~m}$ versus $2.272 \pm 493,6 \mathrm{~m} ; \mathrm{p}<0,001$; ES: 0,40$)$, número de sprints $(100,1 \pm 22,8$ vs. $104,8 \pm 20,8, \mathrm{p}<0,001$; ES: 0,22$)$, distancia de alta velocidad $(2,568$. 
$4 \pm 503,5$ m vs. $2,823.1 \pm 479,2 \mathrm{~m}$; $\mathrm{p}<0,001$; ES: 0,52$)$, y esfuerzos de alta velocidad $(187,5 \pm 36,1$

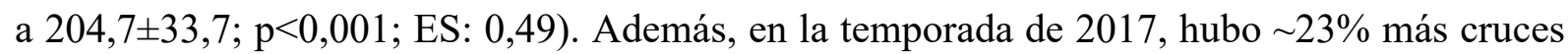
$(\mathrm{p}<0,001$; ES: 0,45), 12\% más tiros al blanco ( $\mathrm{p}<0,001$; ES: 0,22), $\mathrm{y} \sim 11 \%$ más entradas en el área de penalti del oponente $(\mathrm{p}<0,001$; ES: 0,20) que la de 2012.

Estudio 4: Los resultados revelaron que los tiros a la portería, la posesión, la distancia total en posesión, la distancia total fuera de posesión, y el lugar del partido ejercieron una menor influencia sobre la victoria de partidos durante las temporadas 2012 a 2014. Sin embargo, estos indicadores jugaron un papel más importante en la victoria de partidos durante las temporadas 2015 a 2017. Además, la calidad del oponente tiene un efecto negativo creciente sobre el resultado de partidos.

Estudio 5: El rendimiento de los jugadores disminuyó a medida que envejecieron, especialmente en la carrera de alta intensidad. Sin embargo, los mediocampistas y atacantes de mayor edad (más de 30 años) presentaron esfuerzos físicos similares con los más jóvenes. Los laterales y los delanteros realizaron más pases y pases de delantero cuando fueron más mayores. Los mediocampistas realizan más pases y cruces cuando fueron cerca de los 30 años. Los mediocampistas y los atacantes tuvieron una mayor capacidad de tiro cuando fueron mayores.

Conclusiones: En la CSL, los tiros a la portería, la distancia de sprint en posesión, la calidad del oponente, los pases y los pases al frente contribuyeron más para discriminar el resultado del partido en los juegos equilibrados. Las variables situacionales tuvieron efectos importantes en el rendimiento técnico, y los factores ambientales afectaron principalmente al rendimiento físico. Además, el rendimiento físico, especialmente las distancias recorridas en alta intensidad, junto con los parámetros de rendimiento técnico-táctico, como los cruces, los tiros a la portería y las entradas en el área de penalti del oponente, han aumentado a lo largo de seis temporadas. Hay unas tendencias significativas de los factores que influyen en el resultado del partido: los tiros a la portería, la posesión, la distancia total en posesión y el lugar del partido ejercieron una 
menor influencia sobre la victoria de partido durante las temporadas 2012 a 2014 y su impacto se aumentó a partir de la temporada 2014. La calidad del oponente presentó una influencia negativa creciente en el resultado del partido. Por último, La distancia de carrera de alta intensidad disminuyó a medida que su edad aumentaba. Sin embargo, los mediocampistas y atacantes de mayor edad (más de 30 años) presentaron esfuerzos físicos similares con los más jóvenes. Los laterales y los delanteros realizaron más pases y pases de delantero cuando fueron más mayores. Los mediocampistas realizan más pases y cruces cuando fueron cerca de los 30 años. Los mediocampistas y los atacantes tuvieron una mayor capacidad de tiro cuando fueron mayores.

Palabras clave: Análisis de partidos, fútbol chino, longitudinal, evolución, aptitud física, rendimiento en partidos, jugadores de fútbol; edad, desarrollo, valores de referencia/perfil normativo, indicador de rendimiento, variable situacional, perfil de rendimiento, variable ambiental. 


\section{Declaration}

I, Changjing Zhou, declare that the Doctor of Philosophy thesis entitled "Evolution of Chinese Soccer" is no more than 100,000 words in length including quotes and exclusive of tables, figures, appendices, bibliography, references and footnotes. This $\mathrm{PhD}$. thesis contains no material that has been submitted previously, in whole or in part, for the award of any other academic degree or diploma. Except where otherwise indicated, this thesis is my own work.

Signature:

Date: 


\section{Sponsorship}

This doctoral thesis was sponsored by the China Scholarship Council (CSC) from the Ministry of Education of P.R. China under Grant [(2016) 3100]

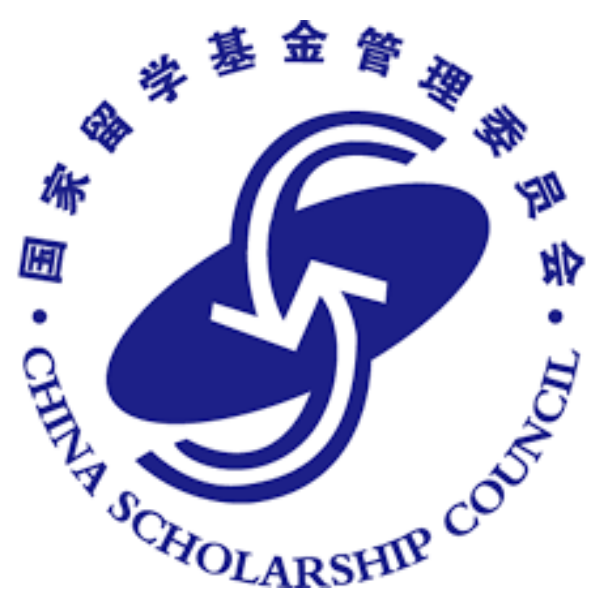




\section{Dedication}

To my parents and relatives

To my wife and future children 


\section{Dedicación}

A mis padres y familiares

A mi mujer y a mis hijos venideros 
谨献给

为我无私奉献的父母及亲人

我的妻子和未来的儿女 


\section{Acknowledgement}

When I started thinking about this topic, I realized that I was about to leave. I will leave Spain, Madrid where I have had a wonderful time. At this moment, my heart is full of sadness. I have been an anxious person, however, I wanted time to pass slowly, more slowly at this moment. First of all, I want to thank my three supervisors. Alberto Lorenzo. His attitude towards the profession and science has deeply affected me. I have learned a lot from him, who has taught me to manage family and career and to analyse a scientific problem with objectivity. Without a doubt, I have benefited greatly from the creative academic thinking of Miguel-Ángel Gómez who is my second supervisor. He is an intelligent man always with diverse fascinating ideas. He always tells me to be calm, do it slowly both in the study and in daily life. Many thanks also for his help during the period when I was applying to study at INEF. I want to thank my dear international supervisor José Manuel Palao, who has guided me in academic research as much as he gave me many tips on the details of the work. His attitude towards family and work has also affected me a lot.

In the meantime, I want to thank Luis Miguel for the office he has offered us during our study abroad. Many thanks to professors Carlos Lago, Sam Robertson and Hongyou Liu for their advice and sincere help in writing my $\mathrm{PhD}$. thesis.

Secondly, thanks to my dear relatives: my parents, my brother and my sister-in-law. Thank you for your support and encouragement. Above all, I want to give my sincere thanks to my wife, Mrs. Yao Chen, a beautiful girl whom I married during my stay abroad. She was who made me work harder and convinced me more of my original choice. She was who made everything meaningful. Although we are separated by the distance, she always gave me a lot of spiritual support.

Thanks to Spain. I have fulfilled my dream of being a soccer player. Here I joined a Spanish soccer team - CANTERA F.C. Although it is not a professional one, training and weekly 
matches have made me feel the amazing football environment in Spain. I learned a lot from the precious experience that will have a great impact on my future career as a coach. At the same time, I would thank the football teammates of "Original Madrid". Playing football with you was the happiest moment I had in Madrid. Thanks to the brothers and sister of INEF, thanks for your help and support. Thanks to my dear roommates during these three years. You make me feel the warmth of home in a foreign country.

Finally, thanks to my country, thanks to the China Scholarship Committee for funding both in the study and in life and for the opportunity offered to come to Spain to study. With all that, I have been able to finish the study career and fulfil my dream.

There are many to whom I wanted to thank, however, I cannot mention them one by one here. Thank you very much for appearing in my short study abroad career. Thank you very much for your help and motivation. 


\section{Agradecimientos}

Cuando empecé a pensar en este tema, me di cuenta de que ya estaba a punto de irme. Voy a salir de España, de Madrid donde he pasado un tiempo maravilloso. En este momento, mi corazón está lleno de tristeza. He sido una persona ansiosa, sin embargo, quería que el tiempo pasara despacio, aún más despacio.

En primer lugar, quiero agradecer a mis tres directores. Mi primer director, Alberto Lorenzo. Su actitud hacia la profesión y la ciencia me ha afectado profundamente. He aprendido mucho de este maestro, quien me ha enseñado a gestionar la familia y la carrera y a analizar un problema con objetividad. Sin ninguna duda, me he beneficiado enormemente del pensamiento creativo y académico de Miguel-Ángel Gómez. Es un hombre inteligente siempre con diversas ideas fascinantes. Siempre me dice que esté tranquilo, haga todo despacio tanto en el estudio como en la vida diaria. Muchas gracias también por tu ayuda durante el periodo cuando estaba solicitando estudiar en INEF. Quiero dar las gracias a mi querido director José Manuel Palao, quien me ha guiado en la investigación académica, tanto como me dio muchos consejos en los detalles del trabajo. Su actitud hacia la familia y el trabajo también me ha ayudado mucho.

Mientras tanto, quiero dar mi agradecimiento a Luis Miguel por la guía y ayuda que nos ha ofrecido durante nuestro estudio en un país extranjero.

Muchas gracias a los profesores Carlos Lago, San Robertson y Hongyou Liu por sus consejos y ayudas sinceras en la redacción de mi tesis doctoral.

En segundo lugar, gracias a mis queridos familiares: mis padres, mi hermano y mi cuñada. Gracias por su apoyo y estímulo. Sobre todo, quiero dar mi sincero agradecimiento a mi esposa, Sra. Yao Chen, una chica hermosa con la que me casé durante mi estancia en el extranjero. Fue ella quien me hizo trabajar más duro y me convenció más para seguir con mi elección original. Fue ella quien lo hizo todo significativo. A pesar de que estamos en diferentes países, ella siempre me da todo su apoyo espiritual. 
Gracias a España. He cumplido mi sueño de ser futbolista. Aquí me uní a un equipo de fútbol español- CANTERA F.C. Aunque no era profesional, el entrenamiento y los partidos semanales me han hecho sentir el cálido ambiente futbolístico de España. Aprendí mucho de la experiencia que tendrá un gran impacto en mi futura carrera como entrenador. A la vez, doy las gracias a los compañeros del equipo Yuan Dian. Jugar al fútbol con vosotros fue el momento más feliz que tuve en Madrid. Gracias a los hermanos y hermanas de INEF, gracias por vuestro ayuda y apoyo. Gracias a mis queridos compañeros de piso durante estos tres años. Me hacen sentir la calidez del hogar en un país extranjero.

Por último, gracias a mi país, gracias al Comité de Becas del Gobierno de China por la financiación tanto en el estudio como en la vida y por la oportunidad que me ofreció para poder venir a estudiar a España. Con todo ello, he podido terminar la carrera de estudiar el doctorado y cumplir mi sueño con tranquilidad.

Son muchos a los que quería dar gracias, sin embargo, no puedo mencionarlos uno por uno aquí. Muchas gracias por aparecer en mi corta carrera de estudio en el extranjero. Muchas gracias por su ayuda y motivación. 


\section{致谢}

当我开始思考这个话题, 我意识到我就要离开。离开西班牙, 离开马德里, 离开这一段 美好的时光。此时内心充满了失落。我一向是个很着急的人, 但是此刻我却想时间慢一 点，再慢一点。

首先, 我要感谢我的第一导师 Alberto Lorenzo Calvo。他在职业以及学术上的态度深深 影响了我。在他身上我学会了很多, 让我学会如何对待家庭, 如何对待事业, 如何理性 的分析问题。

其次, 我要感谢我的第二导师 Miguel-Ángel Gómez, 他在学术上的创新思维让我受益匪 浅。他很聪明, 并且有各种各样的想法。他一直教导我要淡定, 要慢慢来。也感谢他在 我申请来INEF读书时候的帮助。

同样, 我要感谢Luis Miguel在我们留学期间提供的办公室, 以及在学习和生活方面的指 导和帮助。

再次, 我要感谢我在美国交流期间的导师José Manuel Palao。在美国交流学习期间他不 仅在学术研究方面给我指导, 更在工作的一些细节中给了我很多建议。他对待家庭以及 工作的态度也让我受益匪浅。

感谢lago 和 Sam Robertson 以及刘鸿优教授在我文章书写过程中给的建议与帮助.

我要感谢我的家人, 感谢爸妈及哥哥, 嫂子在我留学期间给予的支持和鼓励。在这里尤 其感谢我的妻子, 陈瑶女士。在留学期间, 我迎娶了这位美丽的姑娘。是她让我更加努 力, 更加坚持我的留学选择, 让我觉得这一切更有意义。虽然我们分居两地, 但她在精 神上给予我很多支持和鼓励。

西班牙的生活和经历：来到西班牙, 完成了自己成为一名足球运动员的梦想, 我加入了 西班牙的一只足球队- CANTERA F.C. 虽然球队不是职业球队，但是每周的训练以及比 赛，让这段经历极其珍贵，它让我感受到西班牙的足球氛围。我从中学习，从中汲取营 养，我知道这段经历会对我以后的教练职业产生巨大影响。也非常感谢原点足球队的队 友们。感谢INEF 的师兄师弟及师妹，谢谢你们四年来的的帮助和支持。

最后, 感谢国家, 感谢留学基金委员会 (CSC)。感谢国家给与的学习以及生活上的资助 
, 让我有机会来到西班牙学习, 让我能安心的搞科研。

需要感谢的太多，却来不及一-提及你们的名字，谢谢你们出现在我的短暂的留学生涯 里, 给予我帮助, 给予我激励。 


\section{Table of Contents}

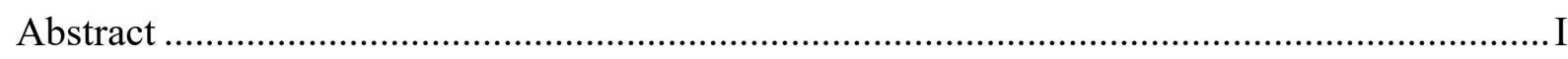

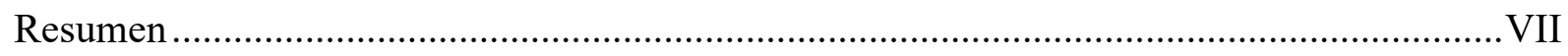

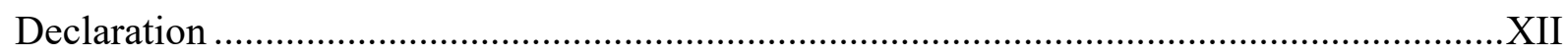

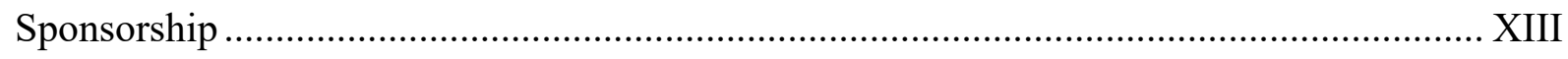

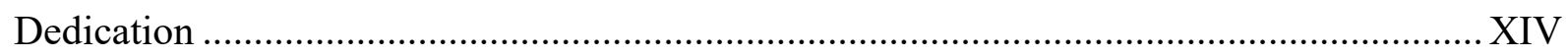

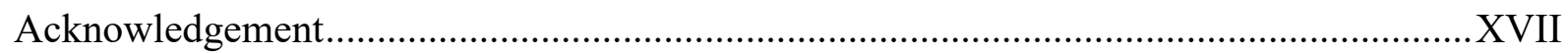

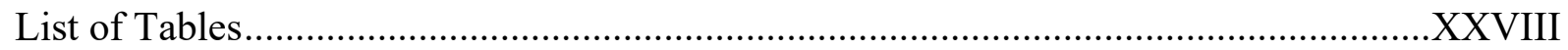

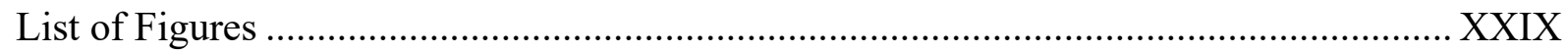

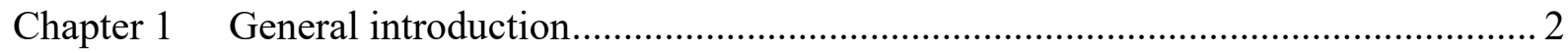

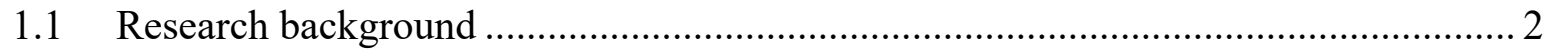

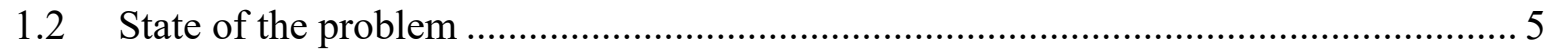

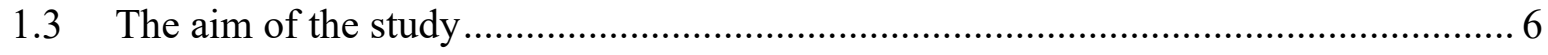

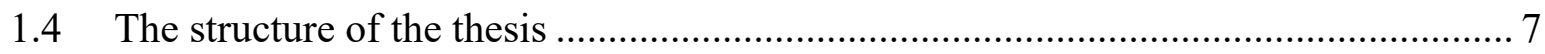

Chapter 2 Chinese soccer association super league, 2012-2017: key performance indicators

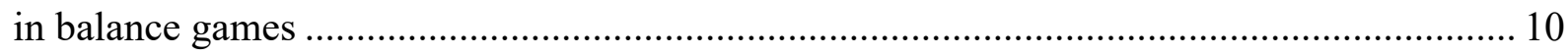

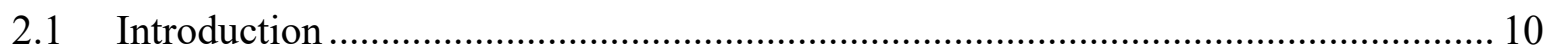

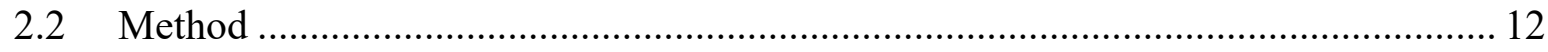

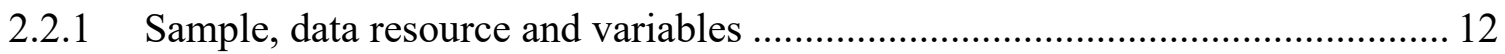

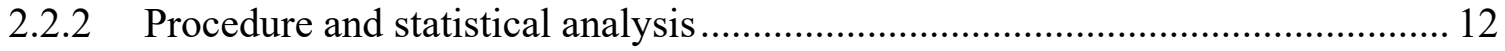

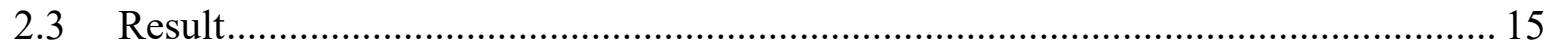




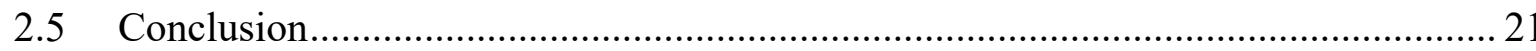

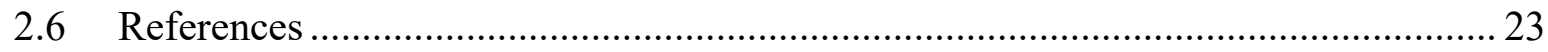

Chapter 3 Match Performance of Soccer Teams in the Chinese Super League: Effects of

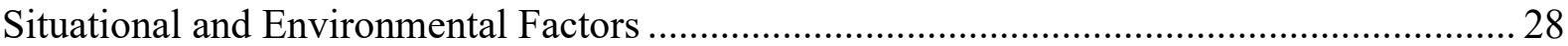

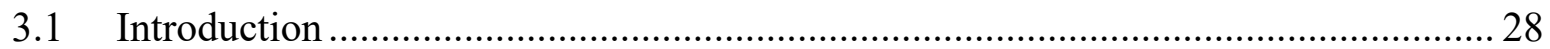

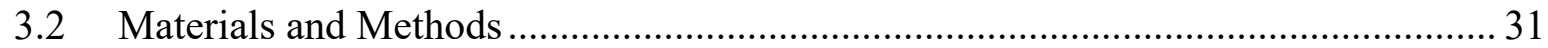

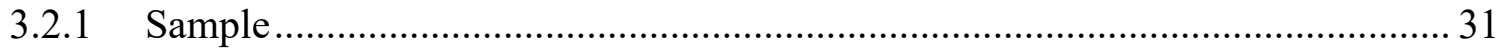

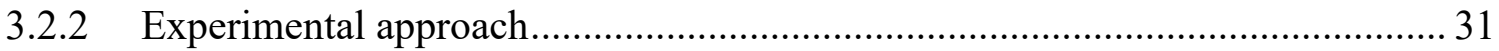

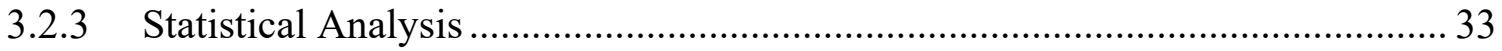

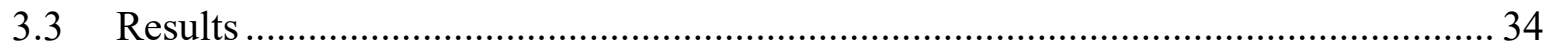

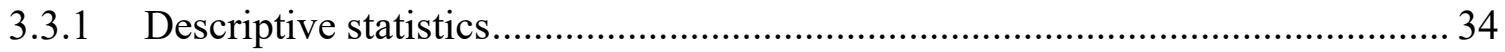

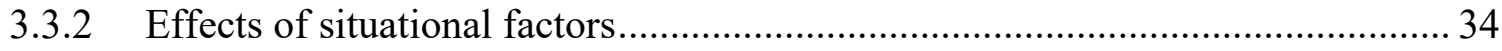

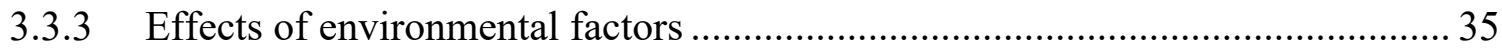

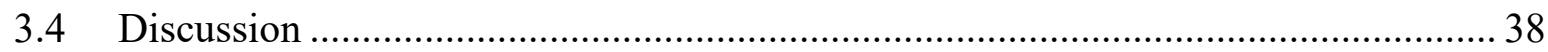

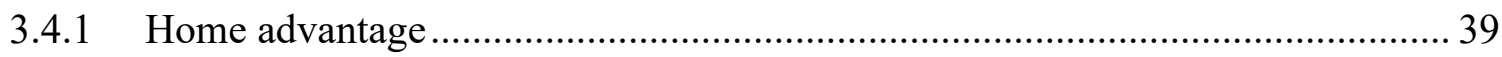

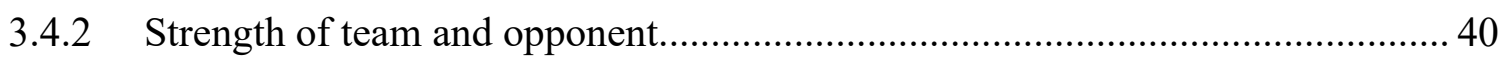

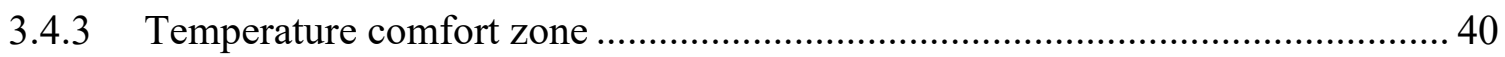

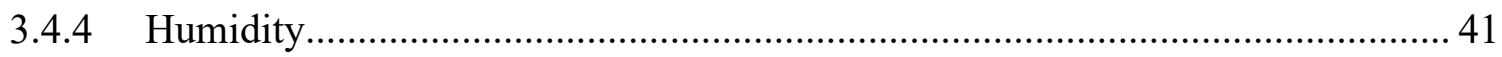

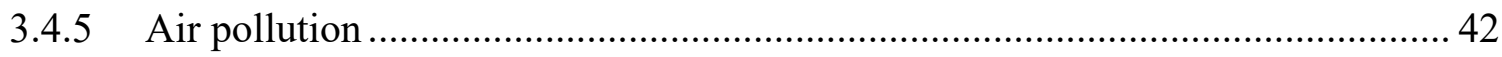

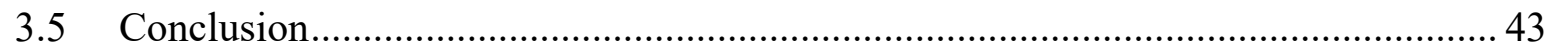

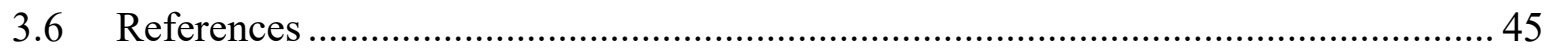


Chapter 4 The evolution of physical and technical performance parameters in the Chinese Soccer Super League

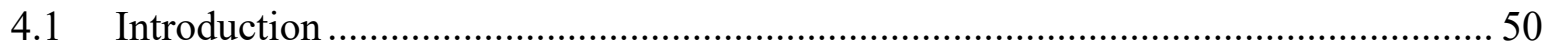

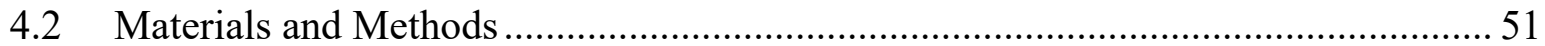

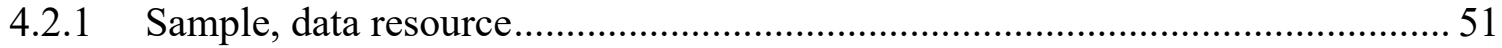

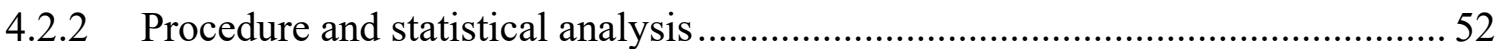

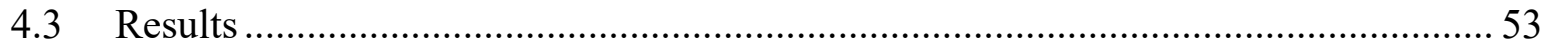

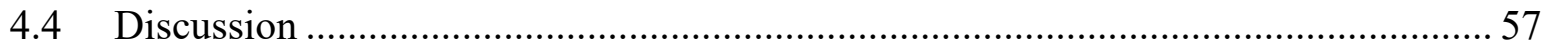

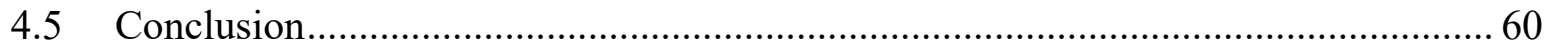

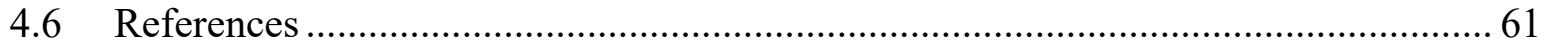

Chapter 5 Long-term influence of technical, physical performance indicators and situational variables on match outcome in male professional Chinese soccer ...................................... 66

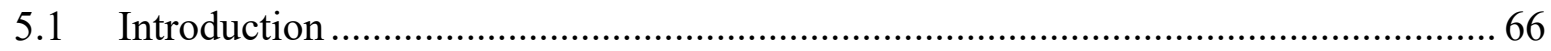

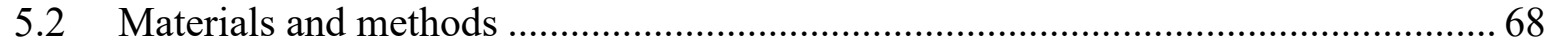

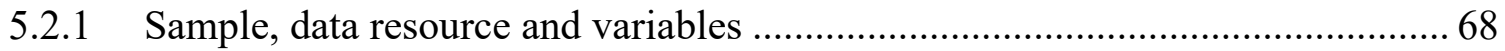

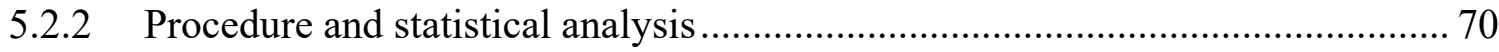

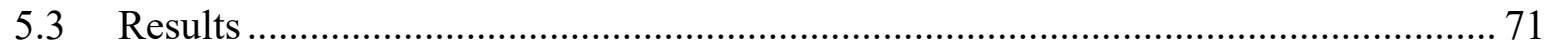

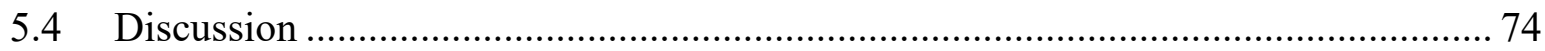

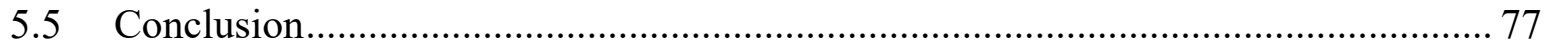

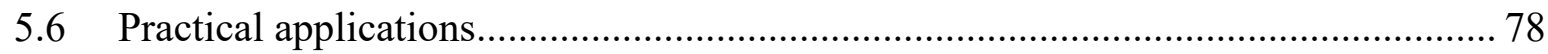

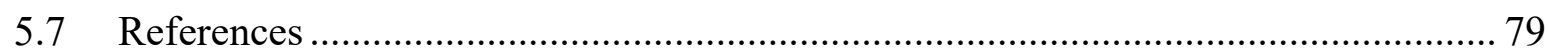

Chapter 6 Players' match demands according to age and playing position in professional 
male soccer players

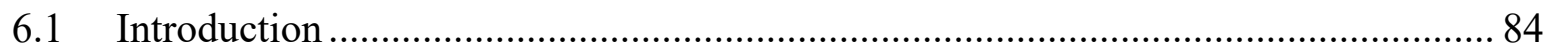

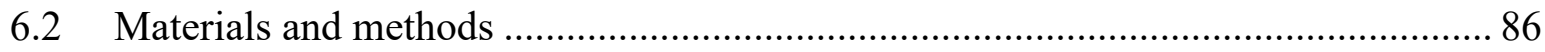

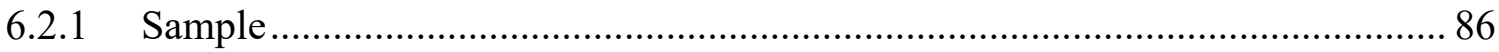

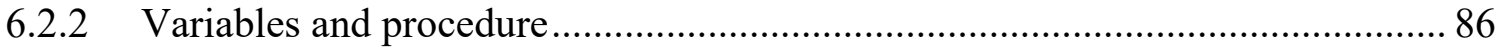

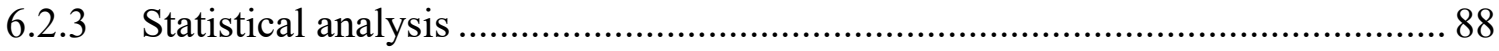

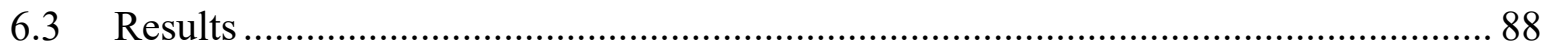

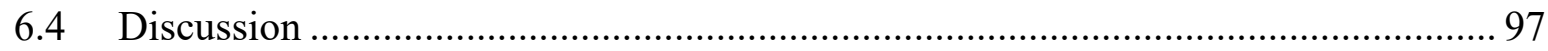

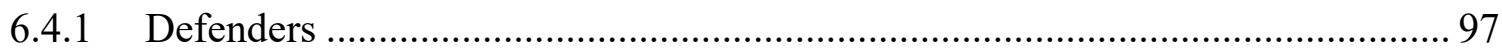

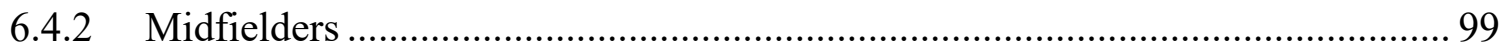

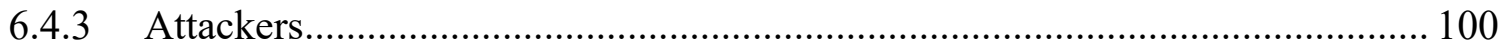

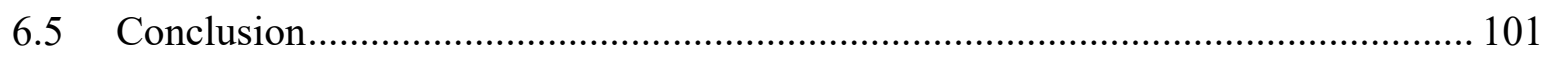

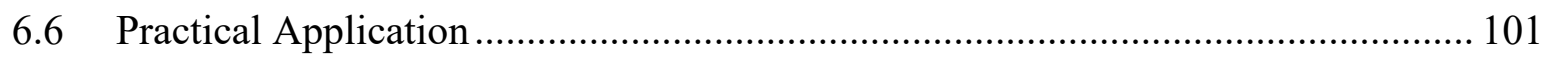

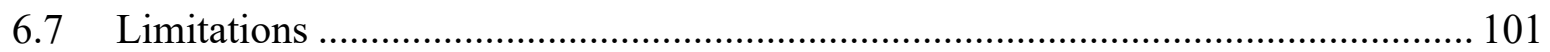

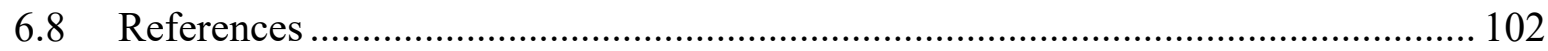

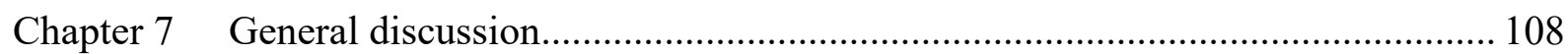

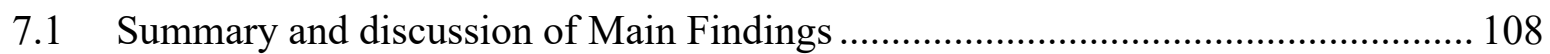

7.1.1 Section 1 - The indicators discriminated match outcome (Chapter 2) ............. 108

7.1.2 Section 2 - Influence of situational and environmental variables (Chapter 3) . 110

7.1.3 Section 3 - The evolution of match performance parameters (Chapter 4,5 and 6) 


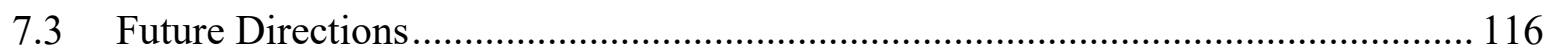

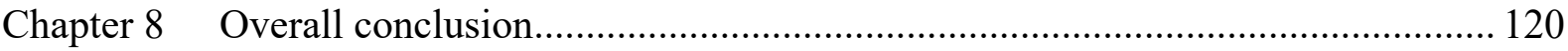

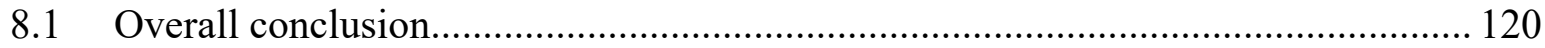

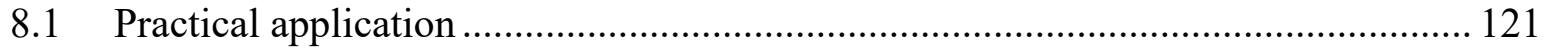

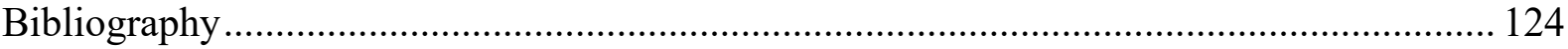

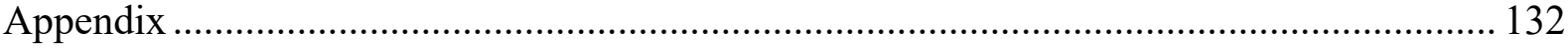




\section{List of Tables}

Table 2.1 Selected technical and physical performance-related parameters

Table 2.2 Differences between winning, drawing and losing teams in game statistics from the

Chinese soccer league.

Table 2.3 Structure coefficients (SC) of technical and physical performance

Table 3.1 Selected technical and physical performance-related parameters (dependent variables).

Table 3.2 Descriptive statistics of all the analysed variables.

Table 3.3 Effects of temperature on the technical and physical performance of CSL teams. . 38

Table 4.1 Definitions of selected technical and physical performance-related parameters. .... 53

Table 4.2 The evolution of technical performance in the Chinese Soccer Super League over 6 seasons (from 2012 to 2017) 56

Table 5.1 Selected variables definition

Table 5.2 Performance indicators across the 2012 to 2017 seasons. Data are displayed as means and standard deviations. 72

Table 5.3 Odds ratios for fixed factors relating to the 6 seasons logistic backward (LR) stepwise regression models .73

Table 6.1 Data distribution according to the age group and playing position. 86

Table 6.2 Operational definition of technical and physical performance-related parameters . 87

Table 6.3 Character descriptions of physical performance variables according to each age group. .93

Table 6.4 Character descriptions of possession-related technical performance variables according to each age group.

Table 6.5 Character descriptions of confrontation-related technical performance variables according to each age group. .95 


\section{List of Figures}

Figure 1.1 Overview of the structure of the thesis

Figure 3.1 Effects of situational variables on the technical and physical performance of Chinese

Soccer Super League (CSL) teams...... 36

Figure 3.2 Effects of humidity and AQI (Air quality index) on the technical and physical performance of CSL teams.

Figure 4.1 The evolution of physical performance in CSL over 6 seasons from 2012 to 2017.

Figure 5.1 Changes in odds ratios for six factors relating to the match outcome over 6 seasons.

Black line represents the mean value of OR and $90 \%$ confidence interval. 74

Figure 6.1 Physical performance variables by age and playing position. 90

Figure 6.2 Possession-related Technical performance variables by age and playing position 91

Figure 6.3 Confrontation-related technical performance variables by age and playing position. 
XXX 


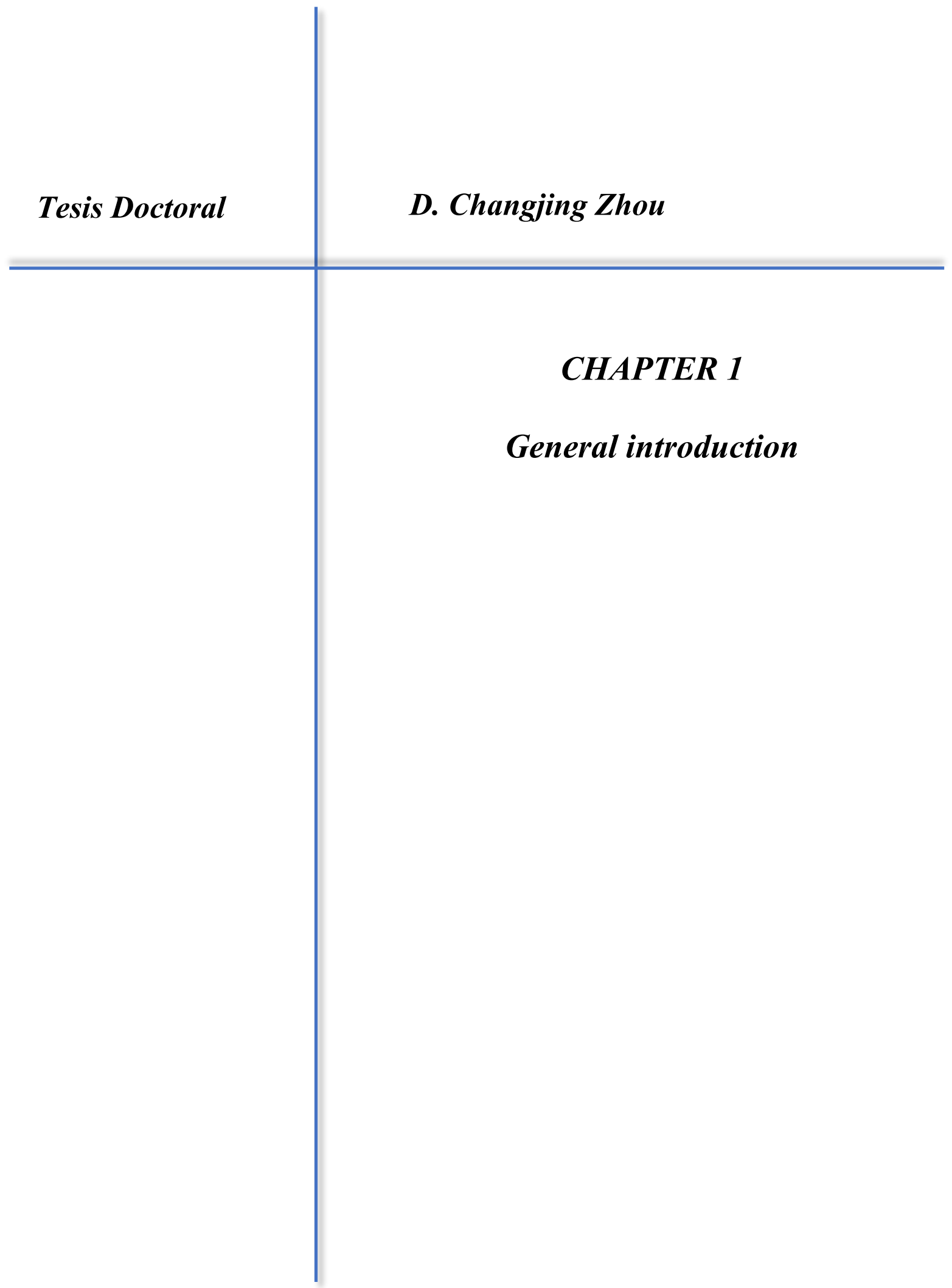




\section{Chapter 1 General introduction}

\subsection{Research background}

Soccer is a team sport involving strategic, tactical and technical dimensions which give rise to different forms of coaching questions and knowledge. Looking for ways of enhancing performance is a main aim of coaching staff (Carling, Williams, \& Reilly, 2005). Soccer is also constantly changing as many factors have changed (e.g., rules, better equipment, improved fitness and diet), and data that were recorded a number of years ago may no longer be pertinent (Carling et al., 2005).

A match analysis is commonly used in many sports and is viewed as a vital process that enables coaches to collect objective information which can be used to provide feedback on performance (Carling et al., 2005). As coaches are prone to making subjective judgments and may be unable to recall events reliably, they are increasingly turning to match analysis as a way of optimizing the training process of their players and teams (Hughes \& Franks, 2004). The main aim of match analysis is to identify the strengths and weaknesses of one's own team and opposing side, thereby enabling the former to be further developed and exploiting its weaknesses (Carling, Bloomfield, Nelsen, \& Reilly, 2008). Performance analysis appears to be widely accepted by players, coaches and sport scientists as useful feedback in the coaching process (Drust, 2010). Professional clubs are applying these results to improve performance and may be partially why increases in match intensity and performance have been recorded (Bush, 2017).

Soccer-related performance analysis researches are focused on the key performance indicators identification. Performance indicators in sport can be defined as the selection and combination of variables that define some aspects of performance and which help to achieve success (Hughes $\&$ Bartlett, 2002). These indicators constitute an ideal profile that can be used to predict future behaviour in a given sporting activity (O'Donoghue, 2005). Usually, researchers tend to imitate the tactics and play of winning teams, seeking to master those aspects of performance which 
are deemed to underlie their success (Hughes \& Franks, 2005). Available research pointed that technical-tactical indicators (e.g., shots on target, successful passes, possession) associated to winning or having positive effects on the match outcome (Harrop \& Nevill, 2017; LagoBallesteros \& Lago-Peñas, 2010; Lago-Peñas, Lago-Ballesteros, Dellal, \& Gómez, 2010; Liu, Gomez, Lago-Penas, \& Sampaio, 2015; Liu, Hopkins, \& Gomez, 2016; Mao, Peng, Liu, \& Gómez, 2017). Although the previous studies indicated that overall technical and tactical effectiveness are more important than physical performance in determining the success in soccer (Di Salvo, Gregson, Atkinson, Tordoff, \& Drust, 2009), the latest studies showed that high-intensity actions are related to the outcome of the match (Aquino, Munhoz Martins, Palucci Vieira, \& Menezes, 2017; Zhou, Zhang, Lorenzo, \& Cui, 2018).

In a football context, the match location (e.g., playing at home or away), quality of opponent (e.g., strong or weak opponents), and match status (e.g., when the team wins, draw, or loses) have been shown as the main factors that influence performance (technical-tactical performance, behavioural strategies, physical performance) even the final outcome during a competition (Aquino et al., 2017; Lago \& Martin, 2007; Taylor, Mellalieu, James, \& Barter, 2010; Taylor, Mellalieu, James, \& Shearer, 2008; Tucker, Mellalieu, James, \& Taylor, 2005). In addition, environmental-related factors, such as relative air humidity, temperature and air quality were also identified to affect soccer match performance (Chmura et al., 2017; Lichter, Pestel, \& Sommer, 2017; Nassis, Brito, Dvorak, Chalabi, \& Racinais, 2015; Trewin, Meylan, Varley, \& Cronin, 2017). As stated by Almeida, Ferreira, and Volossovitch (2014), coaches can use this information to prepare their teams for the specific competitive situation in which they will play.

In recent decades, the evolution of soccer has been influenced by changes in rules and match tactics, increased professionalism, the use of new technologies, wider global exposure, international transfers of players and coaches, and transformations in training and selection 
processes (Bush, Archer, Barnes, Hogg, \& Bradley, 2016; Wallace \& Norton, 2014). This type of information can be very useful to coaches and players in the evolution of a team's play and performance. In turn, this information has had important consequences for contemporary fitness and tech-tactical training strategies. Further research in this area is necessary to understand the changes that are occurring within football and the possible causes of the observed changes.

Player's performance also is impacted by individual factors (Allen \& Hopkins, 2015; Berthelot et al., 2012), such as players' age, height and weight (Allen \& Hopkins, 2015; Carling et al., 2008; Dendir, 2016; Sal de Rellan-Guerra, Rey, Kalen, \& Lago-Penas, 2019; Zhang et al., 2018). Years of training and experience also influence the players' physical, skill, or cognitive development, and then, their competitive performance (Allen \& Hopkins, 2015). Performance peak age of professional soccer players and the normative profile for each age group are important aspects to analyse players properly (Dendir, 2016; Kalen, Rey, de Rellan-Guerra, \& Lago-Penas, 2019).

The performance analysis in soccer is currently Europe-centred (Mao et al., 2017), and most of the scientific research has been focused on describing the technical-tactical and physical performance of European top-league teams and players. Although insightful information is provided for coaches and researchers, there is scarce investigation for Asian soccer, which is comparatively less developed and requires more scientific feedback. Compared to other continents, Asian countries demonstrated lower increases and often performed lower match performances on physical and technical performance parameters and therefore may not be as capable performing the demands required for the European teams, or may be less adaptable or slower to evolve compared to players from other continents (Bush, 2017). Chinese Super League (CSL) would serve as an ideal model as it has attracted huge investment recently and recruited a large number of high-level players and coaches who may have brought in the latest match approaches and tactical concepts (Zhou et al., 2018). 


\subsection{State of the problem}

Despite the current research providing detailed and meaningful information related to soccer game behaviours, there remains a number of limitations as follows:

Firstly, current research is often based on a small number of soccer seasons (generally one or two seasons), therefore the data may only be applicable to the seasons under investigation.

Secondly, soccer has evolved across time (Wallace \& Norton, 2016). However, from the available research in soccer, few studies can provide this information due to most of them were focused on identifying key performance indicators in a single season/championship or few seasons and exploring the variability/stability of performance indicators along the seasons (Barnes, Archer, Hogg, Bush, \& Bradley, 2014; Bradley et al., 2016; Bush, Barnes, Archer, Hogg, \& Bradley, 2015). Either, no research has studied the influence of key performance indicators (KPI) and situational variables on the match outcome in soccer from a longitudinal approach.

Thirdly, existing researches has provided preliminary information on the effects of situational variables and environmental factors such as match location, match status, quality of the opponent, relative air humidity, temperature and air quality in affecting soccer match performance (Chmura et al., 2017; Gomez, Lago-Penas, \& Pollard, 2013; Lichter et al., 2017; Liu, Yi, Giménez, Gómez, \& Lago-Peñas, 2017; Nassis et al., 2015; Sarmento et al., 2014; Trewin et al., 2017). Although the above literature provided insights into soccer behaviours under different match circumstances, the effects of situational and environmental-related factors on soccer match performances were studied separately. Furthermore, most studies have focused on either technical or physical match performances with few combining both categories, especially those investigating environmental-related effects.

Fourthly, most of the research on soccer is now concentrated in Europe, with less research on some less-developed soccer areas. Coaches and performance analysts from developing soccer 
countries may benefit from more detailed knowledge regarding soccer evolution; specifically, a better understanding of the recent evolving trends could, in turn, be used in the daily training and future planning of players.

Fifthly, the influence of age and maturity on elite youth soccer players' performance has been widely studied in the available literature (Al Haddad, Simpson, Buchheit, Di Salvo, \& MendezVillanueva, 2015; Mendez-Villanueva et al., 2011; Rommers et al., 2019; Salinero et al., 2019; Saward, Morris, Nevill, Nevill, \& Sunderland, 2016). However, few studies were focused on the changes of technical-tactical and physical performance on elite adult players according to their ages and playing positions (Sal de Rellan-Guerra et al., 2019). Therefore, there is a need to control players' age and playing position when analysing their performance from a long-term career perspective

\subsection{The aim of the study}

Based on the above discussions, the main aims of the studies contained in the current $\mathrm{PhD}$. thesis are the following ones:

(1) To identify the match statistics (technical and physical variables) and contextual factors (match location and opposition quality) which best discriminated between winning, drawing and losing teams in the CSL.

(2) To identify the influence of situational and environmental factors on the technical and physical performance of the CSL soccer teams.

(3) To examine the evolution in physical and technical performance parameters in the CSL from 2012 season to 2017 season.

(4) To determine whether the role of every performance indicator and situational variables on the match outcome has varied over six seasons in the CSL.

(5) To study the match patterns (technical performance-related parameters and physical performance-related parameters) evolution of elite soccer players according to their playing 
position and age.

\subsection{The structure of the thesis}

The structure of this $\mathrm{PhD}$. thesis included a general introduction in Chapter 1, the specific studies from Chapter 2 to Chapter 6, the general discussion in Chapter 7, and overall conclusions in Chapter 8 (See Figure 1.1). The specific studies of this $\mathrm{PhD}$. thesis were mainly comprised of five inter-linking sections. The first section focused on that match performance factors (technical and physical variables) and contextual factors (match location and opposition quality) can discriminate match outcome in the CSL (Chapter 2). The second section assessed the influence of situational and environmental factors on the technical and physical performance of the CSL soccer teams (Chapter 3). The third and fourth section examined the evolving trends in physical and technical performance parameters according to seasons and players' playing position and age (Chapter 4,5,6). Additionally, the above studies have been specifically written for publication in peer-review scientific journals. For the consistency and ease of reference, all citations have been presented in American Psychological Association (APA) referencing format using a single bibliography at the end of thesis. 
Evolution of Technical and Physical Match performances in

Chinese Soccer Super League

Chapter 1 General introduction
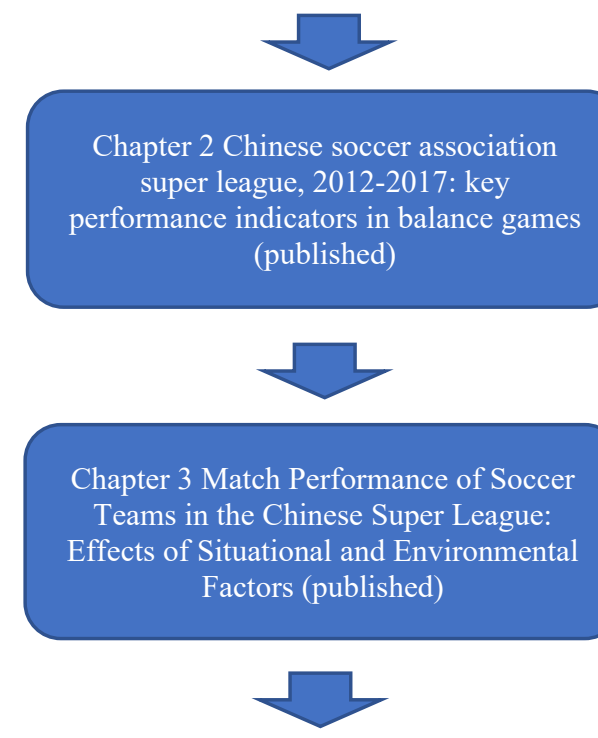

Chapter 4 The evolution of physical and technical performance parameters in the Chinese Soccer Super League (published)

Chapter 5 Long-term influence of technical, physical performance indicators and situational variables on match outcome in male professional Chinese soccer (under review)

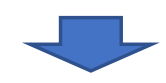

Chapter 7 General discussion

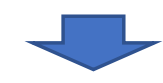

Chapter 8 Overall conclusion
Chapter 6 Players' match demands according to age and playing position in professional male soccer players (major revision)

Figure 1.1 Overview of the structure of the thesis 


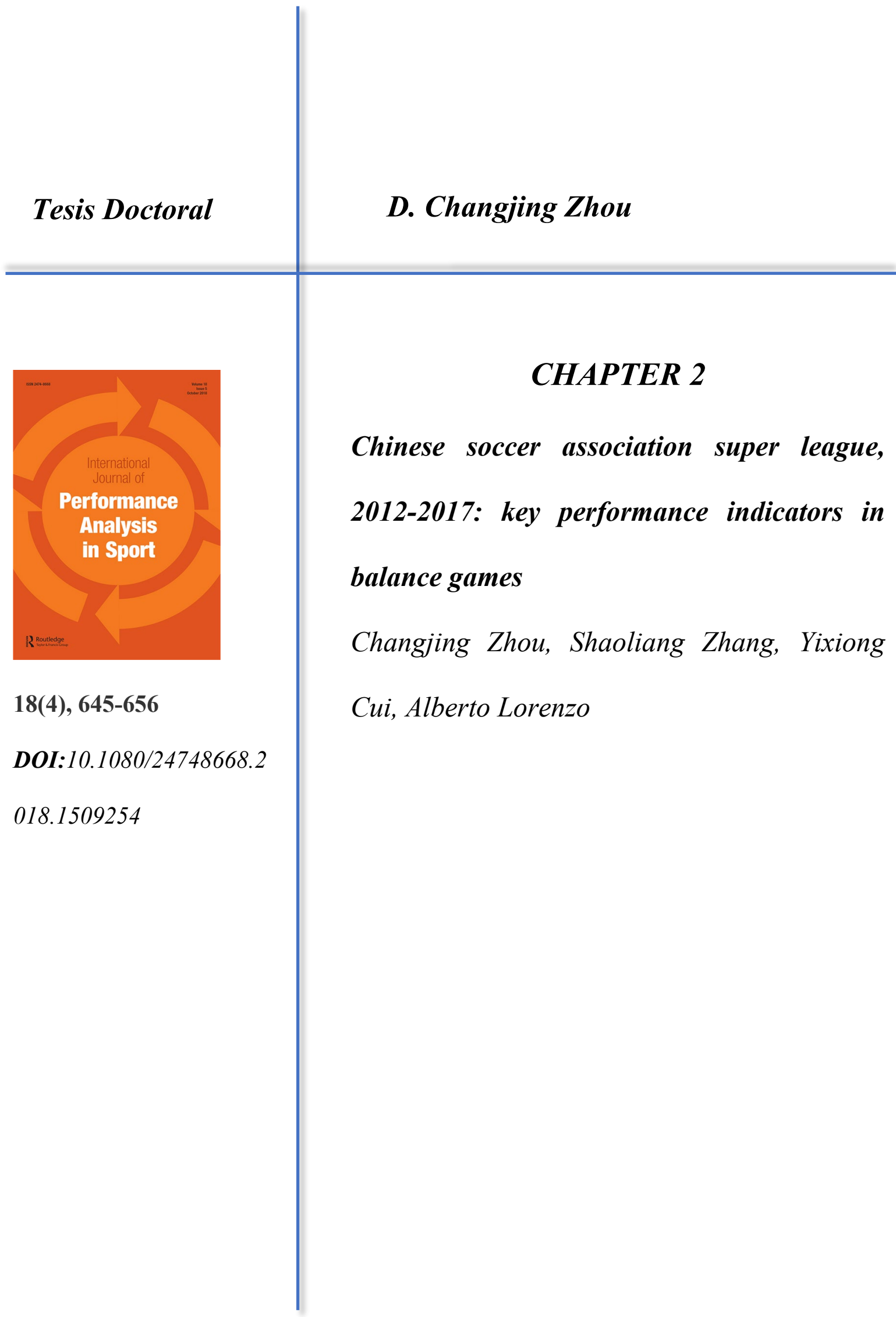




\section{Chapter 2 Chinese soccer association super league, 2012-2017:}

\section{key performance indicators in balance games}

\subsection{Introduction}

Performance indicators in sport can be defined as the selection and combination of variables that define some aspects of performance (Hughes \& Bartlett, 2002). These indicators constitute an ideal profile that can be used to predict future behaviour in a given sporting activity (O'Donoghue, 2005). In the context of soccer, the evolution of performance indicators in successive years is an opportunity to recognize the development of soccer matches.

Lago et al. (2010) found that the variable total shots, shots on target, crosses, crosses against, ball possession and match location had the greatest discriminatory power between winners and losers with regard to matches played in the Spanish league. Castellano, Casamichana, and Lago (2012) also found that the variable total shots, shots on target and ball possession had the greatest discriminatory power with regard to matches played in three World Cups (2002, 2006, 2010). Harrop and Nevill (2014) found that perform fewer passes but complete more successful passes and shots to be successful, however, their result showed that no significant differences for the mean number of total shots or shots on target when a sampled team was successful or unsuccessful.

Several contextual factors influence physical and technical match performance in soccer players, including match location and opposition quality (Aquino et al., 2017; Bradley, Lago-Penas, Rey, \& Sampaio, 2014; Lago \& Martin, 2007; Liu et al., 2016; Taylor et al., 2010; Taylor et al., 2008). It has been noted that a match location may incite adaptations to the team's playing style, but also to the decision making of individual players (Kite \& Nevill, 2017). Thus, home advantage can play an important role in determining the outcome of a match (Lago-Peñas, Lago-Ballesteros, \& Rey, 2011). When considering opponent's quality, the match location has different effects on match performance. Game location had only trivial effects on the winning 
probability for upper ranked teams when playing against upper ranked opponents, but had positive effects for upper ranked teams when facing lower ranked teams and for lower ranked teams when facing oppositions of whatever strengths (Mao et al., 2017). Lago-Penas and LagoBallesteros (2011) also found that stronger teams do not have the same advantages when they play at home, as occurs with weak opponents. In previous studies, the general breakdown of all teams into strong and weak teams does not really show the opponent's strength or weakness relative to itself. Difference between end-of-season rankings of the competing teams can truly reflect the strength gap between the two teams (Bradley et al., 2014).

The literature has previously demonstrated the likely association between physical performance and skill-related performance (Carling \& Dupont, 2011), and physical performance directly interfering in team dynamics and tactical performance (Moura et al., 2013). The result of previous studies (Aquino et al., 2017; Faude, Koch, \& Meyer, 2012) showed that high-intensity actions are related to the outcome of the match. Gómez and his colleagues have highlighted the importance of physical conditioning in the process of winning basketball match (Gómez, Gasperi, \& Lupo, 2016) and water polo (Gómez, Serna, Lupo, \& Sampaio, 2016) balance games. However, the previous study indicated that overall technical and tactical effectiveness of the team rather than high levels of physical performance are more important in determining success in soccer (Di Salvo et al., 2009). In summary, the technical and physical indicators that affect the outcome of the soccer match are not clear, and few studies have been devoted to simultaneously study the effects of technical and physical indicators on match outcomes.

The performance analysis in soccer is currently Europe-centered (Mao et al., 2017), and most of the scientific research has been focused on describing the technical-tactical and physical performance of European top-league teams and players. Although insightful information is provided for coaches and researchers, there is scarce investigation for Asian soccer, which is comparatively less developed and requires more scientific feedback. Chinese Soccer 
Association Super League (CSL) would serve as an ideal model as it has attracted recently a great number of high-level players and coaches to work for the teams, bringing them the latest training program and tactical concepts. Along with that, the recent advanced player-tracking technology has provided a more comprehensive match report. Therefore, it is of great interest to understand the CSL team and players match-play patterns.

The aim of the present study was to identify the match statistics (technical and physical variables) and contextual factors (match location and opposition quality) which best discriminated between winning, drawing and losing teams in Chinese soccer association super league.

\subsection{Method}

\subsubsection{Sample, data resource and variables}

Chinese Soccer Association Super League is the highest level of professional soccer match in China, which starts in March (spring in China) and ends in November (winter) every season. In each season, every team plays against twice with different opponents for home and away match, respectively. There are 240 matches were completed by 16 teams in each season (each team played 30 matches in the league). The end-of-season rank is determined by the final accumulated points (win for 3 points, draw for 1, loss for 0 ). A total of 1430 matches were selected as the sample of the current study from 2012 to 2017 seasons in the Chinese Soccer Association Super League.

Teams' tracking data of 1430 matches were collected by AMISCO (Amisco, Nice, France) tracking system. The reliability and validity of the system in measuring player movement has been evaluated (Zubillaga, Gorospe, Mendo, \& Villaseñor, 2007).

\subsubsection{Procedure and statistical analysis}

As was stated by Gómez, DelaSerna, Lupo, and Sampaio (2014) that match performance should be analyzed in relation to specific margin of victory. The balance matches (close matches) 
represent the highest level of performance between confronting teams in an open outcome. However, due to the emergence of red cards, the decrease in the player number of one team will cause the imbalance of the game. Therefore, in order to differentiate balanced matches and unbalanced matches, firstly we ruled out the match data that emergence of a red card in the match, leaving 1218 matches selected. Then a two-step cluster analysis with Euclidean as the distances measure and Schwartz's Bayesian criterion was carried out to classify final goal differences into balance matches and unbalanced matches (Liu et al., 2015). Results identified one cluster of $162(13.3 \%)$ matches (unbalanced matches with a goal difference of more than 2 goals $(3.51 \pm 0.79$, ranged from 3 to $7, \mathrm{n}=324$ observations $)$ and another cluster of $1056(86.7 \%)$ matches (balance matches with a difference of less than and equal to 2 goals $(0.88 \pm 0.73$, ranged from 0 to $2, \mathrm{n}=2112$ observations), which finally limited to the 1056 matches were proceeded for further statistical analysis. The quality of the clustering model was measured by the average silhouette coefficient, which is a measure of both cohesion and separation. It was assessed as follows: $-1.0-0.2$, poor model, $0.2-0.5$, moderate-to-fair model; $>0.5$, very good model. The average silhouette coefficient in this research is 0.7 .

In line with previous related literature (Carling, Bradley, McCall, \& Dupont, 2016; Mao et al., 2017; Yang, Leicht, Lago, \& Gomez, 2018), 16 technical performance-related parameters and 11 physical performance-related parameters were chosen as dependent variables in the analysis. The grouping and definition of these variables are in Table 2.1. Predictor variables in percent units (Possession, Possession in opponent half, pass accuracy, Forward Pass accuracy, 50-50 challenge won,) and physical variables of all the match (Total distance, Sprinting distance, Sprinting effort, High-speed-running distance, High-speed-running effort) were analysed as original values.

Team ranking was the final position in the end-of-season ranking of each team. Quality of opposition was the difference between end-of-season rankings of the competing teams (Quality 
of Opposition: QO) (Bradley et al., 2014)

Table 2.1 Selected technical and physical performance-related parameters

\section{Technical performance-related parameters: operational definition}

Shot: an attempt to score a goal, made with any (legal) part of the body, either on or off target

Shot on target: an attempt to goal which required intervention to stop it going in or resulted in a goal/shot which would go in without being diverted

Possession (\%): the duration when a team takes over the ball from the opposing team without any clear interruption as a proportion of total duration when the ball was in play

Possession in opponent half (\%): possession of a team in opponent's half of pitch

Pass: an intentional played ball from one player to another

Pass accuracy (\%): successful passes as a proportion of total passes

Forward pass: an intentional played ball from one player to another who is located in opponent's half of pitch

Forward pass accuracy (\%): successful forward passes as a proportion of total forward passes

Opponent 35m entry: number of times when the ball (possessed by the attacking team) enters the $35 \mathrm{~m}$ area of the opponent's half of pitch

Opponent penalty area entry: number of times when the ball (possessed by the attacking team) enters the penalty area of the opponent's half of pitch

Cross: any ball sent into the opposition team's area from a wide position

Corner: ball goes out of play for a corner kick

Offside: being caught in an offside position resulting in a free kick to the opposing team

$50-50$ challenge won (\%): $50 \%-50 \%$ challenge duels won by a team as a proportion of total duels of the match

Foul committed: any infringement that is penalised as foul play by a referee

Yellow card: where a player was shown a yellow card by the referee for reasons of foul, persistent infringement, hand ball, dangerous play, time wasting, etc.

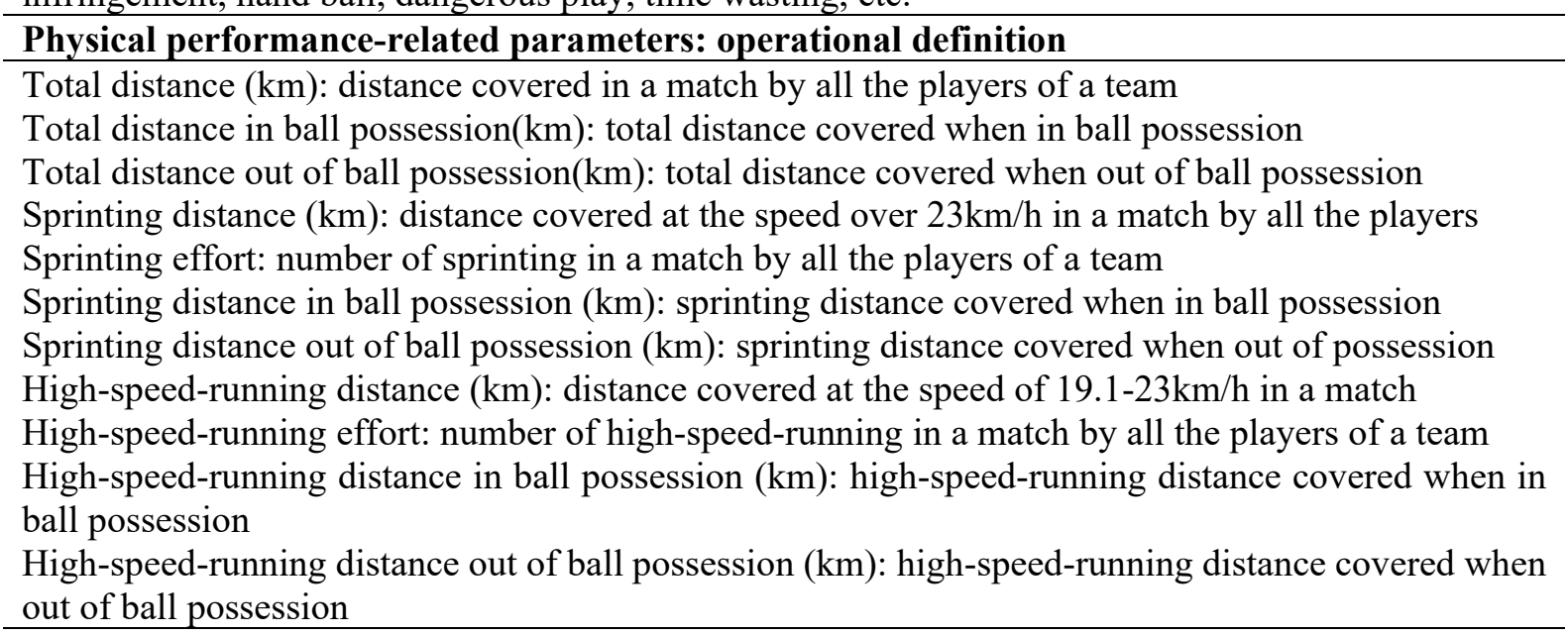
out of ball possession

\section{Contextual Variables}

Match location: Playing at home or away

Quality of opposition: the difference between end-of-season rankings of the competing teams, i.e. Quality of opposition $=R_{A}-R_{B}$ where $R_{A}$ is the ranking of sampled team and $R_{B}$ is the ranking of the opponent 
Other variables related to technical, physical performance were analysed as values adjusted to per $50 \%$ of ball possession of the own team (Liu et al., 2015; Mao et al., 2017), which is:

$$
\begin{gathered}
\mathrm{V}_{\text {ajstd }}=\left(\mathrm{V}_{\text {original }} / \mathrm{P}_{\text {team }}\right) * 50 \% \\
\left(\mathrm{~V}=\text { Value of a variable; } \mathrm{P}_{\text {team }}=\text { Possession of the own team }\right)
\end{gathered}
$$

While other variables related to defending were analysed as values adjusted to per $50 \%$ of ball possession of the opposition team (Liu et al., 2015; Mao et al., 2017), which is:

$$
\begin{gathered}
\mathrm{V}_{\text {ajstd }}=\left(\mathrm{V}_{\text {original }} / \mathrm{P}_{\text {opposition }}\right) * 50 \% \\
\left(\mathrm{~V}=\text { Value of a variable; } \mathrm{P}_{\text {opposition }}=\text { Possession of the opposition team }\right)
\end{gathered}
$$

A one-way ANOVA was carried out to identify univariate differences between the game-related statistics between winning, drawing and losing teams. Afterwards, a discriminant analysis was performed in order to identify which variables best discriminated between winning, drawing and losing teams (Castellano et al., 2012; Lago-Peñas et al., 2010; Ntoumanis, 2001). This was achieved by calculating the structural coefficients (SC), with values $>|0.30|$ being regarded as significant (Tabachnick, Fidell, \& Osterlind, 2001).

\subsection{Result}

The ANOVA results of the game-related statistics for winning, drawing and losing teams are presented in Table 2.2. There were some variables significantly higher for winning teams than drawing and losing teams: shots $(\mathrm{F}=10.84, \mathrm{P}<0.01)$, shots on target $(\mathrm{F}=79.88, \mathrm{P}<0.01), 50-50$ challenge won $(\mathrm{F}=12.06, \mathrm{P}<0.01)$, offsides $(\mathrm{F}=10.00, \mathrm{P}<0.01)$, sprinting distance $(\mathrm{F}=5.74$, $\mathrm{P}<0.01)$, sprinting effort $(\mathrm{F}=4.63, \mathrm{P}=0.01)$, sprinting distance in ball possession $(\mathrm{F}=69.31$, $\mathrm{P}<0.01)$, high-speed-running distance in ball possession $(\mathrm{F}=12.80, \mathrm{P}<0.01)$. However, on the variable crosses $(\mathrm{F}=14.35, \mathrm{P}<0.01)$ was lower than those of both drawing and losing teams. There were some variables significantly higher for losing teams than winning and drawing 
teams: passes $(\mathrm{F}=9.38, \mathrm{P}<0.01)$, forward passes $(\mathrm{F}=13.91, \mathrm{P}<0.01)$, sprinting distance out of ball possession $(\mathrm{F}=30.22, \mathrm{P}<0.01)$, high-speed-running distance out of ball possession $(\mathrm{F}=13.59$, $\mathrm{P}<0.01)$.

The results of the multivariate analysis are presented in Table 2.3. Both discriminant functions obtained were significant $(\mathrm{p}<0.01)$. In first discriminant function, the variables that had a higher discriminatory power were the shots on target $(\mathrm{SC}=-0.33)$, sprinting distance in ball possession $(\mathrm{SC}=-0.32)$, quality of opposition $(\mathrm{SC}=0.40)$, and in second discriminant function the variables that had a higher discriminatory power were the shots on target $(\mathrm{SC}=0.49)$, passes $(\mathrm{SC}=0.40)$, forward passes $(\mathrm{SC}=0.34)$.

\subsection{Discussion}

The aim of this study was to identify the performance indicators that best discriminated between winning, drawing and losing teams in CSL from 2012-2017.

The results of the ANOVA analysis identified thirteen variables that differed between winning, drawing and losing teams (Table 2.2), while in the subsequent multivariate analysis, only five variables were found to discriminate teams in relation to their performance (Table 2.3).

The present study indicate that winning teams have more shots and shots on target than losing and drawing teams, but shots on target best discriminates team performance. Our findings are in line with the study that showed that shot on target may have substantially positive effects on the probability of winning (Mao et al., 2017). Some researchers also found that shots on target had the greatest discriminatory power with regard to matches played in three World Cups (2002,2006,2010)(Castellano et al., 2012), in the Spanish league (Lago-Peñas et al., 2010), and in the Italy league (Rampinini, Impellizzeri, Castagna, Coutts, \& Wisloff, 2009). This is also consistent with the findings of Szwarc (2004), who reported that winning teams made only four more shots than less successful teams, but the effectiveness of their shots was three-fold greater. In addition, this result is in accordance with previous studies that showed that the quality of 
shots rather than the quantity of that in soccer matches determines the game result (Liu et al., 2015; Liu et al., 2016; Yue, Broich, \& Mester, 2014). Considering the high importance of shots on target, training should be more focused on shooting accuracy.

Table 2.2 Differences between winning, drawing and losing teams in game statistics from the Chinese soccer league.

\begin{tabular}{|c|c|c|c|c|c|}
\hline \multirow[t]{2}{*}{ Game related statistics } & \multicolumn{3}{|c|}{$2012-2016$} & \multirow{2}{*}{$\mathrm{F}$} & \multirow{2}{*}{$\mathrm{P}$} \\
\hline & Win (705) & Draw (702) & Loss (705) & & \\
\hline Shots & $12.9(4.2)^{\mathrm{ab}}$ & $12.1(4.3)$ & $11.8(4.4)$ & 10.8 & 0.000 \\
\hline shots on target & $5.5(2.4)^{\mathrm{ab}}$ & $4.3(2.3)$ & $4.1(2.3)$ & 79.9 & 0.000 \\
\hline Corners & $4.5(2.5)$ & $4.7(2.6)$ & $4.7(2.7)$ & 0.8 & 0.457 \\
\hline Crosses & $13.3(5.3)^{\mathrm{ab}}$ & $14.6(6.0)$ & $14.8(5.9)$ & 14.4 & 0.000 \\
\hline Possession & $49.6(7.3)$ & $50.0 \quad(7.4)$ & $50.4(7.3)$ & 2.3 & 0.099 \\
\hline Possession in opponent half & $44.3(7.7)$ & $44.4(7.7)$ & $44.9(7.5)$ & 1.1 & 0.329 \\
\hline Passes & $362.4(62.1)^{\mathrm{b}}$ & $359.5(59.2)^{b}$ & $372.7(58.2)$ & 9.4 & 0.000 \\
\hline Pass accuracy & $78.8(6.3)$ & $78.5(6.1)$ & $78.8(5.2)$ & 0.9 & 0.396 \\
\hline Forward passes & $123.3(18.9)^{\mathrm{b}}$ & $123.7(18.2)^{\mathrm{b}}$ & $128.1(19.2)$ & 13.9 & 0.000 \\
\hline Forward pass accuracy & $63.5(8.8)$ & $62.6(9.0)$ & $63.2(8.1)$ & 2.2 & 0.106 \\
\hline Opponent $35 \mathrm{~m}$ entries & $44.4(10.4)$ & $44(10.4)$ & $44.5(10.3)$ & 0.4 & 0.648 \\
\hline Opponent penalty area entries & $6.7(3.3)$ & $6.6(3.3)$ & $6.9(3.3)$ & 1.5 & 0.230 \\
\hline $50-50$ challenge won & $52.5(6.8)^{\mathrm{ab}}$ & $51.7(6.8)^{\mathrm{b}}$ & $50.7(7.0)$ & 12.1 & 0.000 \\
\hline Fouls committed & $16.7(5.1)$ & $16.4(5.0)$ & $16.5(5.0)$ & 0.7 & 0.522 \\
\hline Offsides & $2.5(2.0)^{\mathrm{ab}}$ & $2.2(1.9)$ & $2.1(1.8)$ & 10.0 & 0.000 \\
\hline Yellow card & $1.9(1.3)$ & $1.9(1.3)$ & $1.9(1.3)$ & 0.0 & 0.971 \\
\hline Total distance & $\begin{array}{c}108,202.3 \\
(5,418.2)\end{array}$ & $\begin{array}{c}107,486.6 \\
(5,806.4)\end{array}$ & $\begin{array}{c}107,876.5 \\
(5,633.9)\end{array}$ & 2.9 & 0.058 \\
\hline Total distance in ball possession & $\begin{array}{l}35,968.2 \\
(3,378.6)\end{array}$ & $\begin{array}{l}35,798.6 \\
(3,502.9)\end{array}$ & $\begin{array}{l}36,221.8 \\
(3,408.4)\end{array}$ & 2.7 & 0.067 \\
\hline Total distance out of ball possession & $\begin{array}{l}38,317.4 \\
(3,577.1)\end{array}$ & $\begin{array}{l}38,035.1 \\
(3,746.1)\end{array}$ & $\begin{array}{l}38,439.6 \\
(3,756.3)\end{array}$ & 2.2 & 0.109 \\
\hline Sprinting distance & $2,141.9(499.2)^{\mathrm{ab}}$ & $2,068.0(501.2)$ & $2,059.4(506.1)$ & 5.7 & 0.003 \\
\hline Sprinting effort & $100.8(21.8)^{\mathrm{ab}}$ & $97.7(21.4)$ & $97.9(22.2)$ & 4.6 & 0.010 \\
\hline Sprinting distance IP & $1,171.6(352.1)^{\mathrm{ab}}$ & $1,046.9(328.3)^{\mathrm{b}}$ & $967.1(303.4)$ & 69.3 & 0.000 \\
\hline Sprinting distance OP & $938.6(310)^{\mathrm{ab}}$ & $995.5(331.1)^{\mathrm{b}}$ & $1,077.0(364.5)$ & 30.2 & 0.000 \\
\hline High-speed-running distance & $2,604.5(496.1)$ & $2,556.2(490.7)$ & $2,597.8(498.8)$ & 2.0 & 0.141 \\
\hline High-speed-running effort & $188.1(35.6)$ & $184.4(35.6)$ & $187(35.6)$ & 2.1 & 0.126 \\
\hline High-speed-running distance IP & $1,180.0(277.3)^{\mathrm{ab}}$ & $1,126(261)$ & $1,111.9(261.4)$ & 12.8 & 0.000 \\
\hline High-speed-running distance OP & $1,320.2(322.4)^{b}$ & $1,345.5(336.8)^{\mathrm{b}}$ & $1,410.7(347.6)$ & 13.6 & 0.000 \\
\hline Home/Away(1/2) & $1.4(0.5)^{\mathrm{ab}}$ & $1.5(0.5)^{\mathrm{b}}$ & $1.6(0.5)$ & 38.0 & 0.000 \\
\hline QO & $-2.4(6.2)^{\mathrm{ab}}$ & $0.0(5.9)^{\mathrm{b}}$ & $2.4(6.2)$ & 106.7 & 0.000 \\
\hline
\end{tabular}

${ }^{a}$ Significantly different from drawing teams, ${ }^{\mathrm{b}}$ Significantly different from losing teams Abbreviations: $\mathrm{IP}=$ in ball possession; $\mathrm{OP}=$ out of ball possession. 


\begin{tabular}{|c|c|c|}
\hline \multirow{2}{*}{ Game related statistics } & \multicolumn{2}{|c|}{ Function } \\
\hline & 1 & 2 \\
\hline Shots & -0.13 & 0.09 \\
\hline shots on target & $-0.33^{*}$ & $0.49 *$ \\
\hline Corners & 0.03 & -0.07 \\
\hline Crosses & 0.14 & -0.19 \\
\hline Possession & 0.06 & 0.02 \\
\hline Possession in opponent half & 0.04 & 0.08 \\
\hline Passes & 0.08 & $0.40^{*}$ \\
\hline Passes accuracy & -0.01 & 0.18 \\
\hline Forward passes & 0.12 & $0.34 *$ \\
\hline Forward pass accuracy & -0.03 & 0.25 \\
\hline Opponent $35 \mathrm{~m}$ entry & 0.00 & 0.12 \\
\hline Opponent enalty area entries & 0.03 & 0.15 \\
\hline 50-50 Challenges won & -0.13 & -0.10 \\
\hline Fouls committed & -0.03 & 0.09 \\
\hline Yellow cards & -0.12 & 0.09 \\
\hline Offsides & -0.01 & -0.02 \\
\hline Total distance & -0.03 & 0.26 \\
\hline Total distance in ball possession & 0.03 & 0.25 \\
\hline Total distance out of ball possession & 0.01 & 0.26 \\
\hline Sprinting distance & -0.09 & 0.14 \\
\hline Sprinting effort & -0.07 & 0.18 \\
\hline Sprinting distance in ball possession & $-0.32 *$ & 0.06 \\
\hline Sprinting distance out of ball possession & 0.21 & 0.19 \\
\hline High-speed-running distance & -0.01 & 0.24 \\
\hline High-speed-running effort & -0.02 & 0.24 \\
\hline High-speed-running distance in ball possession & -0.14 & 0.15 \\
\hline High-speed-running distance out of ball possession & 0.14 & 0.22 \\
\hline Home/Away $(1 / 2)$ & 0.24 & 0.10 \\
\hline Quality of oppsition & $0.40^{*}$ & 0.16 \\
\hline Eigenvalue & 0.63 & 0.03 \\
\hline Wilks’ Lambda & 0.60 & 0.97 \\
\hline Canonical Correlation & 0.62 & 0.17 \\
\hline Chi-square & 1077.76 & 61.36 \\
\hline df & 58 & 28 \\
\hline Significance & 0.000 & 0.000 \\
\hline$\%$ of Variance & 95.46 & 4.54 \\
\hline
\end{tabular}

*SC discriminant value $\geqslant|0.30|$

Concerning the performance indicators related to passes, there were differences between winning, losing and drawing teams in the following variables: passes, crosses, forward passes.

Firstly, losing teams make more passes, crosses and forward passes than winning and drawing teams, but there is no difference in forward pass accuracy. Our results are in line with the finding that cross showed negative between- and within-team effects on probability of winning (Liu et 
al., 2016). This finding demonstrates that players from losing teams employed more strategies of offense (forward passes) and sending the ball from a wide position into the opponent's area through more crosses, but getting less 50-50 challenges win indicates that efficiency of cross is low. This is probably because weak teams are usually less developed and worse prepared in the offensive organisation (Liu et al., 2016).

The results from the present study indicate that winning teams have more 50-50 challenges win and offsides than losing and drawing teams. The research of Liu et al. (2016) also indicated that teams winning more aerial duels tended to win more games. Previous observations on offside showed contradictory conclusions: one showed that there were differences among winning, drawing and losing teams (Lago-Peñas et al., 2010) and another study showed that offside had a clear positive within-team relationship with probability of winning (Liu et al., 2016). While others showed that there were no differences (Castellano et al., 2012; Lago-Peñas et al., 2011). Penetrative passes that could produce shot opportunities that are close to the goal-scoring area are of great importance in attacking, while this type of pass is normally associated with offside (Liu et al., 2016). These results of the present study could suggest that the players of winning teams are more aggressive in the duels process and in the offense process.

The previous studies often postulated that a high-level of match running performance is important for achieving success in professional soccer teams (Hoppe, Slomka, Baumgart, Weber, \& Freiwald, 2015). In addition, previous studies (Aquino et al., 2017; Faude et al., 2012) showed that high-intensity actions are related to match outcome. The present results show that winning teams have more sprinting distance and high-speed-running distance when they are in ball possession than losing teams, but when they are out of ball possession; they covered less sprinting and high-speed-running distance. However, only sprinting distance in ball possession $(>23 \mathrm{~km} / \mathrm{h})$ is a vital variable in discriminating winning, drawing and losing. Hoppe et al. (2015) reported total distance in ball possession as the strongest predictor of point accumulation across 
a season in German Bundesliga soccer teams. Another study also showed that higher-ranked teams from the Italian Series A League run greater distances in total and recorded more highspeed running (running speed $>14 \mathrm{~km} / \mathrm{h}$ ) with the ball possession than lower-ranked teams (Rampinini et al., 2009). However, in the present research, total distance in ball possession is not a variable in discriminating winning, drawing and losing.

Comparisons across studies are difficult due to differences in the technology used to quantify player movement and the speed thresholds used to define movement categories (Carling et al., 2008). Our research indicated that teams of CSL increase more sprinting distance with ball possession to win the match. Although there is no relevant research, compared with European soccer teams (take La Liga for example), teams from CSL have less passing number ( $\sim 365 \mathrm{VS}$ 400) (Liu et al., 2016), indicating that the ability to control the game is significantly lower than that of European teams and the attack of CSL teams is more dependent on direct play than on possession play, this puts high demands on the sprinting ability of the players. If a team has stronger sprint run ability on offense, they are more likely to win the game. The previous study and the present study suggested that the match running performance alone is not a key indicator for achieving success. The previous literature also demonstrated the likely association between physical performance and skill-related performance (Carling \& Dupont, 2011), and physical performance directly interfering in team dynamics and tactical performance (Moura et al., 2013). The results of the present research suggested that combining the technical and physical indicators for analysis can help more fully understand the match performance. These results enhance the importance of player sprinting ability in the attacking process; coaches could improve the sprinting performance of players when their team controls the ball through purposeful training. For example, increase the passing training and shoot accuracy practice in the case of players' rapid movement. In the second discriminant function the variables that had a higher discriminatory power were the shots on target $(\mathrm{SC}=0.49)$, passes $(\mathrm{SC}=0.40)$, forward 
passes $(\mathrm{SC}=0.34)$. Previous studies have concluded that shots on target and passing are mainly evident between winning and losing teams (Grant, Williams, Reilly, \& Borrie, 1999). Additionally, another study found that possession time and passing predicted aggregated team success in domestic league play while both variables were poor predictors at the individual match level considering team quality and home advantage (Collet, 2013). In the present research, regardless of match location and quality of opposition, more shots on target and less passes and forward passes could lead a successful match which means that more directly offense maybe a useful method to win the match. Harrop and Nevill (Harrop \& Nevill, 2014) suggested that the best tactical approach may be directly related to the skill level of the team. If the skill level of the team is insufficient to maintain meaningful possession, a "direct" style of play may be a better tactic to adopt (Kite \& Nevill, 2017). If the objective of playing direct is to move the ball into a shooting position as quickly as possible, the team is also more likely to be successful with more shots on target (Kite \& Nevill, 2017).

Match location is one of the variables that better differentiate winning, losing and drawing teams in Spanish La Liga (Lago-Peñas et al., 2010). In the present study, match location is not a variable that differences between the winning and the losing teams. However, the quality of opposition is a variable that differs between the winning, drawing and the losing matches. It shows that the quality of opposition is the more important index that affects match outcome when both of the home advantage and the opponent's quality are taken into account.

\subsection{Conclusion}

In summary, this study has analysed match statistics related to the technical and physical of winning, drawing and losing teams in CSL. It has sought to identify the performance indicators that best discriminate among winning, drawing and losing teams. The variables that better differentiate winning, drawing and losing teams in a global way were the following: shots on target, sprinting distance in ball possession, quality of opposition, passes and forward passes. 
For teams in CSL to achieve more success, they should attempt fewer passes to move the ball into a shooting position as quickly as possible, then the team is also more likely to be successful if they have more shots on target. The results may be of use to coaches in terms of designing their training programs. 


\subsection{References}

Aquino, R., Munhoz Martins, G. H., Palucci Vieira, L. H., \& Menezes, R. P. (2017). Influence of Match Location, Quality of Opponents, and Match Status on Movement Patterns in Brazilian Professional Football Players. Journal of Strength and Conditioning Research, 31(8), 2155-2161. doi:10.1519/JSC.0000000000001674

Bradley, P. S., Lago-Penas, C., Rey, E., \& Sampaio, J. (2014). The influence of situational variables on ball possession in the English Premier League. Journal of Sports Sciences, 32(20), 1867-1873. doi:10.1080/02640414.2014.887850

Carling, C., Bloomfield, J., Nelsen, L., \& Reilly, T. (2008). The role of motion analysis in elite soccer: contemporary performance measurement techniques and work rate data. Sports Medicine, 38(10), 839-862. doi:10.2165/00007256-200838100-00004

Carling, C., Bradley, P., McCall, A., \& Dupont, G. (2016). Match-to-match variability in highspeed running activity in a professional soccer team. Journal of Sports Sciences, 34(24), 2215-2223. doi:10.1080/02640414.2016.1176228

Carling, C., \& Dupont, G. (2011). Are declines in physical performance associated with a reduction in skill-related performance during professional soccer match-play? Journal of Sports Sciences, 29(1), 63-71. doi:10.1080/02640414.2010.521945

Castellano, J., Casamichana, D., \& Lago, C. (2012). The Use of Match Statistics that Discriminate Between Successful and Unsuccessful Soccer Teams. J Hum Kinet, 31, 139-147. doi:10.2478/v10078-012-0015-7

Collet, C. (2013). The possession game? A comparative analysis of ball retention and team success in European and international football, 2007-2010. Journal of Sports Sciences, 31(2), 123-136. doi:10.1080/02640414.2012.727455

Di Salvo, V., Gregson, W., Atkinson, G., Tordoff, P., \& Drust, B. (2009). Analysis of high intensity activity in Premier League soccer. International Journal of Sports Medicine, 30(3), 205-212. doi:10.1055/s-0028-1105950

Faude, O., Koch, T., \& Meyer, T. (2012). Straight sprinting is the most frequent action in goal situations in professional football. Journal of Sports Sciences, 30(7), 625-631. doi:10.1080/02640414.2012.665940

Gómez, M.-Á., DelaSerna, A., Lupo, C., \& Sampaio, J. (2014). Effects of Situational Variables and Starting Quarter Score in the outcome of elite women's water polo game quarters. International Journal of Performance Analysis in Sport, 14(1), 73-83.

Gómez, M.-Á., Gasperi, L., \& Lupo, C. (2016). Performance analysis of game dynamics during 
the 4th game quarter of NBA close games. International Journal of Performance Analysis in Sport, 16(1), 249-263.

Gómez, M.-Á., Serna, A. D., Lupo, C., \& Sampaio, J. E. (2016). Effects of game location, quality of opposition, and starting quarter score in the outcome of elite water polo quarters. The Journal of Strength \& Conditioning Research, 30(4), 1014-1020.

Grant, A., Williams, A., Reilly, T., \& Borrie, T. (1999). Analysis of the goals scored in the 1998 World Cup. Journal of Sports Sciences, 17(10), 826-827.

Harrop, K., \& Nevill, A. (2014). Performance indicators that predict success in an English professional League One soccer team. International Journal of Performance Analysis in Sport, 14(3), 907-920.

Hoppe, M. W., Slomka, M., Baumgart, C., Weber, H., \& Freiwald, J. (2015). Match Running Performance and Success Across a Season in German Bundesliga Soccer Teams. International Journal of Sports Medicine, 36(7), 563-566. doi:10.1055/s-0034-1398578

Hughes, M. D., \& Bartlett, R. M. (2002). The use of performance indicators in performance analysis. Journal of Sports Sciences, 20(10), 739-754.

Kite, C. S., \& Nevill, A. (2017). The Predictors and Determinants of Inter-Seasonal Success in a Professional Soccer Team. J Hum Kinet, 58(1), 157-167. doi:10.1515/hukin-20170084

Lago-Penas, C., \& Lago-Ballesteros, J. (2011). Game location and team quality effects on performance profiles in professional soccer. Journal of Sports Science \& Medicine, $10(3), 465-471$.

Lago-Peñas, C., Lago-Ballesteros, J., Dellal, A., \& Gómez, M. (2010). Game-related statistics that discriminated winning, drawing and losing teams from the Spanish soccer league. Journal of Sports Science \& Medicine, 9(2), 288.

Lago-Peñas, C., Lago-Ballesteros, J., \& Rey, E. (2011). Differences in performance indicators between winning and losing teams in the UEFA Champions League. Journal of Human Kinetics, 27(1), 137-148. doi:10.2478/v10078-011-0011-3

Lago, C., \& Martin, R. (2007). Determinants of possession of the ball in soccer. Journal of Sports Sciences, 25(9), 969-974. doi:10.1080/02640410600944626

Liu, H., Gomez, M. A., Lago-Penas, C., \& Sampaio, J. (2015). Match statistics related to winning in the group stage of 2014 Brazil FIFA World Cup. Journal of Sports Sciences, 33(12), 1205-1213. doi:10.1080/02640414.2015.1022578

Liu, H., Hopkins, W. G., \& Gomez, M. A. (2016). Modelling relationships between match events and match outcome in elite football. European Journal of Sport Science, 16(5), 
516-525. doi:10.1080/17461391.2015.1042527

Mao, L., Peng, Z., Liu, H., \& Gómez, M.-A. (2017). Identifying keys to win in the Chinese professional soccer league. International Journal of Performance Analysis in Sport, 16(3), 935-947. doi:10.1080/247486688.2016.11868940

Moura, F. A., Martins, L. E., Anido, R. O., Ruffino, P. R., Barros, R. M., \& Cunha, S. A. (2013). A spectral analysis of team dynamics and tactics in Brazilian football. Journal of Sports Sciences, 31(14), 1568-1577. doi:10.1080/02640414.2013.789920

Ntoumanis, N. (2001). A step-by-step guide to SPSS for sport and exercise studies: Routledge London.

O'Donoghue, P. (2005). Normative profiles of sports performance. International Journal of Performance Analysis in Sport, 5(1), 104-119.

Rampinini, E., Impellizzeri, F. M., Castagna, C., Coutts, A. J., \& Wisloff, U. (2009). Technical performance during soccer matches of the Italian Serie A league: effect of fatigue and competitive level. Journal of Science and Medicine in Sport, 12(1), 227-233. doi:10.1016/j.jsams.2007.10.002

Szwarc, A. (2004). EFFECTIVENESS OF BRAZILIAN AND GERMAN TEAMS AND THE TEAMS DEFEATED BY THEM DURING THE 17TH FIFA WORLD CUP. Kinesiology, 36(1).

Tabachnick, B. G., Fidell, L. S., \& Osterlind, S. J. (2001). Using multivariate statistics.

Taylor, J. B., Mellalieu, S. D., James, N., \& Barter, P. (2010). Situation variable effects and tactical performance in professional association football. International Journal of Performance Analysis in Sport, 10(3), 255-269.

Taylor, J. B., Mellalieu, S. D., James, N., \& Shearer, D. A. (2008). The influence of match location, quality of opposition, and match status on technical performance in professional association football. Journal of Sports Sciences, 26(9), 885-895. doi:10.1080/02640410701836887

Yang, G., Leicht, A. S., Lago, C., \& Gomez, M. A. (2018). Key team physical and technical performance indicators indicative of team quality in the soccer Chinese super league. Research in Sports Medicine, 26(2), 158-167. doi:10.1080/15438627.2018.1431539

Yue, Z., Broich, H., \& Mester, J. (2014). Statistical Analysis for the Soccer Matches of the First Bundesliga. International Journal of Sports Science \& Coaching, 9(3), 553-560.

Zubillaga, A., Gorospe, G., Mendo, A., \& Villaseñor, A. (2007). Match analysis of 2005-06 champions league final with Amisco system. Journal of Sports Science \& Medicine, $6(10), 20$. 


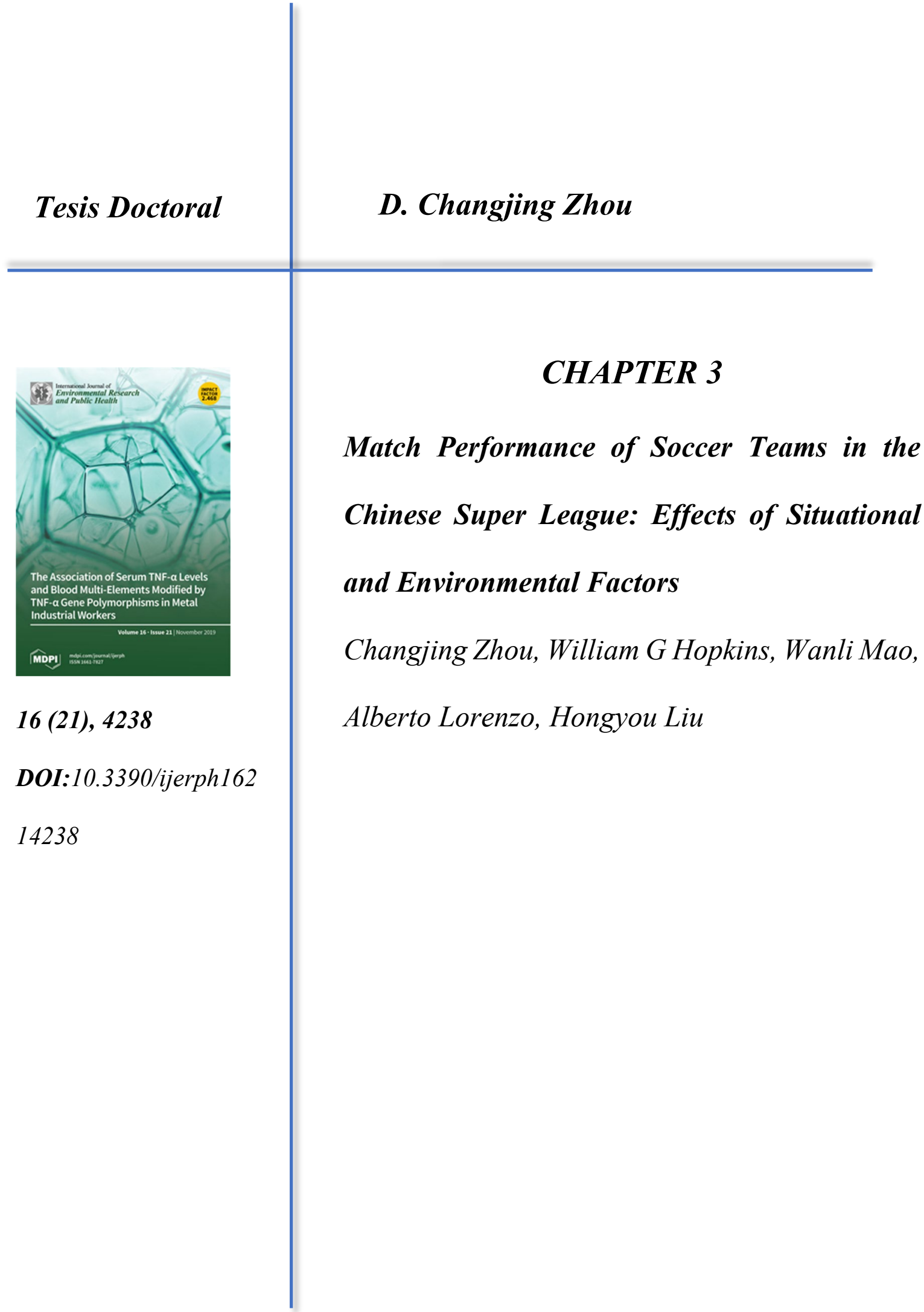




\section{Chapter 3 Match Performance of Soccer Teams in the Chinese}

\section{Super League: Effects of Situational and Environmental}

\section{Factors}

\subsection{Introduction}

Situational factors are the different competitive conditions in which soccer matches are played, and may affect the performance of teams and players at a behavioural level (Gomez et al., 2013). In recent years, intensive research has been conducted to investigate the influence of situational factors, including match location, team and opponent quality, match status/results among others, on soccer match performance (Sarmento et al., 2014; Trewin et al., 2017). Specifically, players and teams playing at home tended to achieve higher numbers in goal scoring, passing and organizing related technical actions, while committing fewer fouls and receiving fewer cards than playing away (Liu et al., 2017; Sarmento et al., 2014). Players from successful teams generally had more possession-related actions (Liu et al., 2017; Trewin et al., 2017), and covered more distance including high-speed-running whilst in ball possession (Hoppe et al., 2015; Trewin et al., 2017). Playing against opposition with higher strength demanded a higher level of technical and tactical performance (Liu et al., 2017; Taylor et al., 2008), as well as higher level of physical performance (Castellano, Blanco-Villasenor, \& Alvarez, 2011; LagoPenas \& Lago-Ballesteros, 2011). Winning teams in elite soccer leagues made more shots and shots on goal and performed fewer high-intensity exercises than drawing and losing teams (Lago-Peñas et al., 2011; Liu et al., 2017; Sarmento et al., 2014).

Environmental factors, such as relative air humidity, temperature and air quality were also identified to affect soccer match performance (Chmura et al., 2017; Lichter et al., 2017; Nassis et al., 2015; Trewin et al., 2017). The number of sprints performed and the distance covered at high-intensity by elite male players in the 2014 FIFA World Cup matches under high 
environmental stress (at $50 \%$ relative humidity, WBGT $28-33^{\circ} \mathrm{C}$ or at $75 \%$ relative humidity, WBGT $25-29^{\circ} \mathrm{C}$ ) were significantly lower than under low environmental stress (at $50 \%$ relative humidity, WBGT $<24^{\circ} \mathrm{C}$ or at $75 \%$ relative humidity, WBGT $<20^{\circ} \mathrm{C}$ ) (Nassis et al., 2015). A subsequent study analyzing the same matches revealed a similar trend and further concluded that the optimum environmental condition for elite male soccer players to perform physical match activity occurred at the temperature of $22{ }^{\circ} \mathrm{C}$ and with under $60 \%$ relative humidity (Chmura et al., 2017). Moreover, a one-percent increase in the concentration of particulate matter in ambient air (PM10) would lead to a $0.021 \%$ decrease in the number of passes of elite male players in German professional soccer matches (Bundesliga) (Lichter et al., 2017). The player 's acclimatization and fitness level can also affect the magnitude of environmental influence on the match performance (Brocherie, Girard, Farooq, \& Millet, 2015; Link \& Weber, 2017). Link and Weber (Link \& Weber, 2017) pointed that compare to players from 2. Bundesliga, players from 1. Bundesliga (better players) reduced their total distance to a greater extent when playing in the warm $\left(\geqslant 14{ }^{\circ} \mathrm{C}\right)$ than in the neutral $\left(-4\right.$ to $\left.13{ }^{\circ} \mathrm{C}\right)$ environments, whilst preserving their ability to undertake the high-intensity activities when required. The teams from Gulf region have more acclimatization to the heat due to their geographical location, the likelihood of favourable outcome (win or draw) for them increased by $3 \%$ for every 1 -unit increase in temperature difference (Brocherie et al., 2015).

Although the above literature provided insights into soccer behaviours under different match circumstances, the effects of situational and environmental factors on soccer match performance were studied separately. Furthermore, most studies have focused on either technical or physical match performance with few combining both categories (Yang et al., 2018), especially those investigating environmental effects. Hence, it is essential to analyse both the technical and physical match performance taking into account the impact of both situational and environmental factors, so that the pure effect of each element on distinct aspect 
of performance would be better assessed.

On the other hand, although research in performance analysis of soccer has been developed in depth in the recent years, there is a scarce investigation of Asian soccer, which is comparatively less developed and is in need for more objective feedback (Mao et al., 2017; Zhou et al., 2018). Chinese Super League (CSL) would serve as an ideal model as it has attracted huge investment recently and recruited a large number of high-level players and coaches who may have brought in the latest match approaches and tactical concepts (Zhou et al., 2018). Recent studies on the CSL by Zhou et al. (Zhou et al., 2018) and Mao et al. (Mao et al., 2017) reported that shots on target, shot accuracy, sprinting distance in ball possession, quality of opposition, number of passes, and number of forward passes have an effect on the match outcome. Furthermore, Yang and colleagues (Yang et al., 2018) found that upper-ranked teams had greater sprinting distance, total distance out of ball possession, possession, possession during the opponent's half, number of entry passes in the final third of the field and penalty area, and 50-50 challenges than did lower-ranked teams. Similarly, Gai et al. (Gai, Leicht, Lago, \& Gomez, 2019) examined the performance characteristics of domestic and foreign players based upon playing position in the CSL. Lago-Peñas et al. (Lago-Peñas, Gómez-Ruano, \& Yang, 2018) identified four playing styles in CSL teams (“possession” play, set pieces attack, counterattacking play, and transitional play) by examining 20 match-performance indicators. Along with that, due to the extensive and complex topography and geography of China, CSL players have to play in environmental conditions varying from bitter coldness in winter to unbearable heat in summer, from dry season to wet monsoons, and from region to region with drastic temperature and humidity differences throughout the year. Moreover, in some cities hosting CSL teams, atmospheric pollution has been very serious with high levels of air quality index. How those could influence match performance of CSL teams and players is to be further investigated and holds a critical applied significance. The aim of the present study was to identify the influence of situational and 
environmental factors on the technical and physical performance of the CSL soccer teams.

\subsection{Materials and Methods}

\subsubsection{Sample}

Match performance statistics of all 240 matches in the 2015 season of the CSL were analysed. Original data were collected by a semi-automatic computerized video tracking system, Amisco Pro®, whose working process, accuracy, validity and reliability have been discussed in detail in prior studies (Zubillaga, 2006; Zubillaga, Gorospe, Hernandez, \& Blanco, 2009).

\subsubsection{Experimental approach}

In line with the previous literature (Carling et al., 2016; Mao et al., 2017), 17 technical performance-related parameters and seven physical performance-related parameters were chosen as dependent variables in the analysis. The grouping and definition of these variables are listed in Table 3.1. Three situational variables (match location, team strength and opponent strength) and three environmental factors (temperature, humidity and air quality index) were chosen as predictor variables. Environmental data were derived from the China National Environmental Monitoring Centre, which publishes publicly real-time data of weather and air condition. The temperature and humidity were calculated as the average real-time value between kicking-off and ending time of each match inside the stadium, while the air quality index (AQI) was collected from the real-time data closest to the kick-off time of each match from the monitoring station nearest to the match stadium (range of distance: 0.4-6.9 km). AQI is used by government agencies to communicate to the public how polluted the air currently is or how polluted it is forecast to become. The AQI level is based on the level of six atmospheric pollutants, namely sulfur dioxide (SO2), nitrogen dioxide (NO2), suspended particulates smaller than $10 \mu \mathrm{m}$ in aerodynamic diameter (PM10), suspended particulates smaller than 2.5 $\mu \mathrm{m}$ in aerodynamic diameter (PM2.5), carbon monoxide (CO), and ozone (O3) measured at the monitoring stations throughout each city. Ethics committee approval of this study was gained 


\section{[19CTY014].}

Table 3.1 Selected technical and physical performance-related parameters (dependent variables).

\section{Technical Performance-Related Parameters: Operational Definition}

Shot: an attempt to score a goal, made with any (legal) part of the body, either on or off target

Shot on target: an attempt to goal which required intervention to stop it going in or resulted in a goal/shot which would go in without being diverted

Possession (\%): the duration when a team takes over the ball from the opposing team without any clear interruption as a proportion of total duration when the ball was in play

Possession in opponent half (\%): possession of a team in opponent's half of pitch

Pass: an intentional played ball from one player to another

Pass accuracy (\%): successful passes as a proportion of total passes

Forward pass: an intentional played ball from one player to another who is located closer to opponent's goal

Forward pass accuracy (\%): successful forward passes as a proportion of total forward passes

Opponent $35 \mathrm{~m}$ entry: number of times when the ball (possessed by the attacking team) enters the $35 \mathrm{~m}$ area

(final third of the field) of the opponent's half of pitch. Each time a player has made an individual possession

in the final third of the field, the AMISCO system qualifies it as an opponent $35 \mathrm{~m}$ entry of the player who did the individual possession.

Opponent penalty area entry: number of times when the ball (possessed by the attacking team) enters the penalty area of the opponent's half of pitch

Cross: any ball sent into the opposition team's area from a wide position

Corner: ball goes out of play for a corner kick

Offside: being caught in an offside position resulting in a free kick to the opposing team

50-50 challenge won (\%): $50-50 \%$ challenge duels won by a team as a proportion of total duels of the match. It is a match action when two players are competing for a ball. A 50-50 challenge must have the following characteristics:

- Ball is not in control by any player.

- The two players have roughly a 50-50\% chance of gaining control of the ball.

- Starts when the two players make an attempt to get the ball.

- Ends when one of the two players touches the ball \& the other competing player stops making an attempt to get the ball.

Foul committed: any infringement that is penalized as foul play by a referee

Yellow card: where a player was shown a yellow card by the referee for reasons of foul, persistent infringement, hand ball, dangerous play, time wasting and so forth.

Red card: where a player was sanctioned a red card by the referee, including straight red card and a red card from the second yellow card.

\section{Physical; Performance-Related Parameters: Operational Definition}

Total distance $(\mathbf{k m})$ : distance covered in a match by all the players of a team

Sprinting distance (km): distance covered at the speed over $23 \mathrm{~km} / \mathrm{h}$ in a match by all the players of a team Sprinting effort: number of sprinting in a match by all the players of a team

High-speed-running distance $(\mathbf{k m})$ : distance covered at the speed of $19.1-23 \mathrm{~km} / \mathrm{h}$ in a match by all the players of a team

High-speed-running effort: number of high-speed-running in a match by all the players of a team High-intensity-running distance (km): distance covered at the speed over $19 \mathrm{~km} / \mathrm{h}$ in a match by all the players of a team

High-intensity-running effort: number of high-intensity-running in a match by all the players of a team 
A generalized mixed linear model was realized with Proc Glimmix in the University Edition of Statistical Analysis System (version SAS Studio 3.6). A random effect for team identity was used to account for repeated measurement on the teams. The fixed effects estimated the effect of situational and environmental factors. Separate Poisson regressions were run in the model taking the value of each of the 17 technical and seven physical performance-related parameters as the dependent variable.

The effect of team strength and opponent strength was estimated by including the difference in the $\log$ of the end-of-season ranks as a predictor (Phillips \& Hopkins, 2017). Game location was included as a nominal variable with two levels (home and away). Humidity and AQI were included as numeric linear effects using their raw values, and their magnitudes were quantified as the effect of two of their standard deviations (Hopkins, Marshall, Batterham, \& Hanin, 2009): the predicted value for a typically high value of the predictor (1SD above the mean) minus that for a typically low value (1SD below the mean). The raw value of temperature was included as a quadratic effect to allow for the possibility and estimation of an optimum temperature defined by the maximum value of the quadratic. If the maximum occurred within the range of environmental temperatures, its confidence limits were derived by parametric bootstrapping (Hébertlosier, Platt, \& Hopkins, 2015). The optimum temperature and confidence limits were reported if at least $90 \%$ of the 10,000 bootstrapped samples produced a maximum; otherwise, it was evident that the effect of temperature was approximately linear and was therefore estimated and reported as the effect of two standard deviations.

\subsubsection{Statistical Analysis}

Uncertainty in the true effects of the predictors was evaluated using non-clinical magnitudebased inference (Hopkins et al., 2009) as implemented in the spreadsheet accompanying the package of materials for generalized mixed modelling with SAS Studio (Hopkins, 2016). Observed magnitudes and their confidence limits were expressed in standardized units, whereby 
the difference in means was divided by the observed between-match standard deviation (SD) derived from the mixed model, and then evaluated qualitatively with the following scale: $<0.2$ trivial, 0.2-0.6 small, 0.6-1.2 moderate, 1.2-2.0 large, >2.0 very large. Effects were deemed clear if the $90 \%$ confidence interval did not include positive and negative substantial values. Clear effects were reported with a qualitative likelihood that the true effect was either substantial or trivial (whichever probability was greater) using the following scale: $<0.5 \%$ most unlikely, $0.5-5 \%$ very unlikely, 5-25\% unlikely, $25-75 \%$ possibly, $75-95 \%$ likely, $95-99.5 \%$ very likely, $>99.5 \%$ most likely.

\subsection{Results}

\subsubsection{Descriptive statistics}

Descriptive statistics of all the dependent and independent variables are presented in Table 3.2.

\subsubsection{Effects of situational factors}

Figure 3.1 presents the effects of situational variables on the match performance-related variables. As can be seen from the figure, increase in the rank difference (a better team vs a worse opponent) would substantially increases shot, shot on target, possession, possession in opponent half, pass, pass accuracy, forward pass, forward pass accuracy, opponent $35 \mathrm{~m}$ entry, opponent penalty area entry, cross, corner, offside, and 50-50 challenge won to a small-tomoderate extent. Meanwhile, it would decrease foul committed, yellow card and red card at a small magnitude. In contrast, change in the rank difference only showed trivial effect on all the seven physical performance-related parameters. Match location (playing at home compared to playing away) had positive small effects on shot, shot on target, possession, possession in opponent half, pass, forward pass, opponent $35 \mathrm{~m}$ entry, opponent penalty area entry, cross, and corner, and a negative small effect on yellow card, and trivial effects on the rest of the variables. 
Table 3.2 Descriptive statistics of all the analysed variables.

\begin{tabular}{|c|c|c|c|c|c|}
\hline Dependent variables & $\mathbf{n}$ & Mean & SD & Min. & Max. \\
\hline Shot & 478 & 12.3 & 4.9 & 1 & 33 \\
\hline Shot on target & 478 & 4.6 & 2.7 & 0 & 16 \\
\hline Possession $(\%)$ & 478 & 50.0 & 7.4 & 31.0 & 69.0 \\
\hline Possession in opponent half $(\%)$ & 478 & 44.3 & 7.5 & 21.0 & 64.0 \\
\hline Pass & 478 & 363 & 95 & 143 & 687 \\
\hline Pass accuracy $(\%)$ & 478 & 79.6 & 5.7 & 52.0 & 92.0 \\
\hline Forward pass & 478 & 123 & 25 & 49 & 202 \\
\hline Forward pass accuracy $(\%)$ & 478 & 63.8 & 8.2 & 34.0 & 94.0 \\
\hline Opponent $35 \mathrm{~m}$ entry & 478 & 44 & 14 & 14 & 94 \\
\hline Opponent penalty area entry & 478 & 6.9 & 3.8 & 0 & 24 \\
\hline Cross & 478 & 14.5 & 6.6 & 2 & 40 \\
\hline Corner & 478 & 4.6 & 2.8 & 0 & 16 \\
\hline Offside & 478 & 2.3 & 1.8 & 0 & 8 \\
\hline $50-50$ challenge won $(\%)$ & 478 & 50.0 & 6.5 & 29.0 & 71.0 \\
\hline Foul committed & 478 & 17.1 & 5.1 & 4 & 33 \\
\hline Yellow card & 478 & 1.9 & 1.4 & 0 & 6 \\
\hline Red card & 478 & 0.07 & 0.28 & 0 & 3 \\
\hline Total distance $(\mathrm{km})$ & 478 & 109.5 & 4.9 & 91.1 & 122.3 \\
\hline Sprinting distance $(\mathrm{km})$ & 478 & 2.11 & 0.46 & 1.1 & 3.7 \\
\hline Sprinting effort & 478 & 100 & 20 & 54 & 171 \\
\hline High-speed-running distance $(\mathrm{km})$ & 478 & 2.62 & 0.44 & 1.5 & 4.2 \\
\hline High-speed-running effort & 478 & 188 & 32 & 103 & 303 \\
\hline High-intensity-running distance $(\mathrm{km})$ & 478 & 4.73 & 0.82 & 2.8 & 7.2 \\
\hline High-intensity-running effort & 478 & 287 & 48 & 164 & 434 \\
\hline \multicolumn{6}{|l|}{ Predictor variables } \\
\hline Temperature $\left({ }^{\circ} \mathrm{C}\right)$ & 472 & 21.4 & 6.4 & 2 & 34 \\
\hline Humidity $(\%)$ & 472 & 66 & 20 & 12 & 100 \\
\hline AQI & 478 & 79 & 56 & 18 & 500 \\
\hline
\end{tabular}

\subsubsection{Effects of environmental factors}

Linear effects of humidity and AQI on the technical and physical performance of CSL teams can be found in Figure 3.2. A two-standard-deviation increment in humidity and AQI would only bring trivial or small effects on all the 17 technical performance-related parameters. The increase in humidity would decrease the seven physical performance-related parameters at a small magnitude. However, a two-standard-deviation increase in AQI would likely bring a small increment in the abovementioned seven physical performance-related parameters. 


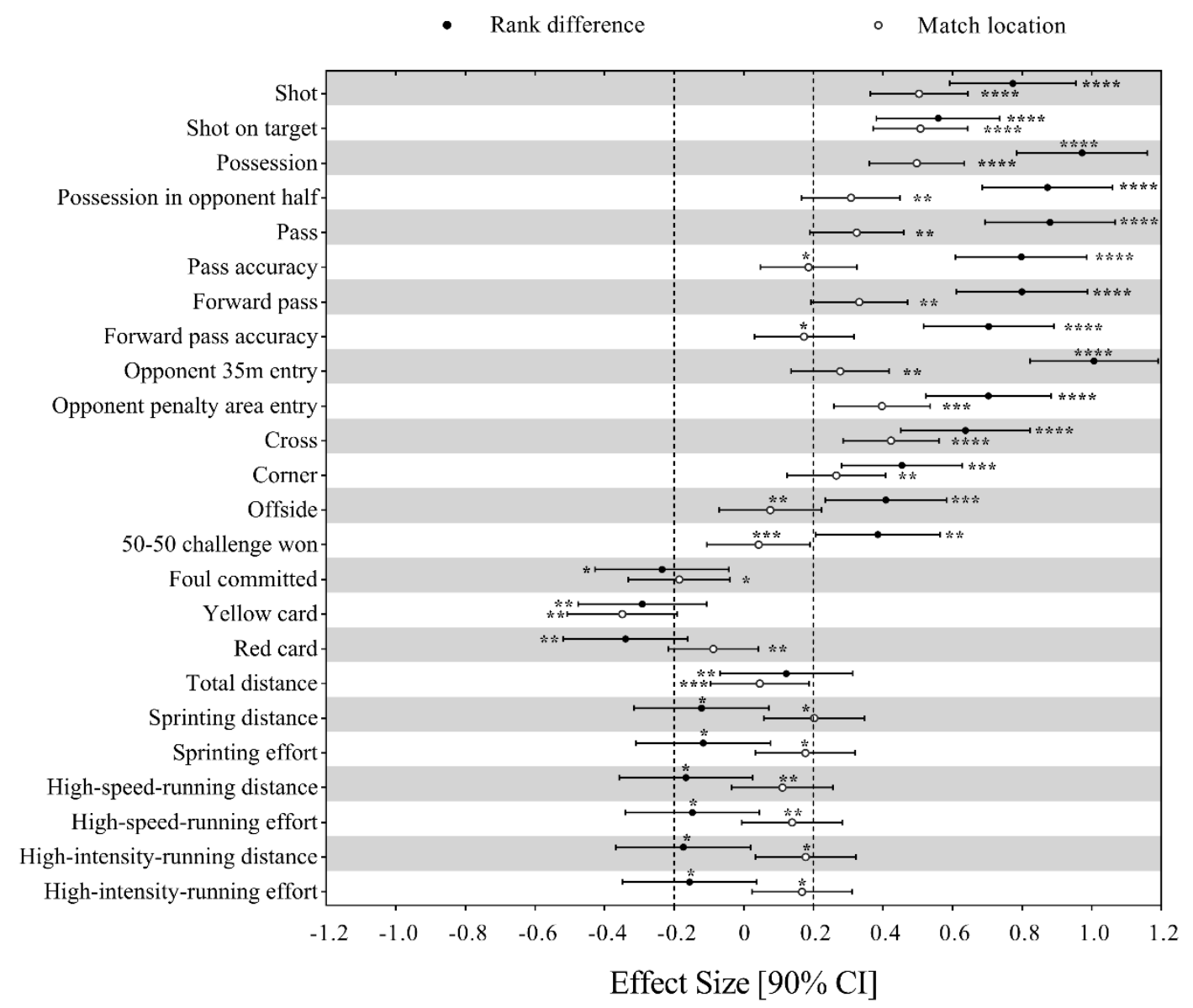

Figure 3.1 Effects of situational variables on the technical and physical performance of Chinese Soccer Super League (CSL) teams.

Effects of team and opponent strength are shown as the effect of an increase of two standard deviations in the value of difference in the log of ranks on the difference of each performance-related parameter. Effects of match location are shown as the effect of playing at home vs. playing away on the difference of each performance-related parameter. Bars are $90 \%$ confidence intervals. Dotted lines represent the smallest worthwhile difference. Asterisks indicate the likelihood for the magnitude of the true effect as follows: * possible; ** likely; *** very likely; *** most likely. Asterisks located in the trivial region denote likelihood of trivial effects.

Effects of temperature on the match performance are presented in Table 3.3. The CSL teams had the highest number of shots, forward passes, offsides and fouls committed whilst playing at the temperature of $18{ }^{\circ} \mathrm{C}, 17^{\circ} \mathrm{C}, 22{ }^{\circ} \mathrm{C}$ and $13{ }^{\circ} \mathrm{C}$, respectively. Teams achieved the most total distance, sprinting distance, sprinting effort, high-speed-running distance, high-speedrunning effort, high-intensity-running distance and high-intensity-running effort at the temperature of $11.6{ }^{\circ} \mathrm{C}, 15.1{ }^{\circ} \mathrm{C}, 13.2^{\circ} \mathrm{C}, 12{ }^{\circ} \mathrm{C}, 10.6{ }^{\circ} \mathrm{C}, 13.6^{\circ} \mathrm{C}$ and $11.6{ }^{\circ} \mathrm{C}$, respectively. While temperature showed trivial or small linear effects on technical performance-related parameters shot on target, possession, possession in opponent half, pass, pass accuracy, forward 


\section{won, yellow card and red card.}

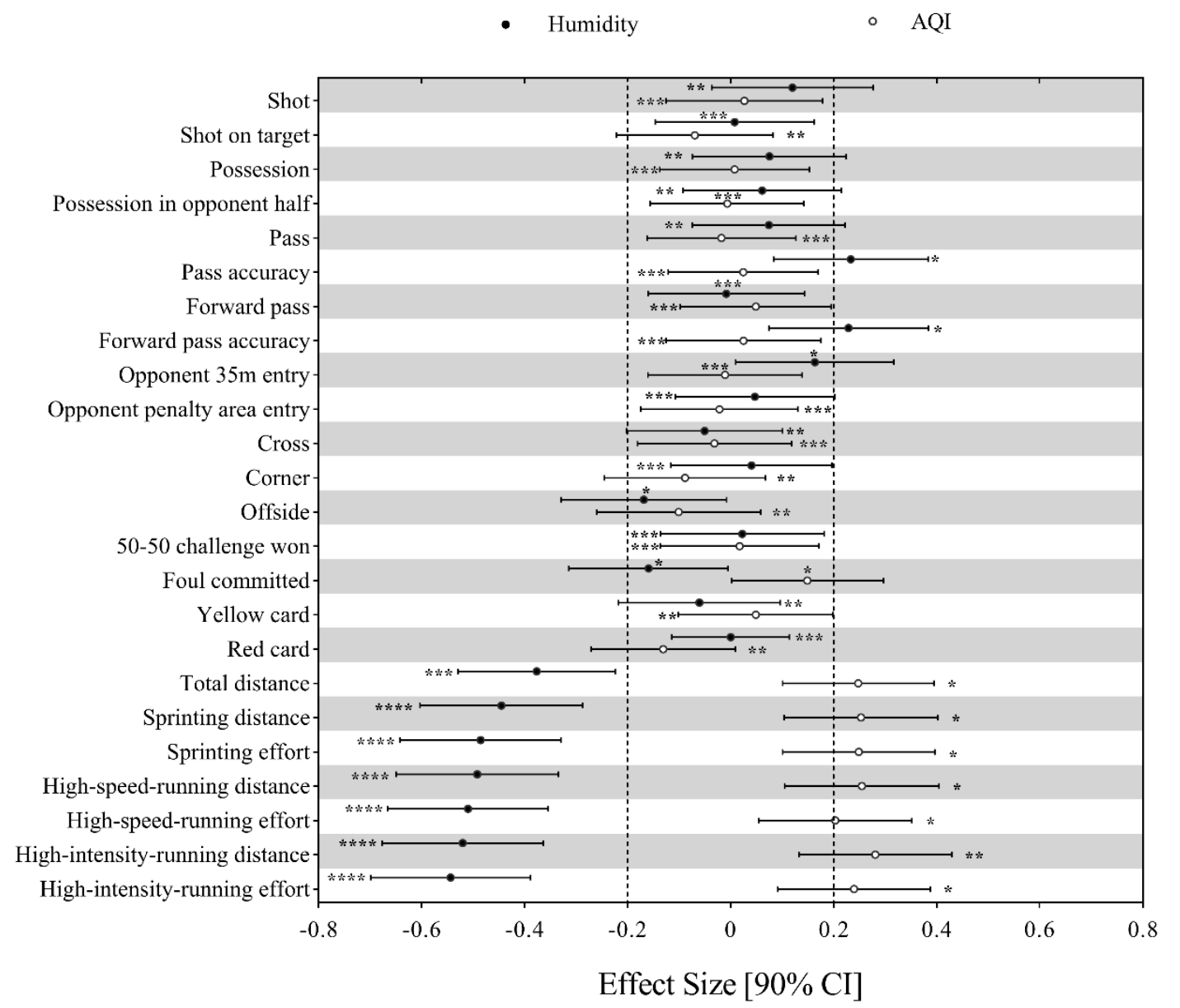

Figure 3.2 Effects of humidity and AQI (Air quality index) on the technical and physical performance of CSL teams. Effects are shown as the effect of an increase of two standard deviations in the value of humidity and AQI on the difference of each performance-related parameter. Dotted lines represent the smallest worthwhile difference. Asterisks indicate the likelihood for the magnitude of the true effect as follows: * possible; ** likely; *** very likely; **** most likely. Asterisks located in the trivial region denote likelihood of trivial effects. 


\begin{tabular}{|c|c|c|}
\hline Variables & $\begin{array}{c}\text { Quadratic Effect } \\
\text { Optimum Temperature; } \\
\pm 90 \% \text { CL }\end{array}$ & $\begin{array}{c}\text { Linear Effect } \\
\text { Standardized Effect; } \\
\pm 90 \% \mathrm{CL}\end{array}$ \\
\hline Shot & $18 ; \pm 12$ & \\
\hline Shot on target & & $0.00 ; \pm 0.16^{000}$ \\
\hline Possession & & $-0.02 ; \pm 0.16^{000}$ \\
\hline Possession in opponent half & & $0.06 ; \pm 0.16^{00}$ \\
\hline Pass & & $0.03 ; \pm 0.16^{000}$ \\
\hline Pass accuracy & & $0.27 ; \pm 0.16 * *$ \\
\hline Forward pass & $17 ; \pm 10$ & \\
\hline Forward pass accuracy & & $0.27 ; \pm 0.16 * *$ \\
\hline Opponent 35 m entry & & $0.10 ; \pm 0.16^{00}$ \\
\hline Opponent penalty area entry & & $0.06 ; \pm 0.16^{000}$ \\
\hline Cross & & $-0.21 ; \pm 0.17 *$ \\
\hline Corner & & $-0.01 ; \pm 0.17^{00}$ \\
\hline Offside & $22 ; \pm 13$ & \\
\hline $50-50$ challenge won & & $0.02 ; \pm 0.17^{00}$ \\
\hline Foul committed & $13 ; \pm 18$ & \\
\hline Yellow card & & $-0.15 ; \pm 0.17^{0}$ \\
\hline Red card & & $-0.16 ; \pm 0.17^{0}$ \\
\hline Total distance & $11.6 ; \pm 4.7$ & \\
\hline Sprinting distance & $15.1 ; \pm 2.7$ & \\
\hline Sprinting effort & $13.2 ; \pm 3.8$ & \\
\hline High-speed-running distance & $12.0 ; \pm 3.5$ & \\
\hline High-speed-running effort & $10.6 ; \pm 4.3$ & \\
\hline High-intensity-running distance & $13.6 ; \pm 2.6$ & \\
\hline High-intensity-running effort & $11.6 ; \pm 3.7$ & \\
\hline
\end{tabular}

\subsection{Discussion}

This study aimed at identifying the influence of situational and environmental factors on the technical and physical performance of the CSL soccer teams. Our main results include: i) situational variables (team and opponent's relative strength, playing at home/away) had major effects on the technical performance but trivial effects on the physical performance; ii) on the contrary, environmental factors affected mainly the physical performance but had only trivial or small effects on the technical performance. Specifically, we found that an increase in humidity would decrease the physical performance-related parameters with a small magnitude. Nevertheless, an increase in AQI would likely bring a small increment in the physical performance-related parameters and would most unlikely bring a decrease of physical performance. From the quadratic effects of temperature, we could conclude that CSL teams 
achieved the most shots, forward pass, offside, foul committed, total distance, sprinting distance, sprinting effort, high-speed-running distance, high-speed-running effort, highintensity-running distance, and high-intensity-running effort at temperatures varying from 10.6$22{ }^{\circ} \mathrm{C}$

\subsubsection{Home advantage}

Home advantage in soccer has been discussed in depth, and it is believed to affect choice of tactic and strategy in competition (Lago-Penas \& Lago-Ballesteros, 2011; Liu et al., 2017). Several authors have shown that, in soccer, home teams generally play better than the away side, making more shots, shots on target, performing better in shot accuracy and other offensive performance measures that are closely related to match success, meanwhile achieving fewer match actions and events related to defending (Liu et al., 2017; Seckin \& Pollard, 2008). A similar advantage in the technical performance for home teams in the CSL was detected in our research as well. Besides, home advantage was also argued as a factor affecting physical performance (high-intensity actions, low-intensity distance covered, total distance covered) in different soccer leagues (Aquino et al., 2017; Castellano et al., 2011; Lago, Casais, Dominguez, \& Sampaio, 2010). Lago, Casais, Dominguez and Sampaio (Lago et al., 2010) pointed out that the home teams covered a greater distance than away teams only during low-intensity activity $(<14.1 \mathrm{~km} / \mathrm{h})$ in the first division of Spanish soccer league. However, Castellano, BlancoVillasenor and Alvarez (Castellano et al., 2011) demonstrated there is no significant differences for distances covered at different intensities in the same league. Aquino, Munhoz Martins, Palucci Vieira and Menezes (Aquino et al., 2017) found that players perform significantly higher values in max speed, average speed and high-intensity actions in home matches when compared with away matches in the fourth division of Brazilian Championship of soccer. Given that the current results are in accordance with Castellano, Blanco-Villasenor and Alvarez (Castellano et al., 2011): no meaningful differences were observed in high-intensity distance 
and total distance covered by teams in matches playing at home and playing away. We could hence conclude that home advantage in the CSL only existed in the technical performance, but not physical aspects. However, it is worth noting that while the overall physical demands did not vary significantly within the match location, the influence of home advantage in technical and tactical aspects might modify the distribution of physical fitness in teams' offense and defence in a match, which may warrant further research.

\subsubsection{Strength of team and opponent}

It has been found that, stronger teams were generally more involved in possession-related actions (Liu et al., 2017; Trewin et al., 2017), and covered more distance and high-speedrunning distance whilst in ball possession than weaker teams (Trewin et al., 2017). Regarding the quality of opponents, previous studies (Bradley et al., 2014; Lago-Penas \& LagoBallesteros, 2011; Trewin et al., 2017; Varley et al., 2017) showed that when playing against weaker teams, the stronger team made more attacking related actions (possession, shots, shots on target, crosses, passes, passing accuracy) and less defensive actions (tackles, yellow cards). Our results showed that the technical match performance of CSL teams presented similar trend regarding the quality difference. However, we identified that changes in the rank difference only brought trivial effects on all the seven physical performance-related parameters, which is different from previous results that showed teams covered greater total distance and performed more high-intensity activities when playing against strong opponents than playing against weak opponents (Aquino et al., 2017; Rampinini, Coutts, Castagna, Sassi, \& Impellizzeri, 2007). This would suggest that physical demands in the matches of CSL were not affected by the difference in the quality of the team and opponent.

\subsubsection{Temperature comfort zone}

Findings from laboratory research showed that high ambient temperature increased the rate at which fatigue in the cardiovascular system and the central nervous system set in (Asmussen \& 
Bøje, 1945; Nybo \& Secher, 2004). At the other end of the temperature spectrum, low temperatures negatively affected fat and glycogen metabolism (Doubt, 1991; Sink, Thomas, Araujo, \& Hill, 1989). These physiological factors mentioned above, which are affected by high and low temperature, impair physical performance to some extent. In other words, there may be a temperature comfort zone to promote athletic performance. Different best temperature comfort zones have been reported in the previous studies. Grantham et al. (Grantham et al., 2010) claimed that the ambient temperature below $22^{\circ} \mathrm{C}$ did not pose a heat stress hazard, while temperatures above $22{ }^{\circ} \mathrm{C}$ increased the risk of hyperthermia. Chmura et al. (Chmura et al., 2017)10] showed that the best comfort zone for players to attain high levels of physical activity entailed an air temperature range below $22{ }^{\circ} \mathrm{C}$ and a relative humidity range below $60 \%$ in 2014 FIFA World Cup Brazil. Link and Weber (Link \& Weber, 2017) found a significant decrease in total distance covered by players in soccer matches from neutral $\left(-4\right.$ to $\left.13{ }^{\circ} \mathrm{C}\right)$ to warm $\left(\geqslant 14^{\circ} \mathrm{C}\right)$ environments in the top German soccer leagues. Therefore, it is logical that soccer players from different countries and competitions may have different best comfort zones of air temperature and humidity as they are living and training in different geographical and climatic conditions. In other words, the size of environmental influence is related with acclimatization and fitness status of players (Brocherie et al., 2015; Link \& Weber, 2017; Trewin et al., 2017). In China, the climate differs from region to region because of the country's extensive and complex topography. Our results tend to reflect that, in general, the CSL teams obtained most shot, forward pass, offside and foul committed at the temperature of 18, 17, 22, and $13{ }^{\circ} \mathrm{C}$, while achieving best physical performance at the temperature between 11.6 and 15.1 ${ }^{\circ} \mathrm{C}$.

\subsubsection{Humidity}

We found that an increase in humidity would decrease the physical performance-related parameters with a small magnitude. This is in accordance with the results of Chmura and 
colleagues (Chmura et al., 2017) which pointed out that high humidity would negatively affect the physical performance by decreasing both total distance covered and distance covered in different intensity zones. Our results already showed that all CSL teams had to play within a very large span of humidity: $12-100 \%$, with an average of over $66 \%$. Past research (Brewer \& Warren, 2014) showed that in high humidity conditions, due to the high moisture content, it was much harder for body heat to be lost by sweat evaporation. It has to divert blood to the skin to increase heat loss from convection and radiation. This would place an additional demand on cardiac output for blood due to the fact that is still required to transport oxygen to the working muscles, so that it will undermine the physical performance. In this research, an increase in humidity would decrease the physical performance-related parameters with a small magnitude but not impair technical performance. But this decrease in physical performance, especially high-intensity actions, was deemed to allow players to maintain a high-level technical performance (pass accuracy, forward pass accuracy) (Nassis et al., 2015; Trewin et al., 2017). All above-mentioned factors are particular challenges for the soccer coaching staff in their efforts to ensure optimal physical preparation of the players. Coaches need to be fully aware of the important impact of temperature and humidity on physical performance, prescribing appropriate training in advance.

\subsubsection{Air pollution}

Last but not least, the unique of this article is considering the impact of air quality on the performance of soccer teams. It is shown that an increase in AQI exhibited only trivial effects on the technical performance, which is different from the findings of Lichter, Pestel and Sommer (Lichter et al., 2017) that showed air pollution had a negative effect on the passes and pass accuracy. Meanwhile, an increase in AQI would likely bring a small increment in the physical performance-related parameters and would most unlikely bring a decrease. At the same time, this result is also contrary to the previous findings (Boussetta, Abedelmalek, Aloui, \& 
Souissi, 2017), which demonstrated that air pollution would decrease the physical performance of soccer players. These divergences can be explained by the difference in the amount of pollutant administered or the nature of exercise protocols. The current finding that the increment of physical performance in high AQI can be interpreted by the fact that the protection against the vascular dysfunction associated with particulate matter (PM) inhalation could potentially improve exercise performance in high-PM conditions (Rundell, 2012). The present finding shows that Chinese soccer players experienced different air quality environments, and an increase in AQI did not decrease the soccer players' acute physical performance. However, Keramidas et al. (Keramidas, Kounalakis, Eiken, \& Mekjavic, 2012) indicated that although air pollution does not affect the exercise performance but will cause some changes in physiological indicators in their experimental subjects. Therefore, the long-term impact of environmental pollution on the athlete's well-being is still under caution.

\subsection{Conclusion}

Our study demonstrated that situational variables had major effects on the technical performance but trivial effects on the physical performance in the CSL. On the contrary, environmental factors affected mainly the physical performance but had only trivial or small effects on the technical performance in the CSL. There may be an ambient temperature comfort zone $\left(10.6-22{ }^{\circ} \mathrm{C}\right)$ to promote soccer performance, and higher or lower temperature may impair soccer match performance. An increase in AQI would likely bring a small increment in the physical performance-related parameters and would most unlikely cause a decrease.

Coaching staff could be aware that temperature and humidity would affect the physical performance, while the game location and strength difference would influence the technical performance of football teams. Hence, physical match preparation could consider environmental factors at first, while technical-tactical match preparation could mainly base on situational factors. Given the fact that there may be a temperature comfort zone to achieve the 
maximum football performance, players could adopt their pacing strategies according to the ambient temperature in match. It can also help the referee set a reasonable water break based on air humidity and temperature.

In the present study, we have not considered the influence of different acclimatization (physiological adaptations) and fitness status of individual players, neither have we investigated the interactive effects of contextual and environmental factors, which could be directions of future research. The AQI values of our study were collected from the air quality monitoring stations nearest to the stadium, which might be not the most accurate real AQI of the playing condition inside the stadium. What is more, our study only focused on the temporary impact of environmental factors on the match performance. Hence, further study could employ more accurate and direct measures to investigate the effects of long-term environmental conditions on the soccer match performance. 


\subsection{References}

Aquino, R., Munhoz Martins, G. H., Palucci Vieira, L. H., \& Menezes, R. P. (2017). Influence of Match Location, Quality of Opponents, and Match Status on Movement Patterns in Brazilian Professional Football Players. Journal of Strength and Conditioning Research, 31(8), 2155-2161. doi:10.1519/JSC.0000000000001674

Asmussen, E., \& Bøje, O. (1945). Body temperature and capacity for work. Acta Physiologica, $10(1), 1-22$.

Boussetta, N., Abedelmalek, S., Aloui, K., \& Souissi, N. (2017). The effect of air pollution on diurnal variation of performance in anaerobic tests, cardiovascular and hematological parameters, and blood gases on soccer players following the Yo-Yo Intermittent Recovery Test Level-1. Chronobiology International, 1-18.

Bradley, P. S., Lago-Penas, C., Rey, E., \& Sampaio, J. (2014). The influence of situational variables on ball possession in the English Premier League. Journal of Sports Sciences, 32(20), 1867-1873. doi:10.1080/02640414.2014.887850

Brewer, J., \& Warren, L. (2014). Review of the potential implications of hot and humid environmental conditions on soccer match-play performance. Int J Sci: Basic Appl Res, 15(1), 584-589.

Brocherie, F., Girard, O., Farooq, A., \& Millet, G. P. (2015). Influence of weather, rank, and home advantage on football outcomes in the Gulf region. Medicine and Science in Sports and Exercise, 47(2), 401-410. doi:10.1249/MSS.0000000000000408

Carling, C., Bradley, P., McCall, A., \& Dupont, G. (2016). Match-to-match variability in highspeed running activity in a professional soccer team. Journal of Sports Sciences, 34(24), 2215-2223. doi:10.1080/02640414.2016.1176228

Castellano, J., Blanco-Villasenor, A., \& Alvarez, D. (2011). Contextual variables and timemotion analysis in soccer. International Journal of Sports Medicine, 32(6), 415-421. doi:10.1055/s-0031-1271771

Chmura, P., Konefal, M., Andrzejewski, M., Kosowski, J., Rokita, A., \& Chmura, J. (2017). Physical activity profile of 2014 FIFA World Cup players, with regard to different ranges of air temperature and relative humidity. International Journal of Biometeorology, 61(4), 677-684. doi:10.1007/s00484-016-1245-5

Doubt, T. J. (1991). Physiology of exercise in the cold. Sports Medicine, 11(6), 367-381. doi:10.2165/00007256-199111060-00003

Gai, Y., Leicht, A. S., Lago, C., \& Gomez, M. A. (2019). Physical and technical differences 
between domestic and foreign soccer players according to playing positions in the China Super League. Research in Sports Medicine, 27(3), 314-325. doi:10.1080/15438627.2018.1540005

Gomez, M. A., Lago-Penas, C., \& Pollard, R. (2013). Situational Variables. In T. MCGARRY, P. O'DONOGHUE, \& J. SAMPAIO (Eds.), Routledge Handbook of sports performance analysis (pp. 259-269). London: Routledge.

Grantham, J., Cheung, S. S., Connes, P., Febbraio, M. A., Gaoua, N., Gonzalez-Alonso, J., . . . Dvorak, J. (2010). Current knowledge on playing football in hot environments. Scandinavian Journal of Medicine and Science in Sports, 20 Suppl 3(s3), 161-167. doi:10.1111/j.1600-0838.2010.01216.x

Hébertlosier, K., Platt, S., \& Hopkins, W. G. (2015). Sources of Variability in Performance Times at the World Orienteering Championships. Medicine \& Science in Sports \& Exercise, 47(7), 1523-1530.

Hopkins, W. G. (2016). SAS (and R) for mixed models. Sportscience, 20, iii.

Hopkins, W. G., Marshall, S. W., Batterham, A. M., \& Hanin, J. (2009). Progressive statistics for studies in sports medicine and exercise science. Medicine and Science in Sports and Exercise, 41(1), 3-13. doi:10.1249/MSS.0b013e31818cb278

Hoppe, M. W., Slomka, M., Baumgart, C., Weber, H., \& Freiwald, J. (2015). Match Running Performance and Success Across a Season in German Bundesliga Soccer Teams. International Journal of Sports Medicine, 36(7), 563-566. doi:10.1055/s-0034-1398578

Keramidas, M. E., Kounalakis, S. N., Eiken, O., \& Mekjavic, I. B. (2012). Carbon monoxide exposure during exercise performance: muscle and cerebral oxygenation. Acta Physiologica (Oxford, England), 204(4), 544-554. doi:10.1111/j.17481716.2011.02363.X

Lago-Peñas, C., Gómez-Ruano, M., \& Yang, G. (2018). Styles of play in professional soccer: an approach of the Chinese Soccer Super League. International Journal of Performance Analysis in Sport, 17(6), 1073-1084. doi:10.1080/24748668.2018.1431857

Lago-Penas, C., \& Lago-Ballesteros, J. (2011). Game location and team quality effects on performance profiles in professional soccer. Journal of Sports Science \& Medicine, $10(3), 465-471$.

Lago-Peñas, C., Lago-Ballesteros, J., \& Rey, E. (2011). Differences in performance indicators between winning and losing teams in the UEFA Champions League. Journal of Human Kinetics, 27(1), 137-148. doi:10.2478/v10078-011-0011-3

Lago, C., Casais, L., Dominguez, E., \& Sampaio, J. (2010). The effects of situational variables 
on distance covered at various speeds in elite soccer. European Journal of Sport Science, 10(2), 103-109. doi:10.1080/17461390903273994

Lichter, A., Pestel, N., \& Sommer, E. (2017). Productivity effects of air pollution: Evidence from professional soccer. Labour Economics, 48, 54-66.

Link, D., \& Weber, H. (2017). Effect of Ambient Temperature on Pacing in Soccer Depends on Skill Level. Journal of Strength and Conditioning Research, 31(7), 1766-1770. doi:10.1519/JSC.0000000000001013

Liu, H., Yi, Q., Giménez, J.-V., Gómez, M.-A., \& Lago-Peñas, C. (2017). Performance profiles of football teams in the UEFA Champions League considering situational efficiency. International Journal of Performance Analysis in Sport, 15(1), 371-390. doi:10.1080/24748668.2015.11868799

Mao, L., Peng, Z., Liu, H., \& Gómez, M.-A. (2017). Identifying keys to win in the Chinese professional soccer league. International Journal of Performance Analysis in Sport, 16(3), 935-947. doi:10.1080/24748668.2016.11868940

Nassis, G. P., Brito, J., Dvorak, J., Chalabi, H., \& Racinais, S. (2015). The association of environmental heat stress with performance: analysis of the 2014 FIFA World Cup Brazil. British Journal of Sports Medicine, 49(9), 609-613. doi:10.1136/bjsports-2014094449

Nybo, L., \& Secher, N. H. (2004). Cerebral perturbations provoked by prolonged exercise. Progress in Neurobiology, 72(4), 223-261. doi:10.1016/j.pneurobio.2004.03.005

Phillips, K. E., \& Hopkins, W. G. (2017). Performance Relationships in Timed and Mass-Start Events for Elite Omnium Cyclists. International Journal of Sports Physiology and Performance, 12(5), 628-633. doi:10.1123/ijspp.2016-0204

Rampinini, E., Coutts, A. J., Castagna, C., Sassi, R., \& Impellizzeri, F. M. (2007). Variation in top level soccer match performance. International Journal of Sports Medicine, 28(12), 1018-1024. doi:10.1055/s-2007-965158

Rundell, K. W. (2012). Effect of air pollution on athlete health and performance. British Journal of Sports Medicine, 46(6), 407-412. doi:10.1136/bjsports-2011-090823

Sarmento, H., Marcelino, R., Anguera, M. T., CampaniCo, J., Matos, N., \& LeitAo, J. C. (2014). Match analysis in football: a systematic review. Journal of Sports Sciences, 32(20), 1831-1843. doi:10.1080/02640414.2014.898852

Seckin, A., \& Pollard, R. (2008). Home advantage in Turkish professional soccer. Perceptual and Motor Skills, 107(1), 51-54. doi:10.2466/pms.107.1.51-54

Sink, K. R., Thomas, T. R., Araujo, J., \& Hill, S. F. (1989). Fat energy use and plasma lipid 
changes associated with exercise intensity and temperature. European Journal of Applied Physiology and Occupational Physiology, 58(5), 508-513.

Taylor, J. B., Mellalieu, S. D., James, N., \& Shearer, D. A. (2008). The influence of match location, quality of opposition, and match status on technical performance in professional association football. Journal of Sports Sciences, 26(9), 885-895. doi:10.1080/02640410701836887

Trewin, J., Meylan, C., Varley, M. C., \& Cronin, J. (2017). The influence of situational and environmental factors on match-running in soccer: a systematic review. Science and Medicine in Football, 1(2), 183-194. doi:10.1080/24733938.2017.1329589

Varley, M. C., Gregson, W., McMillan, K., Bonanno, D., Stafford, K., Modonutti, M., \& Di Salvo, V. (2017). Physical and technical performance of elite youth soccer players during international tournaments: influence of playing position and team success and opponent quality. Science and Medicine in Football, 1(1), 18-29.

Yang, G., Leicht, A. S., Lago, C., \& Gomez, M. A. (2018). Key team physical and technical performance indicators indicative of team quality in the soccer Chinese super league. Research in Sports Medicine, 26(2), 158-167. doi:10.1080/15438627.2018.1431539

Zhou, C., Zhang, S., Lorenzo, A., \& Cui, Y. (2018). Chinese soccer association super league, 2012-2017: key performance indicators in balance games. International Journal of Performance Analysis in Sport, 18(4), 645-656. doi:10.1080/24748668.2018.1509254

Zubillaga, A. (2006). La actividad del jugador de fútbol en alta competición: análisis de variabilidad. (PhD), Universidad de Malaga,

Zubillaga, A., Gorospe, G., Hernandez, A., \& Blanco, A. (2009). Comparative analysis of the high-intensity activity of soccer players in top level competition. Science and Football VI, 182-185. 


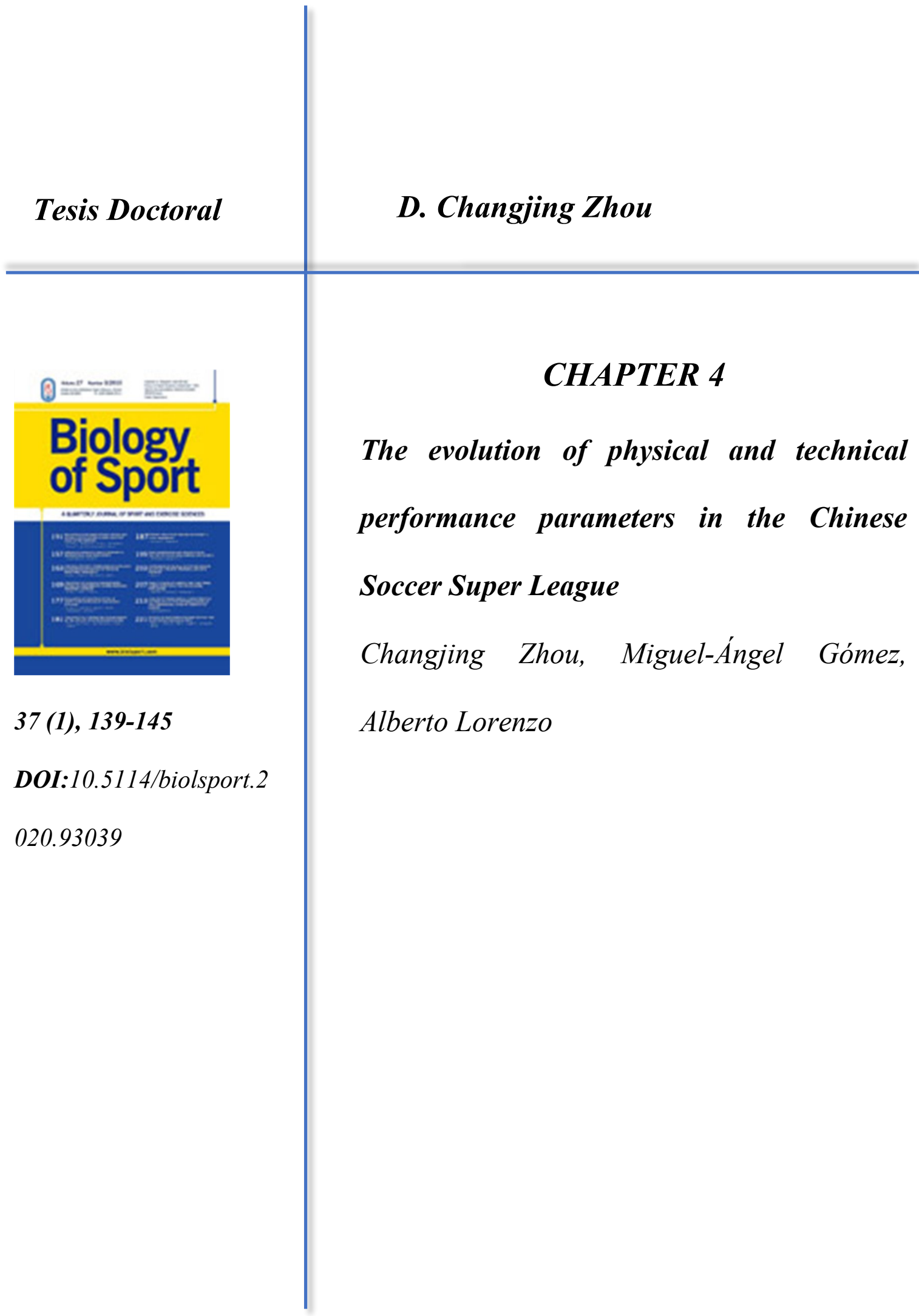




\section{Chapter 4 The evolution of physical and technical performance}

\section{parameters in the Chinese Soccer Super League}

\subsection{Introduction}

The complex nature of soccer requires from players and teams a combination of physical, technical and tactical performances (Bush et al., 2015). In recent decades, its evolution has been influenced by changes in rules and match tactics, increased professionalism, the use of new technologies, wider global exposure, international transfers of players and coaches, and transformations in training and selection processes (Bush et al., 2016; Wallace \& Norton, 2014). These changes open up new demands on coaching staff and recruitment managers, allowing development of their own personal understanding and improving their sport-specific knowledge, which can help to maximize the players' development and soccer club benefits.

Previous studies have shown an increasing trend in both the physical and technical demands of the game at a professional level (Barnes et al., 2014). Specifically, increasing passing rates and ball speeds in World Cup final matches over a 44-year period (1966-2010) have been observed (Wallace \& Norton, 2014). Additionally, Barnes et al. (2014) reported that the English Premier League (EPL) underwent substantial changes from the 2006-2007 seasons to the 2012-2013 seasons, with high-intensity running and sprinting distances increasing by $30 \%-50 \%$ and the number of passes increasing by $40 \%$; subsequent research identified these evolutionary trends as position- and tier-specific (Barnes et al., 2014; Bush et al., 2015). Although these studies provide preliminary knowledge regarding the evolution of international elite soccer before the 2012-2013 seasons, research regarding the evolution of soccer in recent years is limited, especially for low level soccer leagues, such as the Chinese Soccer Super League (CSL).

The majority of teams in the CSL have invested considerable sums in recruiting numerous world-famous foreign coaches and players (Connell, 2018). The increasingly skilled national league has also increased in visibility due to the presence of international stars and greater 
television coverage in Asia (Connell, 2018). However, research on this league is scarce. Recent studies on the CSL by Zhou et al. (2018) and Mao et al. (2017) reported that shots on target, shot accuracy, sprinting distance in ball possession, quality of opposition, number of passes, and number of forward passes have an effect on the match outcome. Furthermore, Yang et al. (2018) found that upper-ranked teams had greater sprinting distance, total distance out of ball possession, possession, possession during the opponent's half, number of entry passes in the final $1 / 3$ of the field and penalty area, and 50-50 challenges than did lower-ranked teams. Similarly, Lago-Peñas et al. (2018) identified four playing styles in CSL teams ("possession" play, set pieces attack, counterattacking play, and transitional play) by examining 20 match performance indicators. These studies mainly focused on the key performance indicators associated with match outcome or team quality in isolated seasons. Consequently, detailed information on longitudinal trends in these indicators, which could help coaches to better monitor, prepare, and conduct training programmes, are currently lacking.

The aim of this study was to examine the evolution in physical and technical performance parameters in the CSL from the 2012 season to the 2017 season. Coaches and performance analysts from developing soccer countries may benefit from more detailed knowledge regarding teams' performances. Specifically, a better understanding of the recent developmental trends could, in turn, be used in the daily training and future planning of players. Furthermore, the development of soccer in a specific country could be related to the quantity and quality of soccer research.

\subsection{Materials and Methods}

\subsubsection{Sample, data resource}

The Chinese Soccer Super League is the highest level of professional soccer matches in China (16 teams playing a regular season with a balanced schedule against their opponents both at home and away from March to November every season; then each team plays 30 matches per 
season and the competition includes a total of 240 matches per season). A total of 1,429 matches out of 1,440 CSL matches (11 matches had missing data) from six seasons (2012 to 2017) were selected. The final sample was composed of the observation of 1,032 players $(n=36,397$ match participations) with a mean age of $26.8 \pm 3.7$ years old. The unit of analysis was the team's match performance. Match statistics were collected using the Amisco Pro (Amisco, Nice, France) tracking system. The reliability and validity of this system for the measurement of player movement have been previously evaluated, and it has been shown to have high precision (Zubillaga et al., 2009). Data were obtained from the original match report provided by AMISCO and transferred to a database. The study design was approved by our local university ethics committee.

\subsubsection{Procedure and statistical analysis}

In accordance with previous studies (Sarmento et al., 2014; Yang et al., 2018; Zhou et al., 2018), 14 technical performance-related indicators and 11 physical performance-related indicators were chosen as dependent variables; the categories and definitions of these variables are shown in Table 4.1 (Zhou et al., 2018). The distribution of each variable was examined for normality using the Kolmogorov-Smirnov test. A mixed linear model for repeated measures (Liu et al., 2016; Malcata, Hopkins, \& Richardson, 2012) was applied to identify the effect of season as a fixed factor on the match performance variables and player ID was considered as a random

effect. Additionally, the Bonferroni correction post-hoc test was used to verify localized differences (multiple comparisons). The effect size (ES) of localized differences was determined by the standardized Cohen's $d$ and classified as trivial $(<0.2)$, small $(>0.2-0.6)$, moderate $(>0.6-1.2)$, or large (>1.2-2.0) (Batterham \& Hopkins, 2006). In addition, data visualizations of performance indicators were plotted using the R software in order to identify trends in performance evolution along the seasons. Statistical significance was set at $\mathrm{p}<0.05$. Statistical analyses were performed using SPSS version 23 (IBM, Armonk, NY, USA). 
Table 4.1 Definitions of selected technical and physical performance-related parameters.

\begin{tabular}{|c|c|}
\hline \multicolumn{2}{|c|}{ Technical performance-related parameters: operational definition } \\
\hline Shot & An attempt to score a goal, made with any (legal) part of the body, either on or off target \\
\hline Shot on target & $\begin{array}{l}\text { An attempt to score a goal, which required intervention to stop the ball going in or resulted in } \\
\text { a goal/shot that would have gone in without diversion } \\
\text { Possession by a team in the opponent's half of the pitch }\end{array}$ \\
\hline Possession in opponent half (\%) & An intentionally played ball from one player to another \\
\hline Pass: & Successful passes as a proportion of the total passes \\
\hline Pass accuracy $(\%)$ & An intentionally played ball from one player to another who is located closer to the opponent \\
\hline Forward pass & goal. \\
\hline & Successful forward passes as a proportion of the total forward passes \\
\hline Forward pass accuracy $(\%)$ & Number of times when the ball (possessed by the attacking team) enters the $35 \mathrm{~m}$ area of the \\
\hline Opponent 35-m entry & opponent's half of the pitch \\
\hline Opponent penalty area entry & $\begin{array}{l}\text { Number of times when the ball (possessed by the attacking team) enters the penalty area of the } \\
\text { opponent's half of the pitch }\end{array}$ \\
\hline & Any ball sent into the opposition team's area from a wide position \\
\hline Cross & Ball goes out of play for a corner kick \\
\hline Corner & Being caught in an offside position resulting in a free kick to the opposing team \\
\hline Offside & Any infringement that is penalised as foul play by a referee \\
\hline Foul committed & A yellow card is shown to a player by the referee for reasons of foul play, persistent \\
\hline Yellow card & infringement, hand ball, dangerous play, time wasting, etc. \\
\hline \multicolumn{2}{|c|}{ Physical performance-related parameters: operational definition } \\
\hline Total distance (m) & Distance covered in a match \\
\hline Total distance IP(m) & Total distance covered when in ball possession \\
\hline Total distance $\mathrm{OP}(\mathrm{m})$ & Total distance covered when out of ball possession \\
\hline Sprinting distance $(\mathrm{m})$ & Distance covered at a speed over $23 \mathrm{~km} / \mathrm{h}$ in a match \\
\hline Sprinting effort & Number of sprints in a match \\
\hline Sprinting distance IP (m) & Sprinting distance covered when in ball possession \\
\hline Sprinting distance OP (m) & Sprinting distance covered when out of possession \\
\hline High-speed running distance (m) & Distance covered at a speed of $19.1-23 \mathrm{~km} / \mathrm{h}$ in a match \\
\hline High-speed running effort & Number of high-speed runs in a match \\
\hline High-speed running distance IP (m) & High-speed running distance covered when in ball possession \\
\hline High-speed running distance OP (m) & High-speed running distance covered when out of ball possession \\
\hline
\end{tabular}

\subsection{Results}

Table 4.2 summarizes the technical performance data according to season. Significant differences among the six seasons were found ( $p<0.05$, range of $\mathrm{CV}: 2.6$ to 93.8$)$ for the shots on target, corners, crosses, passes, pass accuracy, forward passes, forward pass accuracy, opponent 35-m entries, opponent penalty area entries, and fouls committed. Passing-related performance variables (passes, pass accuracy, forward passes, forward pass accuracy) peaked in seasons 2013 and 2014. Players performed more passes in seasons 2013 and 2014 than in 
other seasons $(\mathrm{p}<0.05$; ES: 0.13-0.33), and had higher pass accuracy in seasons 2013 and 2014 than in seasons 2012 and $2017(\mathrm{p}<0.001$; ES: 0.33-0.45). Additionally, players had higher forward pass accuracy in season 2013 than in other seasons $(p<0.05$; ES: 0.17-0.51) and performed more forward passes in season 2014 than in other seasons, with the exception of season $2013(\mathrm{p}<0.05$; ES: 0.15-0.24). Despite variability among seasons, there were clear increasing trends in crosses, shots on target, and opponent penalty area entries across the six seasons. There were $\sim 23 \%$ more crosses $(\mathrm{p}<0.001$; ES: 0.45$), \sim 12 \%$ more shots on target $(p<0.001$; ES: 0.22$)$, and $\sim 11 \%$ more opponent penalty area entries $(p<0.001$; ES: 0.20$)$ in the 2017 season than in the 2012 season.

The regression lines in Figure 4.1 show that most of the physical performance variables, other than the total distance and total distance according to ball possession, had significant increasing trends over the six seasons. However, variability among seasons existed; for example, highspeed running and sprint-related variables had significantly lower values in season 2013 than in other seasons ( $\mathrm{p}<0.001$; ES: $0.31-1.15)$. The total sprinting distance increased by $9.8 \%$ from the 2012 season to the 2017 season $(2069.7 \pm 509.3 \mathrm{~m}$ vs. $2272 \pm 493.6 \mathrm{~m}, \mathrm{p}<0.001$; ES: 0.40$)$, and increased by $4.7 \%$ in the number of sprints $(100.1 \pm 22.8$ vs. $104.8 \pm 20.8, p<0.001$; ES: 0.22$)$. Additionally, the sprinting distance in ball possession increased by $7.6 \%$ from the 2012 season to the 2017 season $(1033.6 \pm 322.2 \mathrm{~m}$ vs. $1112.1 \pm 318.7 \mathrm{~m}, \mathrm{p}<0.001$; ES: 0.24$)$ and that for out of ball possession increased by $12.9 \%(963.3 \pm 310.4$ vs. $1087.7 \pm 307.5, \mathrm{p}<0.001$; ES: 0.40$)$. Furthermore, the high-speed running distance increased by $9.9 \%(2568.4 \pm 503.5 \mathrm{~m}$ vs. 2823.1 $\pm 479.2 \mathrm{~m}, \mathrm{p}<0.001$; ES: 0.52), high-speed effort increased by $9.2 \%$ (187.5 $\pm 36.1 \mathrm{vs}$. 204.7 $\pm 33.7, \mathrm{p}<0.001$; ES: 0.49), high-speed running distance in ball possession increased by $6.6 \%(1131.1 \pm 278$ vs. $1205.4 \pm 275.3, \mathrm{p}<0.001$; ES: 0.27$)$, and high-speed running distance out of ball possession increased by $14.6 \%(1301.8 \pm 314.5$ vs. $1491.5 \pm 331.8, \mathrm{p}<0.001$; ES: 0.59$)$. However, the total distance in ball possession ( $>>0.05$, ES: 0.15$)$ and out of ball possession ( $p$ 
$>0.05$, ES: 0.04) did not significantly differ between the 2012 and 2017 seasons.

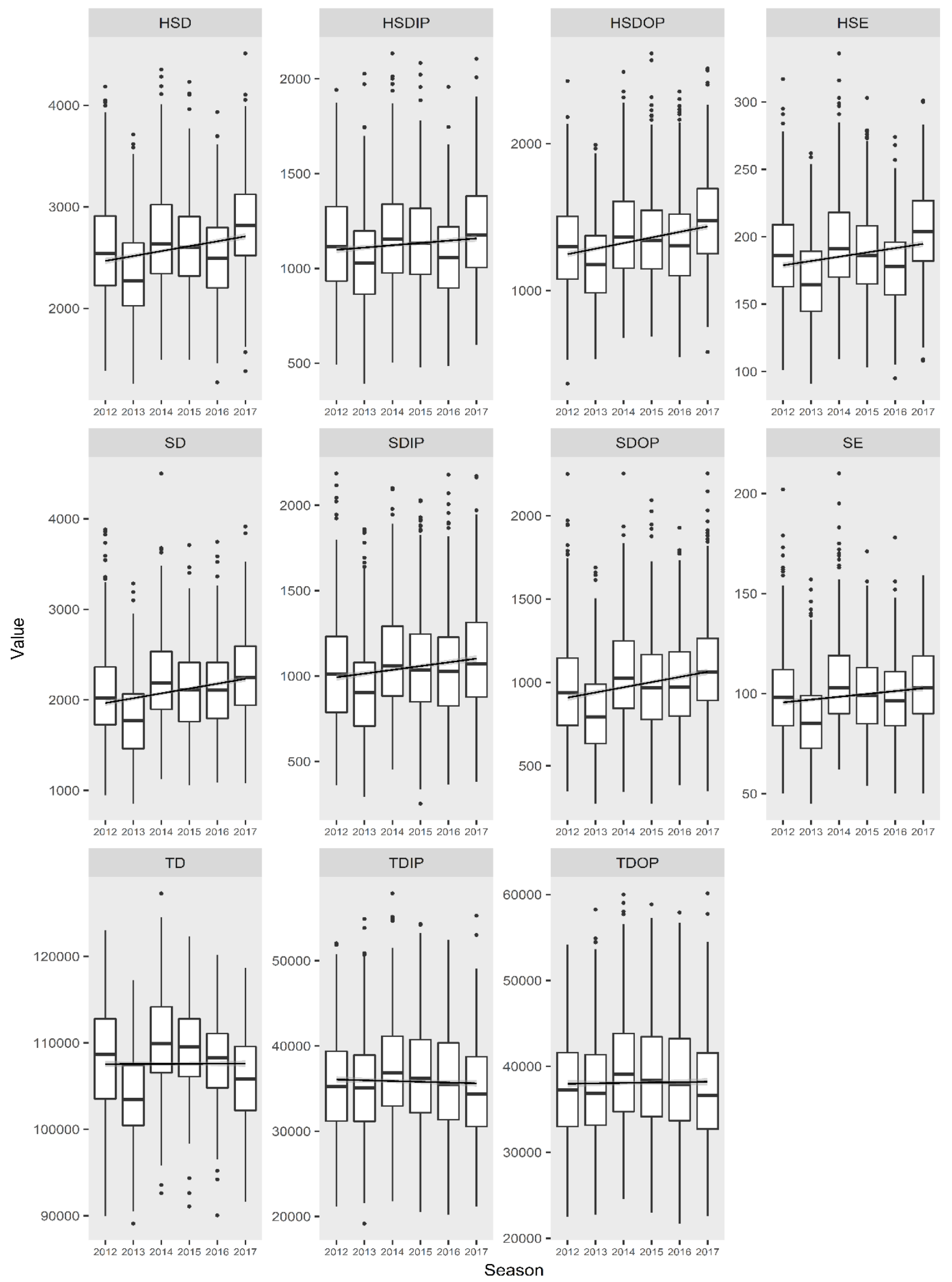

Figure 4.1 The evolution of physical performance in CSL over 6 seasons from 2012 to 2017.

Abbreviations: $T D=$ Total distance; $S D=$ Sprinting distance; $S E=$ Sprinting effort, HSD=High-speed running distance; $\mathrm{HSE}=$ High-speed running effort; $\mathrm{IP}=\mathrm{In}$ ball possession; $\mathrm{OP}=\mathrm{Out}$ of ball possession. Line represents the regression line and $95 \%$ confidence interval. 
Table 4.2 The evolution of technical performance in the Chinese Soccer Super League over 6 seasons (from 2012 to 2017)

\begin{tabular}{|c|c|c|c|c|c|c|c|c|c|c|}
\hline & $2012-2017$ & $2012(478)$ & $2013(480)$ & $2014(478)$ & $2015(478)$ & $2016(470)$ & 2017 (474) & $\mathrm{F}$ & Sig. & $\mathrm{CV}$ \\
\hline Shots & $12.5 \pm 4.9$ & $12.2 \pm 4.7$ & $12.7 \pm 5.0$ & $12.4 \pm 5.2$ & $12.3 \pm 4.9$ & $12.3 \pm 5.0$ & $13.1 \pm 4.7^{*}$ & 2.12 & 0.060 & 4.9 \\
\hline Shots on target & $4.8 \pm 2.6$ & $4.3 \pm 2.3$ & $5.2 \pm 2.7 * * *$ & $4.9 \pm 2.8^{* *}$ & $4.6 \pm 2.7$ & $4.7 \pm 2.7^{*}$ & $4.8 \pm 2.5^{* *}$ & 5.88 & $<0.001$ & 2.6 \\
\hline Corners & $4.7 \pm 2.7$ & $4.6 \pm 2.7$ & $4.6 \pm 2.8$ & $4.8 \pm 2.8$ & $4.6 \pm 2.8$ & $4.4 \pm 2.5$ & $5.0 \pm 2.8$ & 2.59 & 0.024 & 2.7 \\
\hline Crosses & $14.3 \pm 6.7$ & $12.8 \pm 6.0$ & $13.7 \pm 6.3$ & $14.3 \pm 6.8 * *$ & $14.5 \pm 6.6^{* * *}$ & $14.9 \pm 7.2 * * *$ & $15.6 \pm 6.9 * * *$ & 10.72 & $<0.001$ & 6.7 \\
\hline Possession in opponent's half & $44.5 \pm 7.5$ & $43.9 \pm 7.6$ & $44.6 \pm 7.4$ & $44.2 \pm 7.6$ & $44.3 \pm 7.5$ & $45.0 \pm 7.9$ & $44.9 \pm 7.2$ & 1.51 & 0.182 & 7.5 \\
\hline Passes & $369.0 \pm 94.3$ & $357.2 \pm 92.0$ & $387.4 \pm 91.8^{* * *}$ & $379.2 \pm 92.9^{* *}$ & $362.7 \pm 94.7$ & $367.0 \pm 101.1$ & $360.0 \pm 90.0$ & 7.67 & $<0.001$ & 93.8 \\
\hline Pass accuracy & $78.9 \pm 5.8$ & $77.3 \pm 5.9$ & $79.7 \pm 5.6^{* * *}$ & $79.8 \pm 5.5^{* * *}$ & $79.6 \pm 5.7 * * *$ & $79.5 \pm 5.9^{* * *}$ & $77.8 \pm 5.8$ & 17.75 & $<0.001$ & 5.8 \\
\hline Forward passes & $124.7 \pm 25.3$ & $122.1 \pm 27.2$ & $127.1 \pm 27.4^{* *}$ & $128.3 \pm 24.5^{* * *}$ & $122.9 \pm 24.9$ & $123.0 \pm 24.7$ & $124.7 \pm 22.3$ & 4.71 & $<0.001$ & 25.2 \\
\hline Forward pass accuracy & $63.4 \pm 8.5$ & $62.7 \pm 8.8$ & $65.6 \pm 9.1 * * *$ & $64.1 \pm 8.3 *$ & $63.8 \pm 8.2$ & $62.7 \pm 8.5$ & $61.3 \pm 7.7$ & 14.62 & $<0.001$ & 8.5 \\
\hline Opponent $35-\mathrm{m}$ entries & $44.6 \pm 14.1$ & $43.4 \pm 14.1$ & $45.7 \pm 14.4^{*}$ & $45.6 \pm 14.6$ & $44.0 \pm 13.9$ & $45.1 \pm 14.8$ & $43.9 \pm 12.9$ & 2.29 & 0.043 & 14.1 \\
\hline Opponent penalty area entries & $6.9 \pm 3.8$ & $6.4 \pm 3.5$ & $6.9 \pm 3.8$ & $6.7 \pm 3.7$ & $6.9 \pm 3.8$ & $7.2 \pm 4.2 * *$ & $7.1 \pm 3.7^{*}$ & 2.55 & 0.026 & 3.8 \\
\hline Fouls committed & $16.4 \pm 4.7$ & $16.9 \pm 4.4$ & $15.6 \pm 4.5^{* * *}$ & $16.7 \pm 4.6$ & $17.1 \pm 5.1$ & $15.7 \pm 4.8^{* *}$ & $16.1 \pm 4.6$ & 8.76 & $<0.001$ & 4.7 \\
\hline Offsides & $2.2 \pm 1.8$ & $2.2 \pm 1.7$ & $2.3 \pm 1.9$ & $2.2 \pm 1.8$ & $2.3 \pm 1.8$ & $2.2 \pm 1.8$ & $2.3 \pm 1.7$ & 0.80 & 0.547 & 1.8 \\
\hline Yellow cards & $2.0 \pm 1.3$ & $2.1 \pm 1.3$ & $2.0 \pm 1.3$ & $1.9 \pm 1.3$ & $1.9 \pm 1.4$ & $2.0 \pm 1.4$ & $2.1 \pm 1.4$ & 1.91 & 0.089 & 1.3 \\
\hline
\end{tabular}

$* \mathrm{p}<0.05, * * \mathrm{p}<0.01$, and $* * * \mathrm{p}<0.001$ denote a significant difference from the 2012 season; CV $=$ square root of estimates of covariance

parameters. 


\subsection{Discussion}

To our knowledge, the present study is the first to explore the temporal evolution of physical and technical parameters of teams participating in the CSL. The present study found that the high-intensity running distance increased substantially over the six seasons, while the total running distance did not clearly change. Regarding technical performance variables, crosses, shots on target, and opponent penalty area entries showed increasing trends, whereas passingrelated variables showed peak values in seasons 2013 and 2014.

Consistent with a previous study by Barnes et al. (2014), the total distance covered during a match remained constant over time, while high-intensity running distances (sprinting and highspeed running) increased over six seasons in the CSL. Bush et al. (2015) reported that an elevation in high-intensity running in the EPL was due to evolving game patterns, as opposed to natural variability. The authors also speculated that this evolution was a consequence of developments in the physical preparation of the players or an influx of players with innately higher levels of physical fitness (Barnes et al., 2014; Bush et al., 2015). Increased high-intensity running distance would affect the training strategy, as high-intensity running has been shown to be related to the physical capacity of the players (Bradley et al., 2011) and match outcome (Aquino et al., 2017; Faude et al., 2012; Zhou et al., 2018). Interestingly, CSL teams covered less distance, especially high-intensity running distance, in the 2013 season than in other seasons. We presume that this result is related to the superior passing performance of teams participating in the 2013 season. Furthermore, Gai et al. (2019) reported the presence of gaps in physical fitness, especially in high-intensity running capacity, between Chinese and foreign players. In fact, greater recruitment of foreign players within a training squad might have contributed to some of the observed changes, or differences, in physical performance in the CSL league. On the other hand, these gaps indicate a difference in physical fitness between players in the CSL and those from developed soccer leagues. The present study results suggest 
a demand for high-intensity running ability in the modern game, which has increased over six seasons as the level of competition increased in the CSL.

It is important to note that, from the 2012 season to the 2017 season, the increase in highintensity running distances was greater for out of ball possession than for in ball possession (sprinting distance: $12.9 \%$ vs. $7.6 \%$; high-speed running distance: $14.6 \%$ vs. $6.6 \%$, respectively). This trend indicates that changes in physical ability demands in the CSL were greater for defending than for attacking. This result is expected, as the execution of highintensity actions with the ball (i.e. offensive actions) is technically more difficult than that without the ball (i.e. defensive actions). Consequently, increasing the defensive pressure allows more balls to be recovered during high-intensity actions. Previous results imply that there were more balls lost and turnovers in the CSL than in top-level competitions (Vogelbein, Nopp, \& Hokelmann, 2014). Therefore, a constant interchange of ball possession via high-intensity actions and recoveries occurs during the game, resulting in an increased interchange of opportunities occurring close to the opponent's area. Other studies have shown an advantage of recovering ball possession as close to the opponent's goal as possible, increasing goal scoring opportunities (Fernandez-Navarro, Fradua, Zubillaga, Ford, \& McRobert, 2016; LagoBallesteros, Lago-Penas, \& Rey, 2012; Tenga, Holme, Ronglan, \& Bahr, 2010; Tenga, Ronglan, \& Bahr, 2010). Moreover, it has become increasingly common in soccer matches for players to restrict passing options and the available space once a team loses possession of the ball, by immediately applying defensive pressure. This requires high levels of intense running, but can effectively delay the opposition's offensive play, and allow the team to regain possession of the ball as well.

Regarding technical performance parameters, the number of shots on target is an important indicator determining the success of CSL teams (Mao et al., 2017; Yang et al., 2018; Zhou et al., 2018). The present study showed that the number of shots on target increased over six 
seasons. This may result from better player recruitment, both in physical and technical terms, as well as improved tactics due to the influx of experienced coaches (e.g., team coaches, trainers, or managers). Although ball possession in the opponent's half and the number of opponent 35$\mathrm{m}$ entries did not significantly change, the number of opponent penalty area entries increased over six seasons in the CSL. This result may imply that once the team controlled the ball in the opponent's half (including recovering the ball in this area), they tried their best to pass the ball into the opponent's penalty area via more forward passes or crosses. Although the number of crosses is not a key performance indicator affecting the match outcome in the CSL (Zhou et al., 2018), it is an important measure of the playing style, in terms of the offensive pressure against opponents (Fernandez-Navarro, Fradua, Zubillaga, \& McRobert, 2018). Thus, crosses may not directly lead to a goal, but they do contribute to creating more attack opportunities.

Passing performance was better in seasons 2013 and 2014 than in other seasons in the CSL. Pass density (number of passes per minute of possession) and pass precision (number of completed passes relative to the total number of passes) are strongly associated with match success (Hewitt, Greenham, \& Norton, 2017). Additionally, passing rates and ball speeds during World Cup finals have continued to increase over a 44-year period (Wallace \& Norton, 2014). Thus, it could be inferred that CSL teams improved their ability to control the game by making more passes and maintaining higher passing success rates during this period. However, the number of passes and pass accuracy decreased continuously from the 2015 season to the 2017 season; this result may be related to increasingly greater defensive pressure on ball possession when passing the ball, and less available space via more high-intensity activities by opponents, as shown in the current study. As an opponent increases the defensive pressure, the team must constantly adapt their spatial configuration. This requires greater concentration and decision-making capacity from the players, as well as higher levels of physical fitness (Hewitt et al., 2017). 


\subsection{Conclusion}

Physical performance, especially high-intensity running distances, together with technical performance parameters, such as crosses, shots on target, and opponent penalty area entries, have increased over six seasons in the CSL. The evolution in these variables reflects the recent performance trends in CSL match play over a six-season period. The current findings regarding performance evolution in the CSL can enable coaches to better understand the development of Chinese soccer and optimize training methods. Knowledge regarding evolutionary patterns could provide soccer club managers new perspectives in talent identification and player recruitment. The normative profiles and developmental trends in the present study can help elite soccer players (especially for younger players) to better prepare and adapt their physical and technical ability for their professional career. The current results could also be used to compare the current situation in Chinese soccer with that in developed soccer leagues internationally. 


\subsection{References}

Aquino, R., Munhoz Martins, G. H., Palucci Vieira, L. H., \& Menezes, R. P. (2017). Influence of Match Location, Quality of Opponents, and Match Status on Movement Patterns in Brazilian Professional Football Players. Journal of Strength and Conditioning Research, 31(8), 2155-2161. doi:10.1519/JSC.0000000000001674

Barnes, C., Archer, D. T., Hogg, B., Bush, M., \& Bradley, P. S. (2014). The evolution of physical and technical performance parameters in the English Premier League. International Journal of Sports Medicine, 35(13), 1095-1100. doi:10.1055/s-00341375695

Batterham, A. M., \& Hopkins, W. G. (2006). Making Meaningful Inferences About Magnitudes. International Journal of Sports Physiology and Performance, 1(1), 50-57. doi:10.1123/ijspp.1.1.50

Bradley, P. S., Mohr, M., Bendiksen, M., Randers, M. B., Flindt, M., Barnes, C., . . Krustrup, P. (2011). Sub-maximal and maximal Yo-Yo intermittent endurance test level 2: heart rate response, reproducibility and application to elite soccer. European Journal of Applied Physiology, 111(6), 969-978. doi:10.1007/s00421-010-1721-2

Bush, M., Archer, D. T., Barnes, C., Hogg, B., \& Bradley, P. S. (2016). Longitudinal match performance characteristics of UK and non-UK players in the English Premier League. Science and Medicine in Football, 1(1), 2-9. doi:10.1080/02640414.2016.1233347

Bush, M., Barnes, C., Archer, D. T., Hogg, B., \& Bradley, P. S. (2015). Evolution of match performance parameters for various playing positions in the English Premier League. Human Movement Science, 39, 1-11. doi:10.1016/j.humov.2014.10.003

Connell, J. (2018). Globalisation, soft power, and the rise of football in China. Geographical Research, 56(1), 5-15. doi:10.1111/1745-5871.12249

Faude, O., Koch, T., \& Meyer, T. (2012). Straight sprinting is the most frequent action in goal situations in professional football. Journal of Sports Sciences, 30(7), 625-631. doi:10.1080/02640414.2012.665940

Fernandez-Navarro, J., Fradua, L., Zubillaga, A., Ford, P. R., \& McRobert, A. P. (2016). Attacking and defensive styles of play in soccer: analysis of Spanish and English elite teams. Journal of Sports Sciences, 34(24), 2195-2204. doi:10.1080/02640414.2016.1169309

Fernandez-Navarro, J., Fradua, L., Zubillaga, A., \& McRobert, A. P. (2018). Influence of contextual variables on styles of play in soccer. International Journal of Performance 
Analysis in Sport, 18(3), 423-436. doi:10.1080/24748668.2018.1479925

Gai, Y., Leicht, A. S., Lago, C., \& Gomez, M. A. (2019). Physical and technical differences between domestic and foreign soccer players according to playing positions in the China Super League. Research in Sports Medicine, 27(3), 314-325. doi:10.1080/15438627.2018.1540005

Hewitt, A., Greenham, G., \& Norton, K. (2017). Game style in soccer: what is it and can we quantify it? International Journal of Performance Analysis in Sport, 16(1), 355-372. doi:10.1080/24748668.2016.11868892

Lago-Ballesteros, J., Lago-Penas, C., \& Rey, E. (2012). The effect of playing tactics and situational variables on achieving score-box possessions in a professional soccer team. Journal of Sports Sciences, 30(14), 1455-1461. doi:10.1080/02640414.2012.712715

Lago-Peñas, C., Gómez-Ruano, M., \& Yang, G. (2018). Styles of play in professional soccer: an approach of the Chinese Soccer Super League. International Journal of Performance Analysis in Sport, 17(6), 1073-1084. doi:10.1080/24748668.2018.1431857

Liu, H., Hopkins, W. G., \& Gomez, M. A. (2016). Modelling relationships between match events and match outcome in elite football. European Journal of Sport Science, 16(5), 516-525. doi:10.1080/17461391.2015.1042527

Malcata, R. M., Hopkins, W. G., \& Richardson, S. (2012). Modelling the Progression of Competitive Performance of an Academy's Soccer Teams. Journal of Sports Science \& Medicine, 11(3), 533-536.

Mao, L., Peng, Z., Liu, H., \& Gómez, M.-A. (2017). Identifying keys to win in the Chinese professional soccer league. International Journal of Performance Analysis in Sport, 16(3), 935-947. doi:10.1080/24748668.2016.11868940

Sarmento, H., Marcelino, R., Anguera, M. T., CampaniCo, J., Matos, N., \& LeitAo, J. C. (2014). Match analysis in football: a systematic review. Journal of Sports Sciences, 32(20), 1831-1843. doi:10.1080/02640414.2014.898852

Tenga, A., Holme, I., Ronglan, L. T., \& Bahr, R. (2010). Effect of playing tactics on goal scoring in Norwegian professional soccer. Journal of Sports Sciences, 28(3), 237-244. doi:10.1080/02640410903502774

Tenga, A., Ronglan, L. T., \& Bahr, R. (2010). Measuring the effectiveness of offensive matchplay in professional soccer. European Journal of Sport Science, 10(4), 269-277. doi:10.1080/17461390903515170

Vogelbein, M., Nopp, S., \& Hokelmann, A. (2014). Defensive transition in soccer - are prompt possession regains a measure of success? A quantitative analysis of German Fussball- 
Bundesliga 2010/2011. Journal of Sports Sciences, 32(11), 1076-1083. doi:10.1080/02640414.2013.879671

Wallace, J. L., \& Norton, K. I. (2014). Evolution of World Cup soccer final games 1966-2010: game structure, speed and play patterns. Journal of Science and Medicine in Sport, 17(2), 223-228. doi:10.1016/j.jsams.2013.03.016

Yang, G., Leicht, A. S., Lago, C., \& Gomez, M. A. (2018). Key team physical and technical performance indicators indicative of team quality in the soccer Chinese super league. Research in Sports Medicine, 26(2), 158-167. doi:10.1080/15438627.2018.1431539

Zhou, C., Zhang, S., Lorenzo, A., \& Cui, Y. (2018). Chinese soccer association super league, 2012-2017: key performance indicators in balance games. International Journal of Performance Analysis in Sport, 18(4), 645-656. doi:10.1080/24748668.2018.1509254

Zubillaga, A., Gorospe, G., Hernandez, A., \& Blanco, A. (2009). Comparative analysis of the high-intensity activity of soccer players in top level competition. Science and Football VI, 182-185. 


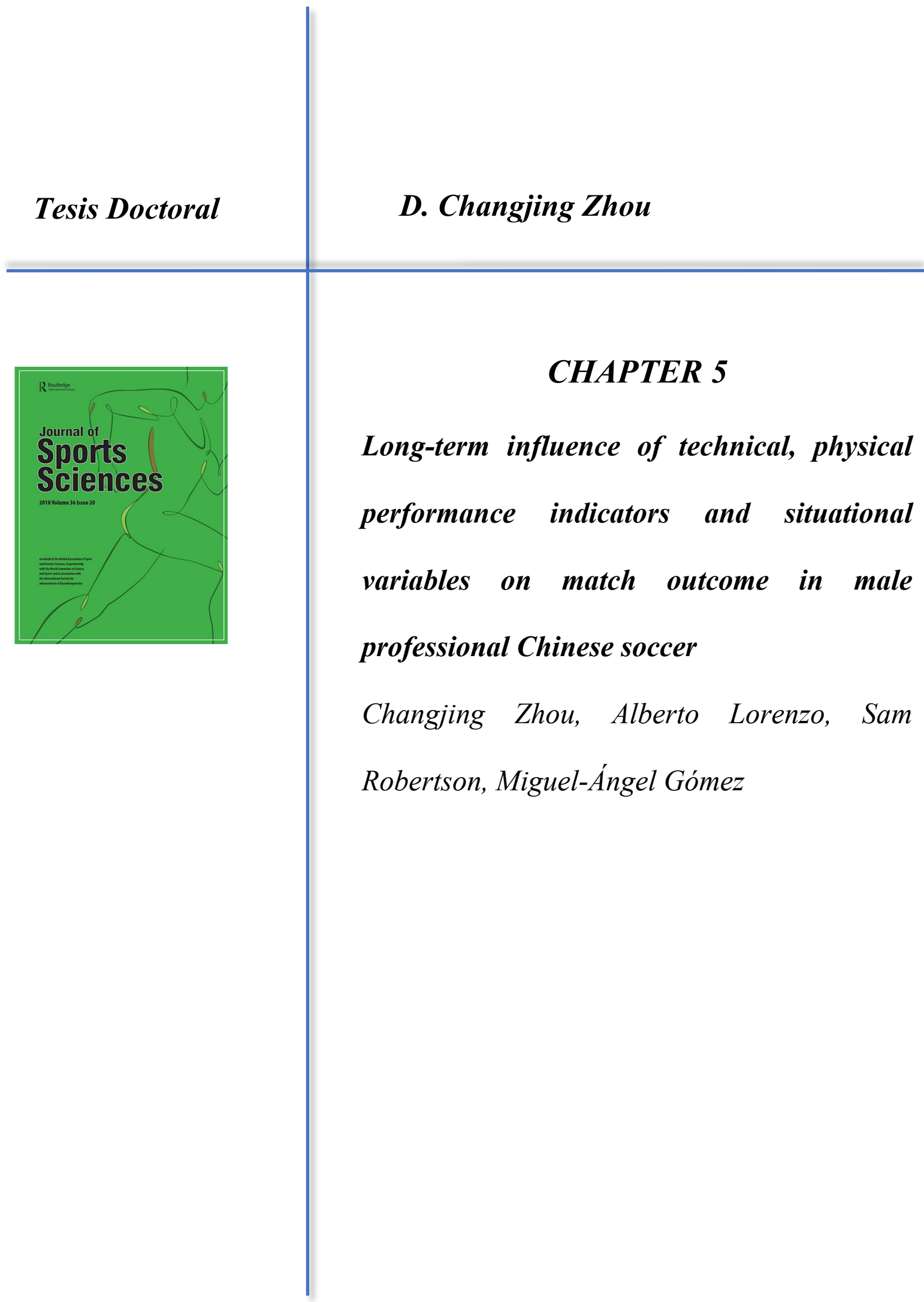




\section{Chapter 5 Long-term influence of technical, physical \\ performance indicators and situational variables on match \\ outcome in male professional Chinese soccer}

\subsection{Introduction}

In game sports, performance indicators can capture global or partial aspects of complex, dynamic and non-linear properties of performance (McGarry, O'Donoghue, \& Sampaio, 2013). The importance of definition and validity of key performance indicators (KPI) has been widely investigated in several sports (e.g., soccer, basketball, handball, water polo, rugby, Australian football, etc.) defining the most relevant aspects of players and teams' performances (Escalante, Saavedra, Mansilla, \& Tella, 2011; Gómez, Lorenzo, Sampaio, José Ibáñez, \& Ortega, 2008; Lago-Peñas et al., 2010; Lorenzo, Gomez, Ortega, Ibanez, \& Sampaio, 2010; Meletakos, Vagenas, \& Bayios, 2017; Robertson, Back, \& Bartlett, 2016; Vaz, Van Rooyen, \& Sampaio, 2010). Specifically, the definition and selection of KPI has been related to winning and losing or successful and unsuccessful teams (Castellano et al., 2012; Gómez et al., 2008; Harrop \& Nevill, 2017; Lago-Ballesteros \& Lago-Peñas, 2010; Vaz et al., 2010).

In terms of the influence of several constraints, it is necessary to combine performance indicators and situational variables (e.g., match location and quality of opposition) to determine match performances (Aquino et al., 2017; Bradley et al., 2014; Liu et al., 2016; Taylor et al., 2010). Firstly, the technical-tactical indicators (e.g., shots on target, successful passes, possession) associated with winning or having positive effects on the match outcome have been identified in the research (Harrop \& Nevill, 2017; Lago-Ballesteros \& Lago-Peñas, 2010; LagoPeñas et al., 2010; Liu et al., 2015; Liu et al., 2016; Mao et al., 2017). Secondly, although previous studies indicate that overall technical and tactical effectiveness are more important than physical performance in determining success in soccer (Di Salvo et al., 2009), recent work 
shows that high-intensity actions are related to the outcome of the match (Aquino et al., 2017; Zhou et al., 2018). Barnes et al. (2014) also revealed that the players' physical ability demands have increased with the soccer development. Thirdly, the situational variables, match location and quality of opposition, are two factors that can affect the match outcome (Lago-Peñas et al., 2011; Ruano, Serna, Lupo, \& Sampaio, 2016). Previous studies have showed that the influence of these two situational variables on match outcome have changed over the development (e.g., the last two decades) of soccer sport (Bradley et al., 2016; Pollard \& Pollard, 2005). In fact, the gap between successful teams was narrowing across seven consecutive England Premier League seasons (2006-07 to 2012-13) (Bradley et al., 2016) indicating that it could change across seasons. Along these lines, soccer has evolved across time because of rule changes and match tactics and strategies, increases in professionalism, the use of new technologies, global exposure, and transformations in training and selection process (Wallace \& Norton, 2014). Understanding these evolutionary tendencies can provide valuable information to estimate, for example, future match and training demands, to assist in the player selection and talent identification, or to predict the impact of rule changes. In practice, soccer coaches not only need to be familiar with the demands of modern players in technical-tactical and physical aspects, but also understand the KPI and their impact along the seasons when determining the match outcome in combination with situational variables (Barnes et al., 2014; Bush et al., 2015; Robertson \& Joyce, 2018). However, from the available research in soccer, few studies can provide this information due to most of them were focused on identifying KPI in single a season/championship or few seasons and exploring the variability/stability of performance indicators along the seasons (Barnes et al., 2014; Bradley et al., 2016; Bush et al., 2015). So far, Robertson and Joyce (2018) used binary logistic regression models to determine the level of association between some factors (performance indicators and situational variables) and match outcome in a long period in Australian football with concluding remarks (e.g., the 
influence of playing away from home on match difficulty became stronger as the season progressed). However, no research has studied the influence of KPI on the match outcome in soccer considering a longitudinal approach.

Recently, there has been growing interest in the Chinese soccer (Gai et al., 2019; Lago-Peñas et al., 2018; Mao et al., 2017; Yang et al., 2018; Zhou et al., 2018) analysing the KPI, team playing styles and comparisons between domestic and foreign soccer players in the Chinese Soccer Super league (CSL). Specifically, technical (e.g., shot on target, shot accuracy, possession) and physical indicators (sprinting distance in ball possession) were related to match outcome in the CSL (Mao et al., 2017; Yang et al., 2018; Zhou et al., 2018). Additionally, investigations have been confined to long-term trend study in Chinese elite soccer. CSL is the highest level of professional soccer match in China, which starts in March (spring in China) and ends in November (winter) every season. As a developing of the league, playing patterns in CSL are different from European leagues or international championships (e.g., World Cup), the effects of match regulation, signing policies, and economical investment, which are unique to China soccer, would lead to some changes in match performances across seasons. Specifically, this information would help to monitor training and match strategy selection for coaching staffs. Therefore, the aim of the present study was to determine whether the role of every performance indicator has varied over six seasons in the CSL. It was hypothesized that the KPI and situational variables were not stable over the seasons showing different performance trends in the CSL.

\subsection{Materials and methods}

\subsubsection{Sample, data resource and variables}

CSL is the highest level of professional soccer match in China (16 teams playing a balanced schedule against their opponents both at home and away from March to November every season, 
Table 5.1 Selected variables definition

\begin{tabular}{|c|c|}
\hline \multicolumn{2}{|c|}{ Technical performance-related parameters: operational definition } \\
\hline Shot & An attempt to score a goal, made with any (legal) part of the body, either on or off target \\
\hline Shot on target & $\begin{array}{l}\text { An attempt to goal which required intervention to stop it going in or resulted in a goal/shot } \\
\text { which would go in without being diverted }\end{array}$ \\
\hline Possession (\%) & $\begin{array}{l}\text { The duration when a team takes over the ball from the opposing team without any clear } \\
\text { interruption as a proportion of total duration when the ball was in play }\end{array}$ \\
\hline Possession in opponent half (\%) (PIOH\%) & Possession of a team in opponent's half of pitch \\
\hline Pass: & An intentional played ball from one player to another \\
\hline Pass accuracy $(\%)$ & Successful passes as a proportion of total passes \\
\hline Forward pass & $\begin{array}{l}\text { An intentional played ball from one player to another who is located closer to the opponent } \\
\text { goal. }\end{array}$ \\
\hline Forward pass accuracy $(\%)($ FPA \% $):$ & Successful forward passes as a proportion of total forward passes \\
\hline Opponent $35 \mathrm{~m}$ entry & $\begin{array}{l}\text { Number of times when the ball (possessed by the attacking team) enters the } 35 \mathrm{~m} \text { area of the } \\
\text { opponent's half of pitch }\end{array}$ \\
\hline Opponent penalty area entry （OPAE） & $\begin{array}{l}\text { Number of times when the ball (possessed by the attacking team) enters the penalty area of } \\
\text { the opponent's half of pitch }\end{array}$ \\
\hline Cross & Any ball sent into the opposition team's area from a wide position \\
\hline Corner & Ball goes out of play for a corner kick \\
\hline Offside & Being caught in an offside position resulting in a free kick to the opposing team \\
\hline $50-50$ challenge won $(\%)$ & $50 \%-50 \%$ challenge duels won by a team as a proportion of total duels of the match \\
\hline Foul committed & Any infringement that is penalised as foul play by a referee \\
\hline Yellow card & $\begin{array}{l}\text { Where a player was shown a yellow card by the referee for reasons of foul, persistent } \\
\text { infringement, hand ball, dangerous play, time wasting, etc. }\end{array}$ \\
\hline Red card & $\begin{array}{l}\text { Where a player was sanctioned a red card by the referee, including straight red card and a } \\
\text { red card from the second yellow card }\end{array}$ \\
\hline \multicolumn{2}{|c|}{ Physical performance-related parameters: operational definition } \\
\hline Total distance $(\mathrm{m})$ : & Distance covered in a match by all the outfield players of a team \\
\hline Total distance IP(m): & Total distance covered when in ball possession \\
\hline Total distance OP(m): & Total distance covered when out of ball possession \\
\hline Sprinting distance $(\mathrm{m})$ : & Distance covered at the speed over $23 \mathrm{~km} / \mathrm{h}$ in a match by all the outfield players of a team \\
\hline Sprinting effort: & Number of sprinting in a match by all the players of a team \\
\hline Sprinting distance IP $(\mathrm{m})$ : & Sprinting distance covered when in ball possession \\
\hline Sprinting distance OP $(\mathrm{m})$ : & Sprinting distance covered when out of possession \\
\hline High-speed running distance $(\mathrm{m})$ : & Distance covered at the speed of $19.1-23 \mathrm{~km} / \mathrm{h}$ in a match by all the outfield players of a team \\
\hline High-speed running effort: & Number of high-speed running in a match by all the outfield players of a team \\
\hline High-speed running distance IP $(\mathrm{m})$ : & High-speed running distance covered when in ball possession \\
\hline High-speed running distance OP $(\mathrm{m})$ : & High-speed running distance covered when out of ball possession \\
\hline \multicolumn{2}{|l|}{ Situational variables } \\
\hline Match location: & Playing at home or away \\
\hline Quality of opposition: & $\begin{array}{l}\text { The difference between end-of-season rankings of the competing teams, i.e. quality of } \\
\text { opposition }=R_{A}-R_{B} \text {, where } R_{A} \text { is the ranking of sampled team and } R_{B} \text { is the ranking of the } \\
\text { opponent }\end{array}$ \\
\hline
\end{tabular}


30 matches per team and 240 matches per season). The end-of-season rank was determined by the final accumulated points (win for 3 points, draw for 1, loss for 0 ). A total of 1,429 matches (data from 11 matches were missed) were selected as the sample of the current study from 2012 to 2017 seasons in the CSL.

Teams' data were collected by AMISCO (Amisco, Nice, France) tracking system. The reliability and validity of the system in measuring player movement has been evaluated and verified (Zubillaga, 2006; Zubillaga et al., 2009). In line with previous related literature (Bradley et al., 2014; Carling et al., 2016; Mao et al., 2017; Yang et al., 2018), 17 technical performance-related parameters, 11 physical performance-related parameters and 2 situational variables were chosen as indicators in the analysis. The grouping and definition of these variables are presented in the Table 5.1.

\subsubsection{Procedure and statistical analysis}

Descriptive statistics (Mean $\pm \mathrm{SD}$ ) were calculated for each indicator during the six seasons under analysis. In addition, in order to make comparisons ignoring the scale units of each indicator, the variables were standardized using $z$-scores (Norman $\&$ Streiner, 2008). A binary logistic regression was used to identify the relationship between match outcome and indicators (Robertson \& Joyce, 2018). In the league, teams usually pursue wining instead of drawing or even losing, so we set match outcome as Win $=1$ and Unwin (Draw and Loss) $=0$ (Liu et al., 2016). We used backward (LR) stepwise method to avoid multicollinearity between variables (Harrop \& Nevill, 2017). Odds ratios (OR) and corresponding 90\% confidence intervals (90\% CI) were also reported in order to provide a standardized measure of the influence of each indicator included in the model of six seasons. Relationships were assessed as effects of onestandard deviation (SD) increase in the value of the indicator on the change (decrease or increase) in the probability of a team winning a match (Menard, 2011). Performance of the model was evaluated as the percentage of match outcomes correctly classified. All analyses 
were undertaken using the statistical software IBM SPSS Statistics 22 (Armonk, NY: IBM Corp) and the level of significance was set at $\mathrm{p} \leq 0.05$.

\subsection{Results}

Descriptive statistics of performance-related match events and actions per season (from 2012 to 2017) and total results in the CSL are presented in Table 5.2.

Table 5.3 shows the OR for fixed factors related to the logistic regression models for each season (six models). The classification accuracies were $82.0 \%, 80.6 \%, 76.8 \%, 83.3 \%, 83.4 \%$ and $85.7 \%$, for the seasons 2012 to 2017 , respectively. The results identified ten statistically significant technical-tactical variables: Shots $(\mathrm{OR}=0.58-0.66)$, Shots on target $(\mathrm{OR}=1.76-4.50)$, Corners $(\mathrm{OR}=0.67)$, Crosses $(\mathrm{OR}=0.29-0.61)$, Possession $(\mathrm{OR}=5.46-138.51)$, Passes $(\mathrm{OR}=$ 2.68-2.69), Pass accuracy $(\mathrm{OR}=0.47-0.50)$, Forward passes $(\mathrm{OR}=0.42-0.62)$, Forward pass accuracy $(\mathrm{OR}=1.78-1.93), 50-50$ challenge won $(\mathrm{OR}=1.72)$, fouls committed $(\mathrm{OR}=1.43)$. In addition, the models showed seven significant physical variables $=$ Total distance $(O R=1.79$ 2.06), Total distance in ball possession $(\mathrm{OR}=0.02-0.16)$, Total distance out of ball possession $(\mathrm{OR}=2.75-57.03)$, Sprinting efforts $(\mathrm{OR}=0.47-5.18)$, High-Speed distance $(\mathrm{OR}=2.23-69.13)$, High- speed distance in ball possession $(\mathrm{OR}=0.11-0.19)$, High-speed distance out of ball possession $(\mathrm{OR}=0.03-0.33)$; and two situational variables $=$ Quality of opponent $(\mathrm{OR}=0.19-$ $0.40)$ and Match location $(\mathrm{OR}=1.78-7.06)$. However, only Shots on target, possession, total distance in possession of the ball, total distance without ball possession, match location and quality of opposition exerted a significant effect on winning the match in all the seasons $(\mathrm{p}<0.05)$.

In order to identify the long-term effect, the six statistically significant KPI and situational variables on winning the match were selected and accounted for into next analysis. Figure 5.1 shows the changes in OR of the six KPI and situational variables during six seasons. Results showed that shots on target, possession, total distance in ball possession, total distance out of 
Table 5.2 Performance indicators across the 2012 to 2017 seasons. Data are displayed as means and standard deviations.

\begin{tabular}{|c|c|c|c|c|c|c|c|}
\hline & Total & 2012 & 2013 & 2014 & 2015 & 2016 & 2017 \\
\hline Shots & $12.5 \pm 4.9$ & $12.2 \pm 4.7$ & $12.7 \pm 5.0$ & $12.4 \pm 5.2$ & $12.3 \pm 4.9$ & $12.3 \pm 5.0$ & $13.1 \pm 4.7$ \\
\hline Shots on target & $4.8 \pm 2.6$ & $4.3 \pm 2.3$ & $5.2 \pm 2.7$ & $4.9 \pm 2.8$ & $4.6 \pm 2.7$ & $4.7 \pm 2.7$ & $4.8 \pm 2.5$ \\
\hline Corners & $4.7 \pm 2.7$ & $4.6 \pm 2.7$ & $4.6 \pm 2.8$ & $4.8 \pm 2.8$ & $4.6 \pm 2.8$ & $4.4 \pm 2.5$ & $5.0 \pm 2.8$ \\
\hline Crosses & $14.3 \pm 6.7$ & $12.8 \pm 6.0$ & $13.7 \pm 6.3$ & $14.3 \pm 6.8$ & $14.5 \pm 6.6$ & $14.9 \pm 7.2$ & $15.6 \pm 6.9$ \\
\hline Possession \% & $50.0 \pm 7.3$ & $50.0 \pm 7.1$ & $50.0 \pm 6.9$ & $50.0 \pm 7.2$ & $50.0 \pm 7.4$ & $50.0 \pm 8.0$ & $50.0 \pm 7.2$ \\
\hline PIOH $\%$ & $44.5 \pm 7.5$ & $43.9 \pm 7.6$ & $44.6 \pm 7.4$ & $44.2 \pm 7.6$ & $44.3 \pm 7.5$ & $45.0 \pm 7.9$ & $44.9 \pm 7.2$ \\
\hline Passes & $369.0 \pm 94.3$ & $357.2 \pm 92.0$ & $387.4 \pm 91.8$ & $379.2 \pm 92.9$ & $362.7 \pm 94.7$ & $367.0 \pm 101.1$ & $360.0 \pm 90.0$ \\
\hline Pass accuracy $\%$ & $78.9 \pm 5.8$ & $77.3 \pm 5.9$ & $79.7 \pm 5.6$ & $79.8 \pm 5.5$ & $79.6 \pm 5.7$ & $79.5 \pm 5.9$ & $77.8 \pm 5.8$ \\
\hline Forward passes & $124.7 \pm 25.3$ & $122.1 \pm 27.2$ & $127.1 \pm 27.4$ & $128.3 \pm 24.5$ & $122.9 \pm 24.9$ & $123 \pm 24.7$ & $124.7 \pm 22.3$ \\
\hline FPA \% & $63.4 \pm 8.5$ & $62.7 \pm 8.8$ & $65.6 \pm 9.1$ & $64.1 \pm 8.3$ & $63.8 \pm 8.2$ & $62.7 \pm 8.5$ & $61.3 \pm 7.7$ \\
\hline Opponent $35 \mathrm{~m}$ entries & $44.6 \pm 14.1$ & $43.4 \pm 14.1$ & $45.7 \pm 14.4$ & $45.6 \pm 14.6$ & $44.0 \pm 13.9$ & $45.1 \pm 14.8$ & $43.9 \pm 12.9$ \\
\hline OPAE & $6.9 \pm 3.8$ & $6.4 \pm 3.5$ & $6.9 \pm 3.8$ & $6.7 \pm 3.7$ & $6.9 \pm 3.8$ & $7.2 \pm 4.2$ & $7.1 \pm 3.7$ \\
\hline $50-50$ challenge won & $51.7 \pm 6.9$ & $54.0 \pm 5.6$ & $55.3 \pm 5.9$ & $50.9 \pm 5.6$ & $50.0 \pm 6.5$ & $50.0 \pm 7.7$ & $50.0 \pm 7.9$ \\
\hline Fouls committed & $16.4 \pm 4.7$ & $16.9 \pm 4.4$ & $15.6 \pm 4.5$ & $16.7 \pm 4.6$ & $17.1 \pm 5.1$ & $15.7 \pm 4.8$ & $16.1 \pm 4.6$ \\
\hline Offsides & $2.2 \pm 1.8$ & $2.2 \pm 1.7$ & $2.3 \pm 1.9$ & $2.2 \pm 1.8$ & $2.3 \pm 1.8$ & $2.2 \pm 1.8$ & $2.3 \pm 1.7$ \\
\hline Yellow card & $2.0 \pm 1.3$ & $2.1 \pm 1.3$ & $2.0 \pm 1.3$ & $1.9 \pm 1.3$ & $1.9 \pm 1.4$ & $2.0 \pm 1.4$ & $2.1 \pm 1.4$ \\
\hline Red card & $0.1 \pm 0.3$ & $0.1 \pm 0.3$ & $0.1 \pm 0.3$ & $0.1 \pm 0.3$ & $0.1 \pm 0.3$ & $0.1 \pm 0.3$ & $0.1 \pm 0.3$ \\
\hline Total distance & $107,575.9 \pm 5,710.6$ & $108,116.1 \pm 6,264.1$ & $103,874.9 \pm 5,251.0$ & $110,203.3 \pm 5,646.4$ & $109,475.9 \pm 4,873.8$ & $107,866.4 \pm 4,741.5$ & $105,925.1 \pm 4,842.6$ \\
\hline Total distance IP & $35,842.2 \pm 6035.0$ & $35,485.1 \pm 5861.4$ & $35,391.3 \pm 5733.4$ & $37,066.2 \pm 6060.4$ & $36,510.1 \pm 6083.6$ & $35,965.4 \pm 6384.3$ & $34,628.9 \pm 5786.6$ \\
\hline Total distance OP & $38,097.2 \pm 6,503.3$ & $37,435.4 \pm 6,279.6$ & $37,357.2 \pm 6,000.8$ & $39,345.8 \pm 6,566.2$ & $38,752.6 \pm 6,555.2$ & $38,496.4 \pm 6,946.6$ & $37,198.2 \pm 6,370.9$ \\
\hline Sprinting distance & $2,098.2 \pm 500.3$ & $2,069.7 \pm 509.3$ & $1,790.4 \pm 444.1$ & $2,234.3 \pm 488.2$ & $2,109.5 \pm 458.5$ & $2,116.3 \pm 457.8$ & $2,272.0 \pm 493.6$ \\
\hline Sprinting efforts & $99.1 \pm 21.9$ & $100.1 \pm 22.8$ & $86.7 \pm 19.7$ & $106.2 \pm 23.0$ & $99.6 \pm 20.0$ & $97.4 \pm 19.1$ & $104.8 \pm 20.8$ \\
\hline Sprinting distance IP & $1,047.2 \pm 313.2$ & $1,033.6 \pm 322.2$ & $915.8 \pm 278.9$ & $1,105.4 \pm 309.1$ & $1,062.9 \pm 300.1$ & $1,054.3 \pm 309.2$ & $1,112.1 \pm 318.7$ \\
\hline Sprinting distance OP & $985.6 \pm 307.7$ & $963.3 \pm 310.4$ & $820.6 \pm 262.6$ & $1,059.3 \pm 303.1$ & $987.1 \pm 293.3$ & $997.6 \pm 295.9$ & $1,087.7 \pm 307.5$ \\
\hline High-Speed distance & $2,587.8 \pm 493.3$ & $2,568.4 \pm 503.5$ & $2,332.6 \pm 456.1$ & $2,692.7 \pm 492$ & $2,616.6 \pm 439.1$ & $2,494.6 \pm 441.1$ & $2,823.1 \pm 479.2$ \\
\hline High-speed effort & $186.7 \pm 35.5$ & $187.5 \pm 36.1$ & $166.8 \pm 32.1$ & $195.8 \pm 36.2$ & $187.9 \pm 31.7$ & $177.7 \pm 29.9$ & $204.7 \pm 33.7$ \\
\hline High-speed distance IP & $1,128.1 \pm 270.1$ & $1,131.1 \pm 278$ & $1,047.1 \pm 262$ & $1,168.5 \pm 275.4$ & $1,146.6 \pm 249.8$ & $1,070.2 \pm 245.8$ & $1,205.4 \pm 275.3$ \\
\hline High-speed distance OP & $1,341.6 \pm 327.0$ & $1,301.8 \pm 314.5$ & $1,184.3 \pm 283.8$ & $1,393.9 \pm 319.7$ & $1,360.1 \pm 308.5$ & $1,319.6 \pm 321.7$ & $1,491.5 \pm 331.8$ \\
\hline
\end{tabular}


Table 5.3 Odds ratios for fixed factors relating to the 6 seasons logistic backward (LR) stepwise regression models

\begin{tabular}{|c|c|c|c|c|c|c|}
\hline & \multicolumn{6}{|c|}{ Standardized OR mean $( \pm 90 \% \mathrm{CI})$} \\
\hline & 2012 & 2013 & 2014 & 2015 & 2016 & 2017 \\
\hline Shots & $0.58(0.39,0.85) *$ & $0.59(0.40,0.87) *$ & $0.66(0.49,0.89) *$ & & & $0.63(0.43,0.92) *$ \\
\hline Shots on target & $4.50(3.01,6.72) *$ & $2.64(1.88,3.72) *$ & $1.86(1.41,2.45) *$ & $2.91(2.17,3.90) *$ & $2.69(1.98,3.64) *$ & $3.44(2.36,5.01) *$ \\
\hline Corners & $0.71(0.52,0.96)$ & $0.67(0.51,0.89) *$ & & $0.76(0.58,0.99)$ & & \\
\hline Crosses & $0.51(0.35,0.74) *$ & $0.55(0.39,0.78) *$ & & $0.52(0.37,0.73) *$ & $0.29(0.21,0.41) *$ & $0.61(0.45,0.84) *$ \\
\hline Possession \% & $138.51(28.53,672.44) *$ & $14.31(3.29,62.32) *$ & $5.46(1.47,20.38) *$ & $15.47(3.03,78.96)^{*}$ & $51.22(8.39,312.55) *$ & $108.49(19.05,618.02)$ * \\
\hline Passes & & & $2.68(1.30,5.50) *$ & & & $2.69(1.16,6.25) *$ \\
\hline Pass accuracy \% & & & $0.50(0.32,0.80) *$ & $1.54(1.04,2.29)$ & $0.47(0.25,0.88) *$ & \\
\hline Forward passes & & & & & $0.62(0.40,0.98)$ & $0.42(0.25,0.70) *$ \\
\hline FPA \% & & & $1.93(1.34,2.79) *$ & & $1.78(1.04,3.05)$ & \\
\hline $50-50$ challenge won & & & & & $1.72(1.36,2.17)^{*}$ & \\
\hline Fouls committed & & & & & & $1.43(1.11,1.83) *$ \\
\hline Red card & & & & $0.66(0.46,0.96)$ & & \\
\hline Total distance & $1.79(1.18,2.72) *$ & & $2.06(1.27,3.33) *$ & $1.98(1.14,3.43) *$ & & \\
\hline Total distance IP & $0.02(0.01,0.05) *$ & $0.15(0.05,0.41) *$ & $0.09(0.03,0.25)$ * & $0.08(0.03,0.22)^{*}$ & $0.16(0.05,0.49) *$ & $0.02(0.01,0.09) *$ \\
\hline Total distance OP & $15.40(5.53,42.90) *$ & $7.32(2.68,19.97) *$ & $2.75(1.16,6.51)^{*}$ & $5.13(1.68,15.63)^{*}$ & $19.32(6.11,61.08) *$ & $57.03(17.23,188.68)^{*}$ \\
\hline Sprinting distance & & & $3.43(2.30,5.11) *$ & $0.31(0.19,0.53) *$ & $0.06(0.02,0.15) *$ & \\
\hline Sprinting efforts & & $0.47(0.28,0.78) *$ & & & $5.18(2.12,12.65)^{*}$ & \\
\hline Sprinting distance IP & $2.57(1.91,3.46) *$ & $5.13(3.18,8.28) *$ & & $4.53(2.80,7.35)^{*}$ & $9.79(5.58,17.17)^{*}$ & $1.81(1.34,2.45)^{*}$ \\
\hline Sprinting distance OP & $0.31(0.21,0.44) *$ & & $0.18(0.12,0.27) *$ & & & $0.68(0.49,0.96)$ \\
\hline High-Speed distance & $1.61(1.06,2.43)$ & $2.41(1.26,4.62) *$ & & $2.23(1.15,4.31) *$ & $42.00(4.11,429.80) *$ & $69.13(11.04,432.73) *$ \\
\hline High- speed distance IP & & & & & $0.11(0.03,0.44) *$ & $0.19(0.06,0.54) *$ \\
\hline High-speed distance OP & & $0.33(0.17,0.64) *$ & & $0.45(0.23,0.90)$ & $0.05(0.01,0.27) *$ & $0.03(0.01,0.11) *$ \\
\hline Quality of opponent & $0.40(0.31,0.51) *$ & $0.35(0.27,0.45) *$ & $0.36(0.27,0.48) *$ & $0.24(0.18,0.32) *$ & $0.35(0.26,0.47) *$ & $0.19(0.13,0.27) *$ \\
\hline Match location & $4.69(2.85,7.72) *$ & $4.54(2.82,7.30)^{*}$ & $1.78(1.17,2.71)^{*}$ & $2.41(1.50,3.87) *$ & $3.36(2.05,5.49) *$ & $7.06(4.01,12.43) *$ \\
\hline Chi-square & 254.36 & 224.08 & 184.32 & 256.36 & 273.92 & 287.16 \\
\hline Cases correctly classified & $82.0 \%$ & $80.6 \%$ & $76.8 \%$ & $83.3 \%$ & $83.4 \%$ & $85.7 \%$ \\
\hline
\end{tabular}


ball possession, and match location exerted a decreased influence on winning the game from 2012 to 2014 season. However, these variables have a more powerful role when winning the match from 2014 to 2017 season. Additionally, the quality of opposition has a continuously increased role on the match outcome.

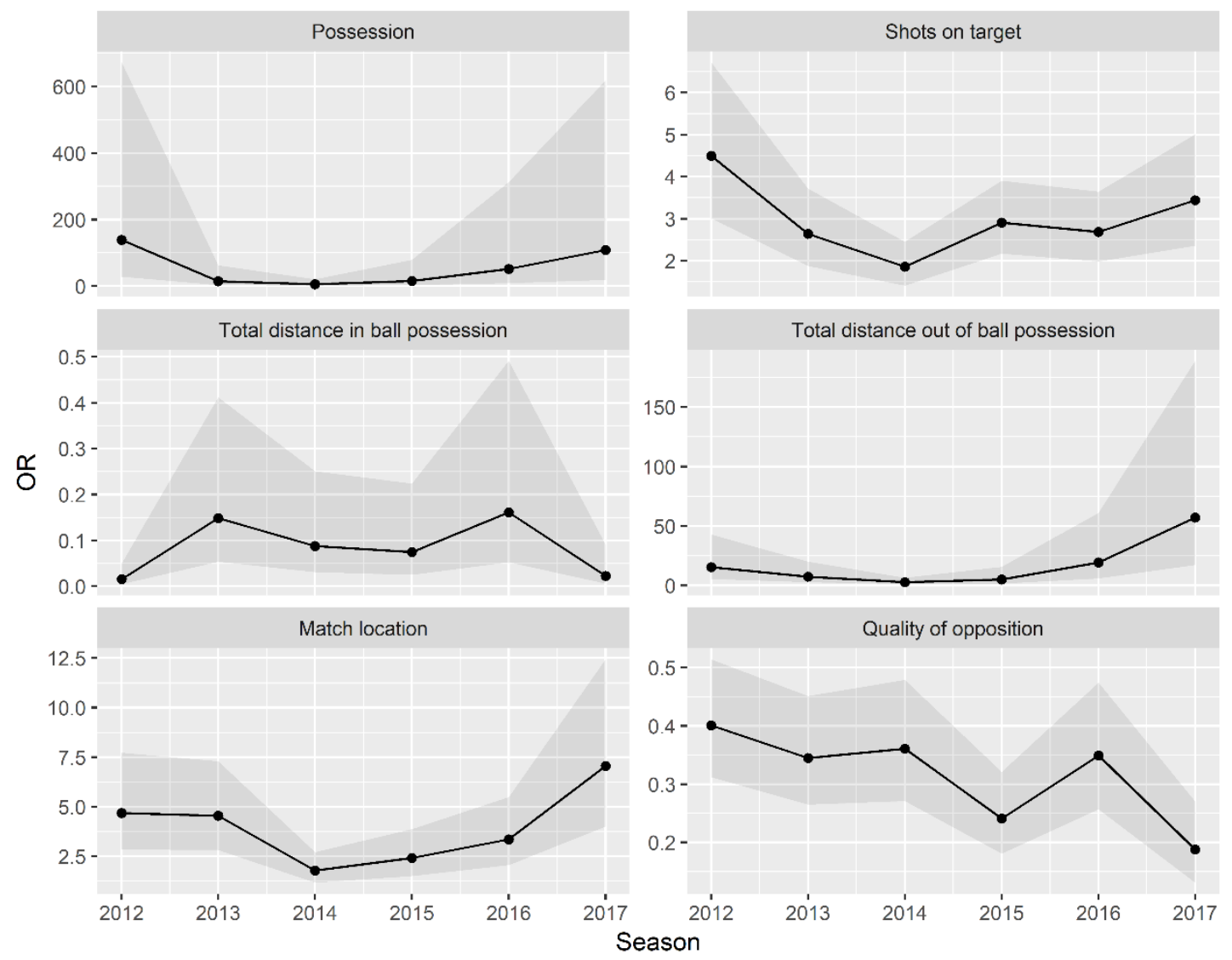

Figure 5.1 Changes in odds ratios for six factors relating to the match outcome over 6 seasons. Black line represents the mean value of $O R$ and $90 \%$ confidence interval.

\subsection{Discussion}

The aim of this study was twofold: (i) to explore key performance indicators across six seasons; and (ii) to determine whether the role of every KPI in impacting on match outcome has varied over the six seasons in the CSL. As was argued, the KPI and situational variables were not stable in affecting the match outcome over the seasons and showing different performance trends in the CSL. The main findings showed that the significant KPI were not same during the seasons under analysis. Specifically, there were six significant variables (Shots on target, 
possession, total distance in possession of the ball, total distance out of ball possession, match location and quality of opposition) that exerted a meaningful influence on winning the match in all the seasons and every KPI plays a different role across six seasons.

Although the role of shots on target on winning the match has declined from 2012 to 2014 season, it has rebounded and stabilized in recent years. In recent years, the CSL teams have increased its financial budged for players' recruitment. Especially in the 2015 season, CSL clubs spent $£ 81 \mathrm{~m}$ on players and coaches, placing in the second league that most invested (most of the players signed were midfielders or forward foreign players), and only the EPL spent more money than CSL (Connell, 2018). The advantage of these foreign attackers in offense, especially in shooting skills, may be the cause of the increase roles of shots on target on winning the match in recent years (Gai et al., 2019). The number of shots on target is the most important factor affecting the match outcome in soccer (Lago-Ballesteros \& Lago-Peñas, 2010; LagoPeñas et al., 2010; Mao et al., 2017; Yang et al., 2018). The current results showed that a oneSD increase in the value of shot on target could bring a $0.79-3.50$ times higher probability of winning matches. Then, the sustaining positive impact of the shots on target on winning the match, requires the soccer coaches to still pay attention to this indicator and set more practice to improve players' shot capacity. In addition to the number of shots, the match competition and trainings should be more focused on shooting accuracy (Mao et al., 2017).

In the present study, possession is a factor affecting the match outcome positively and plays a more important role in the match during the recent seasons. The current result is supported by a previous study focused on the EPL (Bush, Archer, Barnes, Hogg, \& Bradley, 2017) that found the recruitment of more outstanding foreign players and coaches could contribute to the development of possession-based playing strategies in the CSL. This finding indicates that obtain and use more possession is essential to win the match in the CSL. It is arguable whether the possession is a key performance indicator in determining the match outcome (Collet, 2013; 
Kempe, Vogelbein, Memmert, \& Nopp, 2014; Lago-Peñas \& Dellal, 2010; Lago, 2009; Lago \& Martin, 2007). In particular, Chassy (2013) demonstrated that speed and precision of passes generated positive match outcomes rather than the percentage of possession. However, Kempe et al. (2014) showed that not only the percentage of ball possession but also the variables related to the possession have an impact on the match outcome. In one study related to the CSL (Zhou et al., 2018), the authors found that the number of passes per possession was the variable that best differentiated winning, drawing and losing (match outcomes) during close matches when KPI were normalized by possession of the ball. The different influence of possession on the match outcome in these studies may be related to the differences of match samples used, different variables selected and different methods of analysis. Further research on CSL should pay more attention on the relationship between possessions and passing patterns.

Regarding the physical aspect, although the total distance does not influence the match outcome in the CSL, the physical distribution does. Total distance in possession has a negative effect on winning the game while total distance out of possession has a positive effect on winning the match. Hoppe et al. (2015) pointed out that the total distance in possession of the ball has a positive correlation with final points accumulated in the German Bundesliga, and it is related to the high-level of ball possession due to the superior technical/tactical skills of successful teams. The present results suggested that when teams have the same percentage of possession, less distance covered in ball possession and more distance covered out of ball possession can increase the winning probability. This is in accordance with previous studies (Almeida et al., 2014; Vogelbein et al., 2014) which indicated that the players from better teams employed proactive defensive strategies via covering more distance to press the opposition and regain the ball possession quickly when their teams are out of the ball possession. Once the winning team regains the ball in CSL, they prefer to maintain the ball possession to keep the physical conditioning, creating the space to attack in CSL. 
In this study, match location and quality of opposition have a significant influence on the match outcome, which is in accordance with the previous studies (Lago, 2009; Liu et al., 2016). For instance, the home advantage (HA) has experienced some changes and plays a more important role when winning the match (shown in Figure 5.1) in the latest four seasons. There may be several factors that contribute to this phenomenon. On the one hand, Pollard and Gómez (2014) identified a HA effect of $63.82 \%$ in Chinese Super League (the fourth league in the Asian countries ranked by HA effect and similar to the main European countries such as England or Spain). Specifically, some factors are likely to affect the degree of home advantage such as crowed effects, travel effects, local derbies, familiarity with local conditions, referee bias, territoriality, special tactics, rule factors, team composition and psychological factors. In particular, the increasing financial budged of clubs, players' recruitment or the increased match attendance (crowd size) due to society and economy development in China could be related to the increased importance of HA.

Differences between the end-of-season rankings of the competing teams can truly reflect the strength gap between the two teams (Bradley et al., 2014). The increased role of the quality of the opposition on match results demonstrates that the performance gap between the teams in the CSL is widening, it is getting harder to beat stronger opponents. This phenomenon may indicate that the Chinese teams acknowledge more about each opponent and can arrange the corresponding tactics in advance. On the other hand, the weaker teams lack corresponding changes in tactics in the face of the stronger teams.

\subsection{Conclusion}

This study demonstrates that the influence of various factors exerts on match outcome change over six seasons. The results showed the significant trends of factors influencing the match outcome: shots on target, possession, total distance possession of the ball, total distance out of ball possession. Additionally, match location exerted a decreased influence on winning the 
game from 2012 to 2014 season and increased their impact when winning the match from 2014 season. Lastly, the quality of opposition has a continuously increased negative influence on the match outcome.

\subsection{Practical applications}

The role of KPI and situational variables in the CSL was evaluated over the six seasons. Therefore, identifying how these factors alter their influence on the match outcome throughout the seasons is of practical use in monitoring the training, players' selection, even talent identification. On the one hand, the more percentage of ball possession is related when winning the match in the CSL, less distance covered when a team in ball possession and more distance covered without ball possession could be the most important task in the training practice. On the other hand, match location and quality of opposition have a huge influence on the match outcome. The coach should set up some targeted training (e.g., psychological skill) and try to improve the stability of player's performance in home and away. The coach should consider the quality of the opponent and analyse the playing patterns of the opponent, formulating the corresponding match strategy and practice in advance. 


\subsection{References}

Almeida, C. H., Ferreira, A. P., \& Volossovitch, A. (2014). Effects of Match Location, Match Status and Quality of Opposition on Regaining Possession in UEFA Champions League. J Hum Kinet, 41(1), 203-214. doi:10.2478/hukin-2014-0048

Aquino, R., Munhoz Martins, G. H., Palucci Vieira, L. H., \& Menezes, R. P. (2017). Influence of Match Location, Quality of Opponents, and Match Status on Movement Patterns in Brazilian Professional Football Players. Journal of Strength and Conditioning Research, 31(8), 2155-2161. doi:10.1519/JSC.0000000000001674

Barnes, C., Archer, D. T., Hogg, B., Bush, M., \& Bradley, P. S. (2014). The evolution of physical and technical performance parameters in the English Premier League. International Journal of Sports Medicine, 35(13), 1095-1100. doi:10.1055/s-00341375695

Bradley, P. S., Archer, D. T., Hogg, B., Schuth, G., Bush, M., Carling, C., \& Barnes, C. (2016). Tier-specific evolution of match performance characteristics in the English Premier League: it's getting tougher at the top. Journal of Sports Sciences, 34(10), 980-987. doi:10.1080/02640414.2015.1082614

Bradley, P. S., Lago-Penas, C., Rey, E., \& Sampaio, J. (2014). The influence of situational variables on ball possession in the English Premier League. Journal of Sports Sciences, 32(20), 1867-1873. doi:10.1080/02640414.2014.887850

Bush, M., Archer, D. T., Barnes, C., Hogg, B., \& Bradley, P. S. (2017). Longitudinal match performance characteristics of UK and non-UK players in the English Premier League. Science and Medicine in Football, 1(1), 2-9.

Bush, M., Barnes, C., Archer, D. T., Hogg, B., \& Bradley, P. S. (2015). Evolution of match performance parameters for various playing positions in the English Premier League. Human Movement Science, 39, 1-11. doi:10.1016/j.humov.2014.10.003

Carling, C., Bradley, P., McCall, A., \& Dupont, G. (2016). Match-to-match variability in highspeed running activity in a professional soccer team. Journal of Sports Sciences, 34(24), 2215-2223. doi:10.1080/02640414.2016.1176228

Castellano, J., Casamichana, D., \& Lago, C. (2012). The Use of Match Statistics that Discriminate Between Successful and Unsuccessful Soccer Teams. J Hum Kinet, 31, 139-147. doi:10.2478/v10078-012-0015-7

Chassy, P. (2013). Team Play in Football: How Science Supports F. C. Barcelona's Training Strategy. Psychology, 04(09), 7-12. doi:10.4236/psych.2013.49A2002 
Collet, C. (2013). The possession game? A comparative analysis of ball retention and team success in European and international football, 2007-2010. Journal of Sports Sciences, 31(2), 123-136. doi:10.1080/02640414.2012.727455

Connell, J. (2018). Globalisation, soft power, and the rise of football in China. Geographical Research, 56(1), 5-15. doi:10.1111/1745-5871.12249

Di Salvo, V., Gregson, W., Atkinson, G., Tordoff, P., \& Drust, B. (2009). Analysis of high intensity activity in Premier League soccer. International Journal of Sports Medicine, 30(3), 205-212. doi:10.1055/s-0028-1105950

Escalante, Y., Saavedra, J. M., Mansilla, M., \& Tella, V. (2011). Discriminatory power of water polo game-related statistics at the 2008 Olympic Games. Journal of Sports Sciences, 29(3), 291-298. doi:10.1080/02640414.2010.532230

Gai, Y., Leicht, A. S., Lago, C., \& Gomez, M. A. (2019). Physical and technical differences between domestic and foreign soccer players according to playing positions in the China Super League. Research in Sports Medicine, 27(3), 314-325. doi:10.1080/15438627.2018.1540005

Gómez, M.-Á., Lorenzo, A., Sampaio, J., José Ibáñez, S., \& Ortega, E. (2008). Game-related statistics that discriminated winning and losing teams from the Spanish men's professional basketball teams. Collegium Antropologicum, 32(2), 451-456.

Harrop, K., \& Nevill, A. (2017). Performance indicators that predict success in an English professional League One soccer team. International Journal of Performance Analysis in Sport, 14(3), 907-920. doi:10.1080/24748668.2014.11868767

Hoppe, M. W., Slomka, M., Baumgart, C., Weber, H., \& Freiwald, J. (2015). Match Running Performance and Success Across a Season in German Bundesliga Soccer Teams. International Journal of Sports Medicine, 36(7), 563-566. doi:10.1055/s-0034-1398578

Kempe, M., Vogelbein, M., Memmert, D., \& Nopp, S. (2014). Possession vs. direct play: evaluating tactical behavior in elite soccer. International journal of sports science, 4(6A), 35-41. doi:10.5923/s.sports.201401.05

Lago-Ballesteros, J., \& Lago-Peñas, C. (2010). Performance in Team Sports: Identifying the Keys to Success in Soccer. Journal of Human Kinetics, 25(1), 85-91. doi:10.2478/v10078-010-0035-0

Lago-Peñas, C., \& Dellal, A. (2010). Ball Possession Strategies in Elite Soccer According to the Evolution of the Match-Score: the Influence of Situational Variables. Journal of Human Kinetics, 25(1), 93-100. doi:10.2478/v10078-010-0036-z

Lago-Peñas, C., Gómez-Ruano, M., \& Yang, G. (2018). Styles of play in professional soccer: 
an approach of the Chinese Soccer Super League. International Journal of Performance Analysis in Sport, 17(6), 1073-1084. doi:10.1080/24748668.2018.1431857

Lago-Peñas, C., Lago-Ballesteros, J., Dellal, A., \& Gómez, M. (2010). Game-related statistics that discriminated winning, drawing and losing teams from the Spanish soccer league. Journal of Sports Science \& Medicine, 9(2), 288.

Lago-Peñas, C., Lago-Ballesteros, J., \& Rey, E. (2011). Differences in performance indicators between winning and losing teams in the UEFA Champions League. Journal of Human Kinetics, 27(1), 137-148. doi:10.2478/v10078-011-0011-3

Lago, C. (2009). The influence of match location, quality of opposition, and match status on possession strategies in professional association football. Journal of Sports Sciences, 27(13), 1463-1469. doi:10.1080/02640410903131681

Lago, C., \& Martin, R. (2007). Determinants of possession of the ball in soccer. Journal of Sports Sciences, 25(9), 969-974. doi:10.1080/02640410600944626

Liu, H., Gomez, M. A., Lago-Penas, C., \& Sampaio, J. (2015). Match statistics related to winning in the group stage of 2014 Brazil FIFA World Cup. Journal of Sports Sciences, 33(12), 1205-1213. doi:10.1080/02640414.2015.1022578

Liu, H., Hopkins, W. G., \& Gomez, M. A. (2016). Modelling relationships between match events and match outcome in elite football. European Journal of Sport Science, 16(5), 516-525. doi:10.1080/17461391.2015.1042527

Lorenzo, A., Gomez, M. A., Ortega, E., Ibanez, S. J., \& Sampaio, J. (2010). Game related statistics which discriminate between winning and losing under-16 male basketball games. Journal of Sports Science and Medicine, 9(4), 664-668.

Mao, L., Peng, Z., Liu, H., \& Gómez, M.-A. (2017). Identifying keys to win in the Chinese professional soccer league. International Journal of Performance Analysis in Sport, 16(3), 935-947. doi:10.1080/24748668.2016.11868940

McGarry, T., O'Donoghue, P., \& Sampaio, J. (2013). Routledge handbook of sports performance analysis: Routledge.

Meletakos, P., Vagenas, G., \& Bayios, I. (2017). A multivariate assessment of offensive performance indicators in Men's Handball: Trends and differences in the World Championships. International Journal of Performance Analysis in Sport, 11(2), 284294. doi:10.1080/24748668.2011.11868548

Menard, S. (2011). Standards for Standardized Logistic Regression Coefficients. Social Forces, 89(4), 1409-1428. doi:10.1093/sf/89.4.1409

Norman, G. R., \& Streiner, D. L. (2008). Biostatistics: the bare essentials: PMPH-USA. 
Pollard, R., \& Pollard, G. (2005). Long-term trends in home advantage in professional team sports in North America and England (1876-2003). Journal of Sports Sciences, 23(4), 337-350. doi:10.1080/02640410400021559

Robertson, S., Back, N., \& Bartlett, J. D. (2016). Explaining match outcome in elite Australian Rules football using team performance indicators. Journal of Sports Sciences, 34(7), 637-644. doi:10.1080/02640414.2015.1066026

Robertson, S., \& Joyce, D. (2018). Evaluating strategic periodisation in team sport. Journal of Sports Sciences, 36(3), 279-285. doi:10.1080/02640414.2017.1300315

Ruano, M. Á., Serna, A. D., Lupo, C., \& Sampaio, J. E. (2016). Effects of Game Location, Quality of Opposition, and Starting Quarter Score in the Outcome of Elite Water Polo Quarters. Journal of Strength and Conditioning Research, 30(4), 1014-1020. doi:10.1519/JSC.0b013e3182aa5f59

Taylor, J. B., Mellalieu, S. D., James, N., \& Barter, P. (2010). Situation variable effects and tactical performance in professional association football. International Journal of Performance Analysis in Sport, 10(3), 255-269.

Vaz, L., Van Rooyen, M., \& Sampaio, J. (2010). Rugby game-related statistics that discriminate between winning and losing teams in IRB and Super twelve close games. Journal of Sports Science and Medicine, 9(1), 51-55.

Vogelbein, M., Nopp, S., \& Hokelmann, A. (2014). Defensive transition in soccer - are prompt possession regains a measure of success? A quantitative analysis of German FussballBundesliga 2010/2011. Journal of Sports Sciences, 32(11), 1076-1083. doi:10.1080/02640414.2013.879671

Yang, G., Leicht, A. S., Lago, C., \& Gomez, M. A. (2018). Key team physical and technical performance indicators indicative of team quality in the soccer Chinese super league. Research in Sports Medicine, 26(2), 158-167. doi:10.1080/15438627.2018.1431539

Zhou, C., Zhang, S., Lorenzo, A., \& Cui, Y. (2018). Chinese soccer association super league, 2012-2017: key performance indicators in balance games. International Journal of Performance Analysis in Sport, 18(4), 645-656. doi:10.1080/24748668.2018.1509254

Zubillaga, A. (2006). La actividad del jugador de fútbol en alta competición: análisis de variabilidad. $(\mathrm{PhD})$, Universidad de Malaga,

Zubillaga, A., Gorospe, G., Hernandez, A., \& Blanco, A. (2009). Comparative analysis of the high-intensity activity of soccer players in top level competition. Science and Football VI, 182-185. 


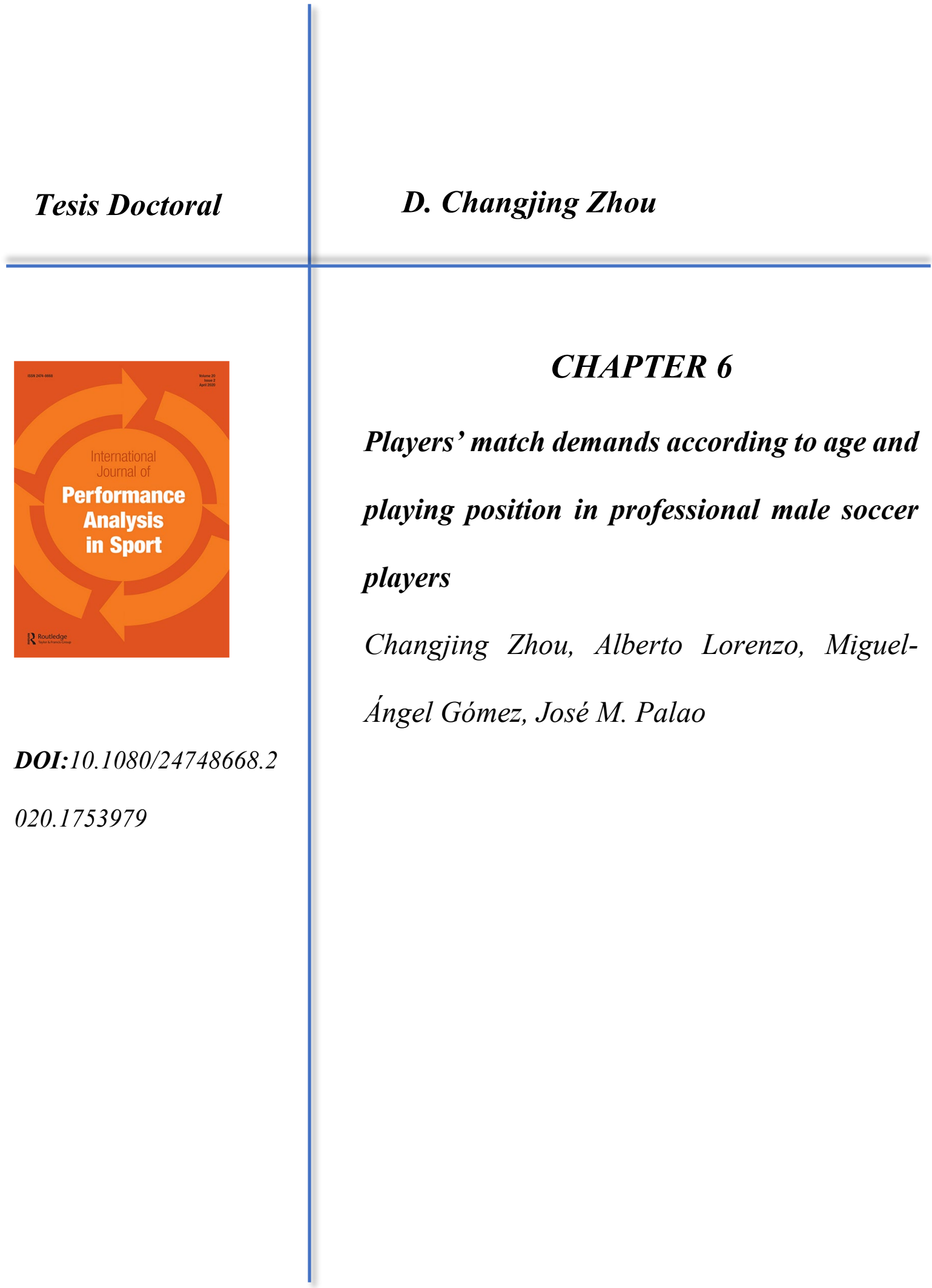




\section{Chapter 6 Players' match demands according to age and playing}

\section{position in professional male soccer players}

\subsection{Introduction}

Player development and lifespan are two issues that concern managers, coaches, and players (Allen \& Hopkins, 2015; Berthelot et al., 2012). A player's age is a factor that affects his performance profile (Carling et al., 2008). The player's years of training and experience influence his physical, skill, and cognitive capacities (Allen \& Hopkins, 2015). Peak performance age (PPA) of professional soccer players and the normative profile for each age group are important aspects to consider in order to analyse players properly (Dendir, 2016; Kalen et al., 2019). Soccer players from different playing positions require different physical capacities and technical abilities, due to the different roles and tasks that they perform during the match (Bradley et al., 2009; Dellal, Wong, Moalla, \& Chamari, 2010; Di Salvo et al., 2007; Taylor, Mellalieu, \& James, 2017). The different demands that each position requires could be one of the reasons for the fact that players from different playing positions have different playing lifespans and PPAs(Dendir, 2016; Kalen et al., 2019).

Central defenders perform fewer high-intensity activities than outside defenders, external midfielders and forwards. Central midfielders cover the greatest distance (Ade, Fitzpatrick, \& Bradley, 2016; Bradley et al., 2009; Di Salvo et al., 2007; Taylor et al., 2017). Midfielders perform more passes and do so more successfully. Forwards execute more shots and defenders have a higher percentage of successful duels. Fullbacks and wide midfielders perform more crosses (Ade et al., 2016; Bloomfield, Polman, \& O'Donoghue, 2007; Dellal et al., 2010). These differences are most likely a direct consequence of the tactical role of these positions within the team during the matches (Reilly, 2003; Taylor et al., 2017).

The influence of age and maturity on youth soccer players' performance has been extensively studied in the literature (Al Haddad et al., 2015; Mendez-Villanueva et al., 2011; Rommers et 
al., 2019; Salinero et al., 2019; Saward et al., 2016). Few studies have studied the changes in technical-tactical and physical performance of elite adult players according to their chronological age (Sal de Rellan-Guerra et al., 2019) (Dendir, 2016; Kalen et al., 2019). Coaches need objective information about how physical and technical performance change throughout players' careers. A study in the Bundesliga (the highest professional German soccer competition) found that players aged $>30$ years had significantly lower physical performance in the total distance covered, the number of fast runs, and the number of sprints compared with younger players ( $\leq 30$ years). A player's ability to make successful passes increased with age in the Bundesliga (Sal de Rellan-Guerra et al., 2019).

These changes in the playing profile could be directly related to the player's PPA (Dendir, 2016; Kalen et al., 2019). The average player's PPA occurs in the 25-27 year age range, and forwards peak (at approximately 25 years) earlier than defenders (at approximately 27 years) and midfielders (at approximately 27 years) (Dendir, 2016). However, match knowledge, anticipation, and tactical awareness can minimize the effects of physical decline (Dendir, 2016). For example, the defender is the one position where acquired learning and experience can be most utilized to compensate for age-induced deterioration in physical performance. For this reason, defenders tend to have a longer near-peak performance duration (Dendir, 2016). Based on this rationale, there is a need to consider a player's age and playing position when analysing his performance from a long-term career perspective. It was hypothesized that a player's performance is not linear in the different age groups and there are different trends by playing position. The aim of this paper was to study the changes of match patterns (technical performance-related parameters and physical performance-related parameters) in elite soccer players according to their playing position and age. 


\subsection{Materials and methods}

\subsubsection{Sample}

The study included information about outfield players from the first professional men's soccer league of China (Chinese Super League, CSL). Data included the actions of a total of 923 players in 1,427 matches during the 2012 to 2017 seasons (six seasons total). Data were provided by the Amisco (Amisco, Nice, France) tracking system. Only data from players that played more than half of the match time were included in the analysis (whether they were starters or substitutes) (McCormack et al., 2015). The unit of analysis was the player's matchperformance. The final sample consisted of 28,547 match observations. Data distribution according to age and playing position is shown in Table 6.1.

Table 6.1 Data distribution according to the age group and playing position.

\begin{tabular}{|c|c|c|c|c|c|}
\hline Position & Group 1 (17-22.9) & Group 2(23-28.9) & Group 3 (29-34.9) & Group 4 (35-40.9) & Total \\
\hline Central defender & $516(9 \%)$ & $2,929(49 \%)$ & $2,211(37 \%)$ & $350(6 \%)$ & 6,006 \\
\hline Full-Back & $659(12 \%)$ & $3,591(63 \%)$ & $1,337(24 \%)$ & $85(1 \%)$ & 5,672 \\
\hline Central midfielder & $702(10 \%)$ & $3,517(48 \%)$ & $3,022(41 \%)$ & $148(2 \%)$ & 7,389 \\
\hline Wide midfielder & $897(16 \%)$ & $3,476(63 \%)$ & $1,062(19 \%)$ & $72(1 \%)$ & 5,507 \\
\hline Attacker & $262(7 \%)$ & $2,045(51 \%)$ & $1,579(40 \%)$ & $87(2 \%)$ & 3,973 \\
\hline Total & $3,036(11 \%)$ & $15,558(54 \%)$ & $9,211(32 \%)$ & $742(3 \%)$ & 28,547 \\
\hline
\end{tabular}

\subsubsection{Variables and procedure}

A non-experimental retrospective design was carried out to analyse the difference in the football players' game patterns according to their position and age. Positions were categorized as central defenders (CD), fullbacks (FB), central midfielders (CM), wide midfielders (WM), and attackers (A) (Bradley et al., 2009). The age span of all players was 24 years (17-40 years). Due to the $\mathrm{U} 23$ policy in the CSL, players younger than 23 years of age are considered as a special development group; thus, players younger than 23 years old were separated as a group: Group 1 (17-22.9 years). Then, the remaining players were divided into three groups: Group 2 (2328.9 years), Group 3 (29-34.9 years), and Group 4 (35-40.9 years). There were 648 players who 
participated in only 1 group, 273 players who participated in two groups, and there were two players who participated in 3 groups. In accordance with other similar studies (Sal de RellanGuerra et al., 2019; Sarmento et al., 2014; Zhou et al., 2018), 14 technical performance-related parameters and six physical performance-related parameters were chosen as performance variables in the analysis (shown in Table 6.2).

Table 6.2 Operational definition of technical and physical performance-related parameters
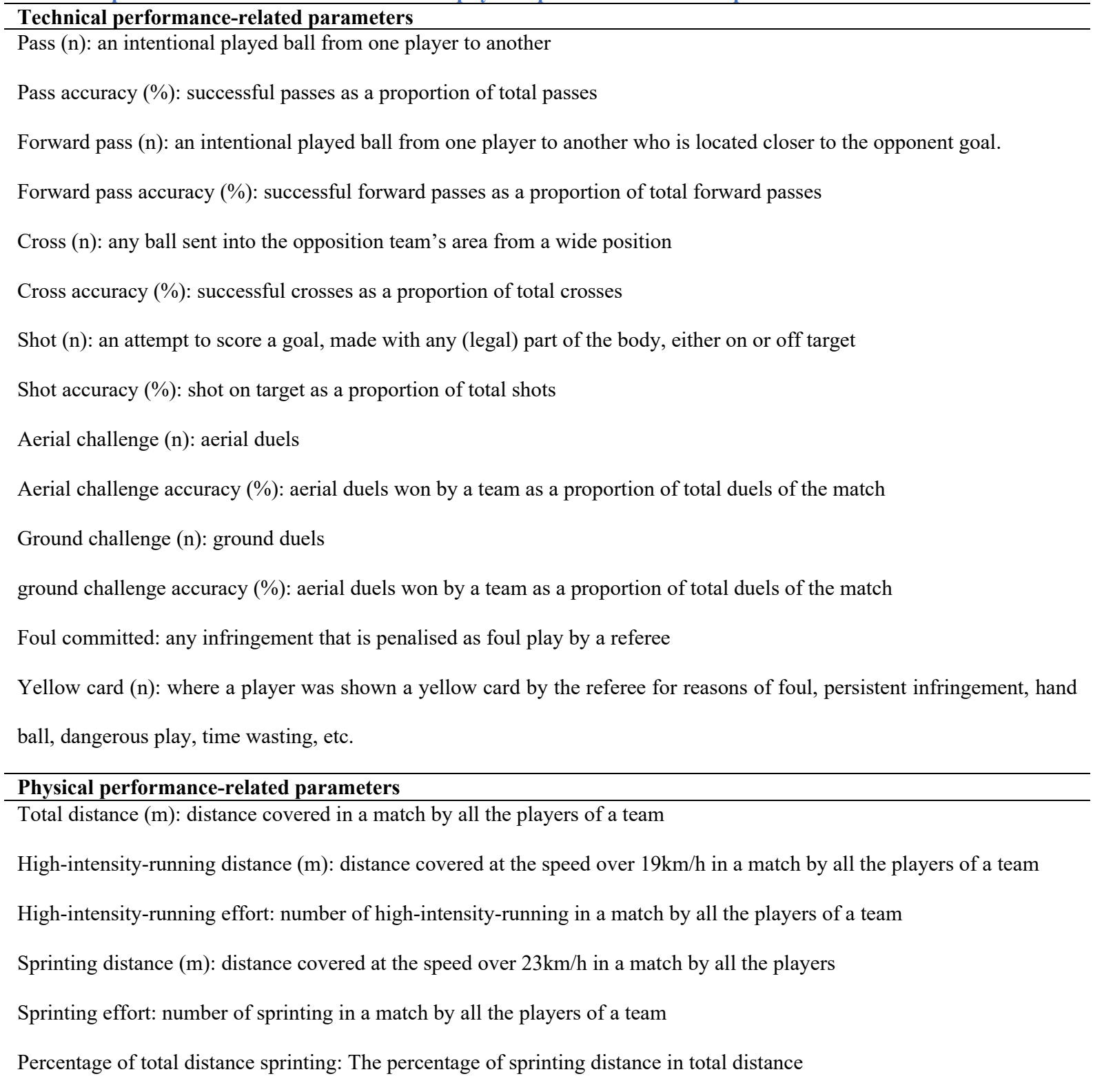

The reliability and validity of the Amisco system for measuring players' actions (technical and physical performance-related parameters) has been assessed (Zubillaga et al., 2007). Data were 
obtained from the original reports and transferred to a database. The players' match data were standardized using the following formula: $\mathrm{V}_{\text {standardized }}=\left(\mathrm{V}_{\text {original }} /\right.$ played time $*$ full match time $)$ $* 100 \%$. Standardization was carried out to prevent the influence of substitutions made at the end of matches on the data as well as to provide more reliable normative match profiles to coaches. Each performance variable was bound to the corresponding age, using the formula developed/used by Berthelot et al. (2012):

$\mathrm{T}=\lfloor\Delta \mathrm{Y}+\Delta \mathrm{M} / 12+\Delta \mathrm{D} / 365.25\rfloor$

where $T$ (in years) is the age, when a given performance is established; $\Delta Y$ (years) is the difference between the year when the performance is established and the performer birth year; $\Delta M$ (months) is the difference between the performer birth month and the month of performance and $\Delta D$ (days) is the difference between the day of birth and the day of performance. "I ]" is the notion of the integral part.

\subsubsection{Statistical analysis}

The relationship between age and the remaining variables measured in this investigation was assessed by computing LOESS smooth lines. Differences between the four age groups were determined using one-way analysis of variance (ANOVA). In the event of a significant difference, Bonferroni's post-hoc tests were used to identify any localized effects. Pairwise comparisons between the four groups were further analysed using, Cohen's $d$ effect size test (Cohen, 2013). Magnitudes of the standardized effects were interpreted using thresholds of $<0.19,0.2-0.59,0.6-1.19,1.2-1.9,2.0-4.0$ (Batterham \& Hopkins, 2006). Data were presented as means and standard deviations unless otherwise stated. All statistical analyses were conducted using the statistical software IBM SPSS Statistics for Windows Version 25.0 (Armonk, NY: IBM Corp). Statistical significance was set at $p<.05$.

\subsection{Results}

Results showed statistically significant differences among groups for all the physical indicators in all playing positions $(\mathrm{p}<0.05)$ with the only exception being sprinting percentage for wide midfielders (Table 6.3). For possession-related technical performance variables, age has more 
impact on the number of shots and pass-related variables, and it has less impact on their accuracy, especially for the defenders $(\mathrm{p}<0.05)$ (Table 6.4). Age has different effects on the confrontation-related technical performance variables, depending on the playing position (Table 6.5).

For central defenders, the players from group 4 covered less total distance (ES: 0.22-0.88; $\mathrm{p}<.001)$ than players from other groups. Groups 3 and 4 covered less high-intensity running distance (ES: 0.17-0.27; $<<.001)$ and performed fewer high-intensity running efforts (ES: 0.16$0.28 ; \mathrm{p}<.001)$ than groups 1 and 2 . Group 3 covered significantly less sprinting distance (ES: $0.17-0.19 ; \mathrm{p}<.001$ ) and performed fewer sprinting efforts (ES: $0.18-0.21 ; \mathrm{p}<.001$ ) than groups 1 and 2 (Table 6.3). Regarding the technical performance variables, group 4 made more passes (ES: $0.22-0.25 ; p<.001)$ than groups 2 and 3 , and made more forward passes (ES: $0.17 ; p=.011$ ) than group 2. Pass accuracy did not change between the different age groups. Groups 1 and 4 performed fewer shots (ES: 0.16-0.17; $p<.001$ ) than groups 2 and 3 (Table 6.4). Central defenders from group 3 had more aerial challenges (ES: $0.14-0.35 ; p<.001$ ) than central defenders from groups 1 and 4. Groups 2 and 3 had higher accuracy in aerial challenges than group 1 (ES: $0.15-0.18 ; p<.001$ ). Central defenders from group 3 made fewer fouls than central defenders from group 2 (ES: $0.09 ; p=.048$ ). The players from group 4 got more yellow cards (ES: $0.08-0.20 ; p<.001)$ than players from groups 2 and 3 (Table 6.5).

Full-backs from group 1 covered more total distance (ES: $0.17-0.36 ; p<.001)$ than the other groups, group 3 covered less high-intensity running distance (ES: $0.14-0.19 ; p<.001$ ), less sprinting distance (ES: 0.15-0.24; $p<.001$ ), less sprinting efforts (ES: $0.17-0.26 ; p<.001$ ) and sprinting percentage (ES: $0.15-0.21 ; p<.001)$ than groups 1 and 2 (Table 6.3). As shown in Table 6.4, group 4 made more passes (ES: $0.11-0.88 ; p<.001$ ), forward passes (ES: $0.19-0.22$; $p<.001$ ), and crosses (ES: $0.67-1.03 ; p<.001)$ than younger players, but there was no difference in passes accuracy between them. The full-backs aged in group 2 have more successful aerial 
challenges percentage (ES: $0.14 ; p=.001)$ and more fouls (ES: $0.09 ; p=.048$ ) than group 3 , and group 4 got more yellow cards than group 3 (ES: 0.32; $p=.039$ ) (Table 6.5).
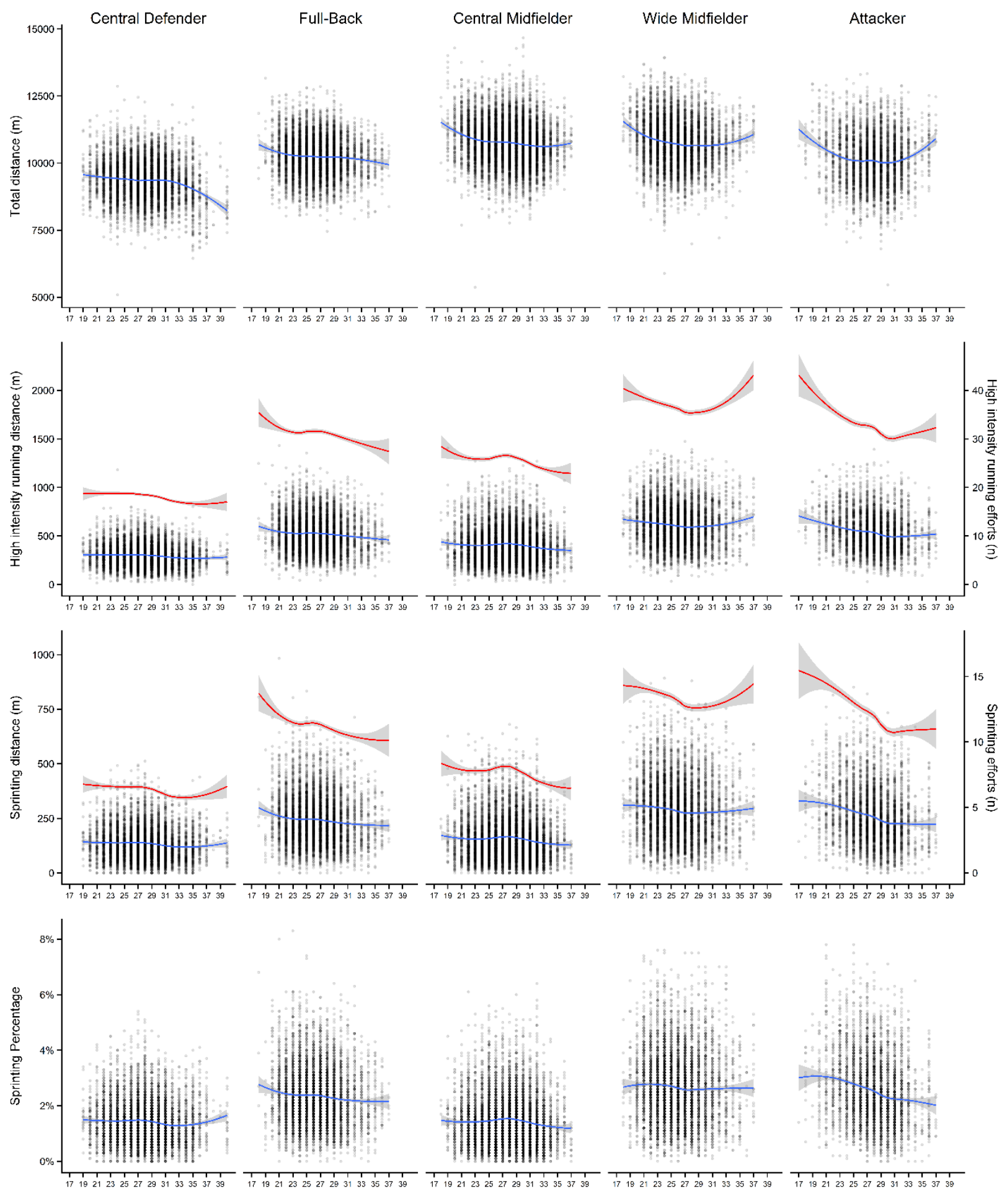

Ages

Figure 6.1 Physical performance variables by age and playing position.

Each point represents the players' performance indicator per match according their ages and playing positions. The line represents a LOESS smooth to the data. 

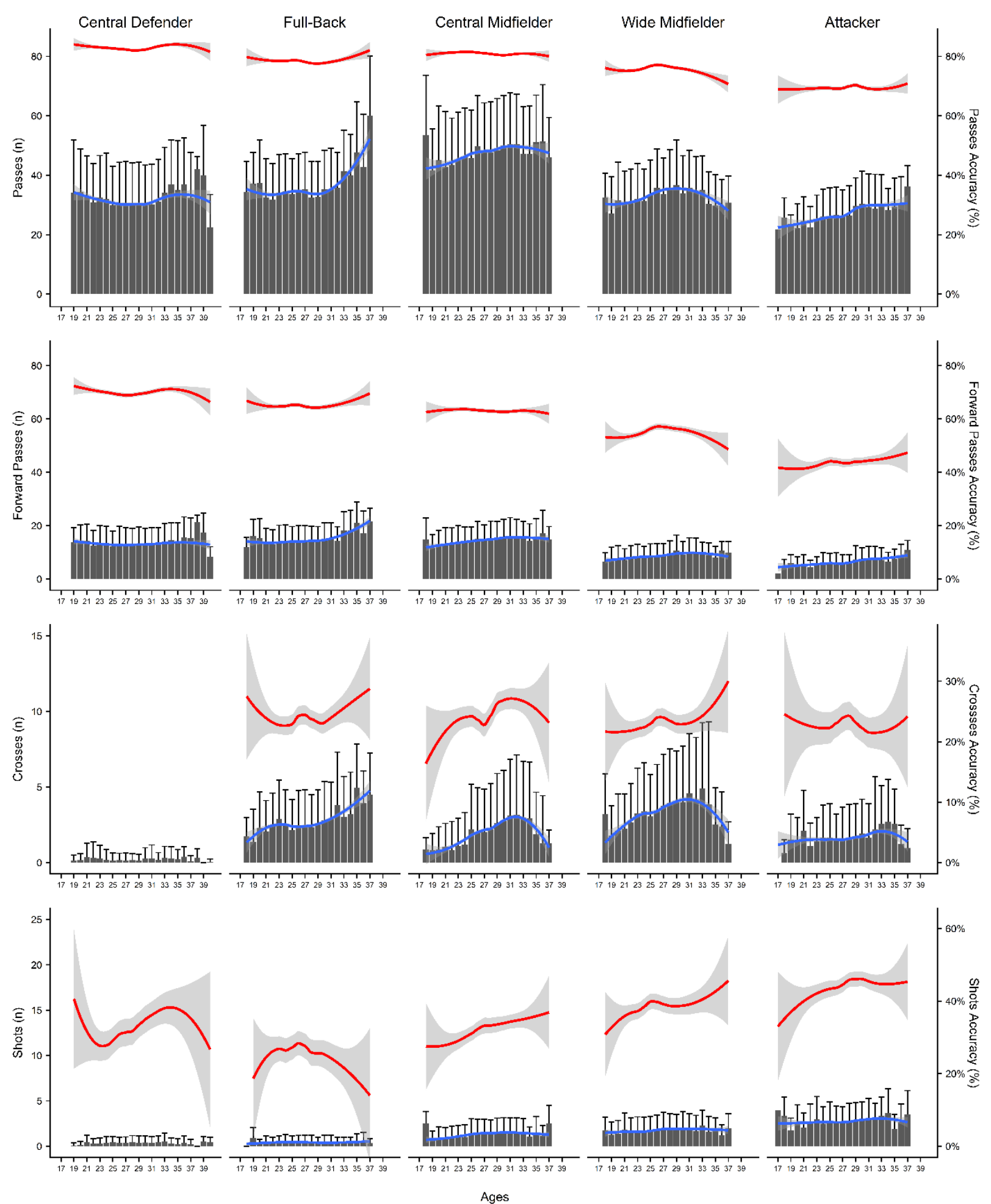

Figure 6.2 Possession-related Technical performance variables by age and playing position 

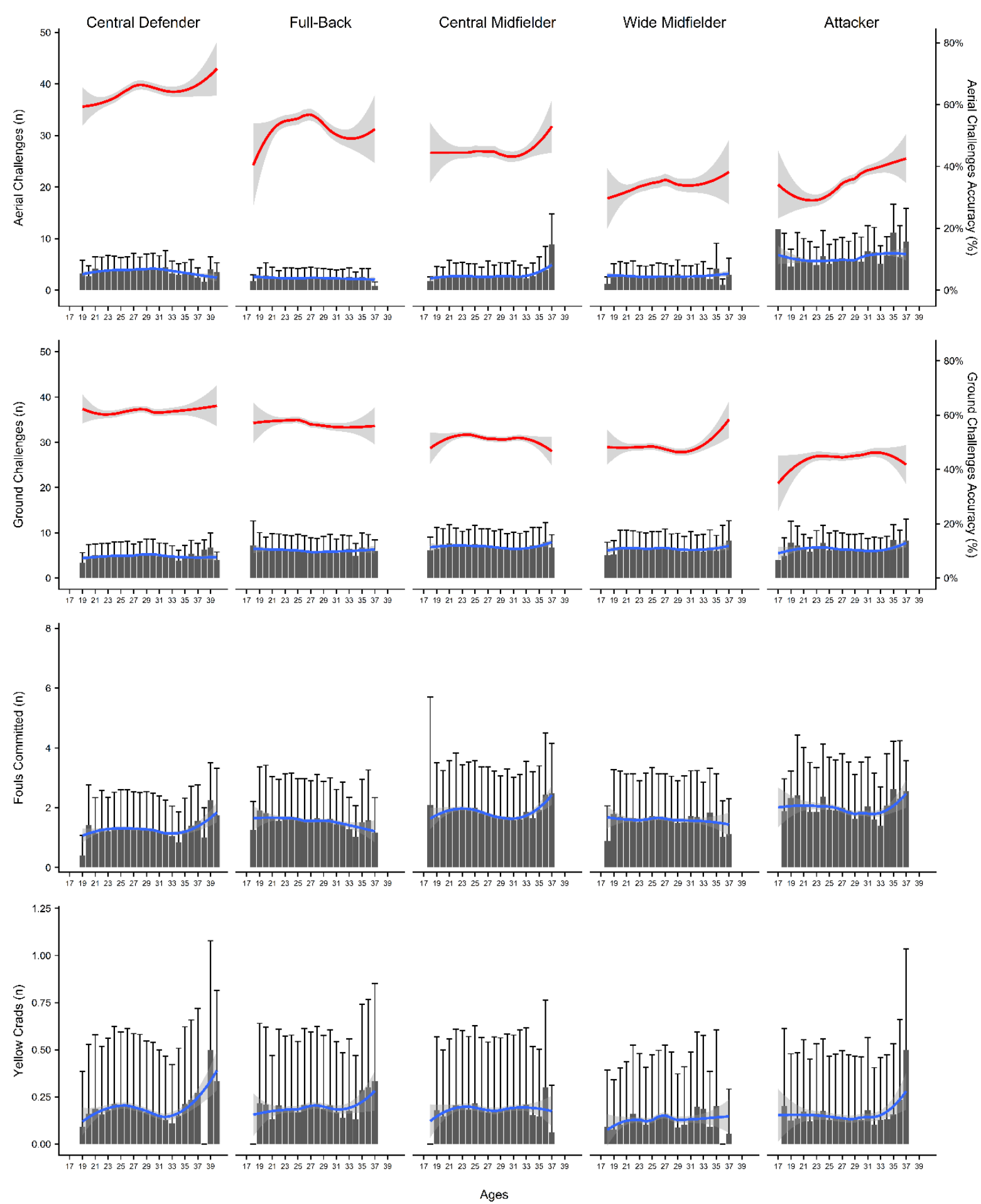

Figure 6.3 Confrontation-related technical performance variables by age and playing position. 
Table 6.3 Character descriptions of physical performance variables according to each age group.

\begin{tabular}{|c|c|c|c|c|c|c|}
\hline Variables & Group 1 (17-22.9) & $\begin{array}{ll}\text { Group } 2 & (23-28.9) \\
\end{array}$ & $\begin{array}{l}\text { Group } 3 \text { (29-34.9) } \\
\end{array}$ & $\begin{array}{l}\text { Group } 4 \text { (35-40.9) } \\
\end{array}$ & $\mathbf{P}$ & Difference between Groups \\
\hline \multicolumn{7}{|l|}{ Central defender } \\
\hline Total distance $(\mathrm{m})$ & $9,529.3 \pm 685.4$ & $9,370.4 \pm 743.9$ & $9,350.1 \pm 748.4$ & $8,823.3 \pm 943.7$ & $<0.001$ & $\mathrm{G} 1>(\mathrm{G} 2=\mathrm{G} 3)>\mathrm{G} 4$ \\
\hline High-intensity running distance $(\mathrm{m})$ & $307.5 \pm 116.4$ & $305.1 \pm 122.8$ & $285.1 \pm 113.9$ & $276.8 \pm 110.3$ & $<0.001$ & $(\mathrm{G} 1=\mathrm{G} 2)>(\mathrm{G} 3=\mathrm{G} 4)$ \\
\hline High-intensity running efforts (n) & $18.9 \pm 6.8$ & $18.7 \pm 7.1$ & $17.6 \pm 6.7$ & $17.0 \pm 6.6$ & $<0.001$ & $(\mathrm{G} 1=\mathrm{G} 2)>(\mathrm{G} 3=\mathrm{G} 4)$ \\
\hline Sprinting distance $(\mathrm{m})$ & $138.8 \pm 74.7$ & $138.3 \pm 78.9$ & $124.9 \pm 72.0$ & $125.3 \pm 70.4$ & $<0.001$ & $(\mathrm{G} 1=\mathrm{G} 2)>\mathrm{G} 3, \mathrm{G} 2>\mathrm{G} 4$ \\
\hline Sprinting efforts (n) & $6.6 \pm 3.2$ & $6.6 \pm 3.4$ & $6.0 \pm 3.2$ & $6.2 \pm 3.3$ & $<0.001$ & $(\mathrm{G} 1=\mathrm{G} 2)>\mathrm{G} 3$ \\
\hline Sprinting percentage & $1.46 \% \pm 0.76 \%$ & $1.47 \% \pm 0.82 \%$ & $1.33 \% \pm 0.74 \%$ & $1.43 \% \pm 0.81 \%$ & $<0.001$ & $(\mathrm{G} 1=\mathrm{G} 2)>\mathrm{G} 3$ \\
\hline \multicolumn{7}{|l|}{ Full-back } \\
\hline Total distance (m) & $10,368.7 \pm 780.1$ & $10,240.2 \pm 735.1$ & $10,209.1 \pm 720.5$ & $10,091.6 \pm 644.1$ & $<0.001$ & $\mathrm{G} 1>(\mathrm{G} 2=\mathrm{G} 3=\mathrm{G} 4)$ \\
\hline High-intensity running distance (m) & $534.8 \pm 187.9$ & $525.8 \pm 175.8$ & $501.1 \pm 179.0$ & $486.6 \pm 151.9$ & $<0.001$ & $(\mathrm{G} 1=\mathrm{G} 2)>\mathrm{G} 3$ \\
\hline High-intensity running efforts (n) & $31.8 \pm 10.6$ & $31.4 \pm 9.9$ & $30.0 \pm 10.1$ & $29.1 \pm 8.6$ & $<0.001$ & $(\mathrm{G} 1=\mathrm{G} 2)>\mathrm{G} 3$ \\
\hline Sprinting distance $(\mathrm{m})$ & $254.8 \pm 121.6$ & $244.4 \pm 111.7$ & $227.5 \pm 110.4$ & $225.2 \pm 94.6$ & $<0.001$ & $(\mathrm{G} 1=\mathrm{G} 2)>\mathrm{G} 3$ \\
\hline Sprinting efforts (n) & $11.8 \pm 5.2$ & $11.4 \pm 4.7$ & $10.6 \pm 4.7$ & $10.5 \pm 3.9$ & $<0.001$ & $(\mathrm{G} 1=\mathrm{G} 2)>\mathrm{G} 3$ \\
\hline Sprinting percentage & $2.44 \% \pm 1.09 \%$ & $2.37 \% \pm 1.03 \%$ & $2.21 \% \pm 1.02 \%$ & $2.22 \% \pm 0.88 \%$ & $<0.001$ & $(\mathrm{G} 1=\mathrm{G} 2)>\mathrm{G} 3$ \\
\hline \multicolumn{7}{|l|}{ Central midfielder } \\
\hline Total distance $(\mathrm{m})$ & $11,106.9 \pm 830.3$ & $10,779.0 \pm 816.2$ & $10,670.9 \pm 829.9$ & $10,705.5 \pm 678.1$ & $<0.001$ & $\mathrm{Gl}>\mathrm{G} 2>\mathrm{G} 3, \mathrm{G} 1>\mathrm{G} 4$ \\
\hline High-intensity running distance (m) & $417.7 \pm 189.3$ & $408.0 \pm 175.9$ & $391.0 \pm 170.9$ & $371.6 \pm 146.6$ & $<0.001$ & $\mathrm{G} 1>\mathrm{G} 2>\mathrm{G} 3, \mathrm{G} 1>\mathrm{G} 4$ \\
\hline High-intensity running efforts (n) & $26.9 \pm 11.8$ & $26.0 \pm 10.7$ & $24.9 \pm 10.2$ & $24.2 \pm 9.3$ & $<0.001$ & $\mathrm{G} 1>\mathrm{G} 2>\mathrm{G} 3, \mathrm{G} 1>\mathrm{G} 4$ \\
\hline Sprinting distance $(\mathrm{m})$ & $161.5 \pm 99.2$ & $159.3 \pm 99.2$ & $148.4 \pm 94.8$ & $135.4 \pm 81.2$ & $<0.001$ & $(\mathrm{Gl}=\mathrm{G} 2)>(\mathrm{G} 3=\mathrm{G} 4)$ \\
\hline Sprinting efforts $(\mathrm{n})$ & $8.1 \pm 4.6$ & $7.9 \pm 4.6$ & $7.3 \pm 4.2$ & $6.8 \pm 3.7$ & $<0.001$ & $(\mathrm{G} 1=\mathrm{G} 2)>(\mathrm{G} 3=\mathrm{G} 4)$ \\
\hline Sprinting percentage & $1.45 \% \pm 0.86 \%$ & $1.47 \% \pm 0.89 \%$ & $1.39 \% \pm 0.88 \%$ & $1.26 \% \pm 0.74 \%$ & $<0.001$ & $\mathrm{G} 2>(\mathrm{G} 3=\mathrm{G} 4)$ \\
\hline \multicolumn{7}{|l|}{ Wide midfielder } \\
\hline Total distance $(\mathrm{m})$ & $11,048.9 \pm 907.3$ & $10,718.3 \pm 894.1$ & $10,680.2 \pm 828.8$ & $11,086.2 \pm 640.0$ & $<0.001$ & $(\mathrm{G} 1=\mathrm{G} 4)>(\mathrm{G} 2=\mathrm{G} 3)$ \\
\hline High-intensity running distance (m) & $645.2 \pm 211.3$ & $607.3 \pm 204.4$ & $606.2 \pm 213.2$ & $673.8 \pm 248.0$ & $<0.001$ & $(\mathrm{G} 1=\mathrm{G} 4)>(\mathrm{G} 2=\mathrm{G} 3)$ \\
\hline High-intensity running efforts (n) & $38.6 \pm 12.0$ & $36.3 \pm 11.6$ & $36.2 \pm 11.9$ & $41.5 \pm 14.3$ & $<0.001$ & $(\mathrm{G} 1=\mathrm{G} 4)>(\mathrm{G} 2=\mathrm{G} 3)$ \\
\hline Sprinting distance $(\mathrm{m})$ & $305.6 \pm 140.9$ & $286.3 \pm 132.6$ & $280.8 \pm 141.1$ & $279.7 \pm 146.6$ & $<0.001$ & $\mathrm{G} 1>(\mathrm{G} 2=\mathrm{G} 3)$ \\
\hline Sprinting efforts (n) & $14.1 \pm 5.8$ & $13.2 \pm 5.6$ & $12.9 \pm 5.8$ & $13.5 \pm 6.6$ & $<0.001$ & $\mathrm{G} 1>(\mathrm{G} 2=\mathrm{G} 3)$ \\
\hline Sprinting percentage & $2.76 \% \pm 1.25 \%$ & $2.67 \% \pm 1.21 \%$ & $2.64 \% \pm 1.32 \%$ & $2.49 \% \pm 1.26 \%$ & 0.068 & \\
\hline \multicolumn{7}{|l|}{ Attacker } \\
\hline Total distance (m) & $10,478.3 \pm 1,091.4$ & $10,099.7 \pm 911.5$ & $10,056.4 \pm 969.0$ & $10,695.7 \pm 766.4$ & $<0.001$ & $(\mathrm{G} 1=\mathrm{G} 4)>(\mathrm{G} 2=\mathrm{G} 3)$ \\
\hline High-intensity running distance (m) & $608.6 \pm 194.3$ & $554.4 \pm 194.4$ & $499.0 \pm 186.7$ & $504.1 \pm 176.6$ & $<0.001$ & $\mathrm{G} 1>\mathrm{G} 2>\mathrm{G} 3, \mathrm{G} 1>\mathrm{G} 4$ \\
\hline High-intensity running efforts (n) & $36.3 \pm 10.8$ & $33.2 \pm 11.0$ & $30.5 \pm 10.9$ & $31.3 \pm 10.6$ & $<0.001$ & $\mathrm{G} 1>\mathrm{G} 2>\mathrm{G} 3, \mathrm{G} 1>\mathrm{G} 4$ \\
\hline Sprinting distance $(\mathrm{m})$ & $307.9 \pm 141.8$ & $274.4 \pm 130.9$ & $230.7 \pm 119.5$ & $215.9 \pm 115.7$ & $<0.001$ & $\mathrm{G} 1>\mathrm{G} 2>(\mathrm{G} 3=\mathrm{G} 4)$ \\
\hline Sprinting efforts (n) & $14.1 \pm 5.7$ & $12.7 \pm 5.6$ & $11.0 \pm 5.2$ & $10.6 \pm 5.3$ & $<0.001$ & $\mathrm{G} 1>\mathrm{G} 2>(\mathrm{G} 3=\mathrm{G} 4)$ \\
\hline Sprinting percentage & $2.98 \% \pm 1.41 \%$ & $2.70 \% \pm 1.23 \%$ & $2.29 \% \pm 1.15 \%$ & $2.01 \% \pm 1.05 \%$ & $<0.001$ & $\mathrm{G} 1>\mathrm{G} 2>(\mathrm{G} 3=\mathrm{G} 4)$ \\
\hline
\end{tabular}


Table 6.4 Character descriptions of possession-related technical performance variables according to each age group.

\begin{tabular}{|c|c|c|c|c|c|c|}
\hline Variables & Group 1 (17-22.9) & $\begin{array}{ll}\text { Group 2 } & (23-28.9) \\
\end{array}$ & Group 3 (29-34.9) & $\begin{array}{l}\text { Group } 4(35-40.9) \\
\end{array}$ & $\mathbf{P}$ & \begin{tabular}{|l} 
Difference between Groups \\
\end{tabular} \\
\hline \multicolumn{7}{|l|}{ Central defender } \\
\hline Passes (n) & $32.1 \pm 13.7$ & $30.7 \pm 14.3$ & $31.2 \pm 14.0$ & $34.3 \pm 16.2$ & $<0.001$ & $(\mathrm{G} 2=\mathrm{G} 3)<\mathrm{G} 4$ \\
\hline Passes accuracy & $83.2 \% \pm 11.3 \%$ & $82.6 \% \pm 10.9 \%$ & $82.9 \% \pm 10.9 \%$ & $84.0 \% \pm 10.6 \%$ & 0.105 & \\
\hline Forward passes (n) & $13.3 \pm 6.0$ & $12.9 \pm 6.5$ & $13.2 \pm 6.4$ & $14.0 \pm 7.5$ & 0.011 & $\mathrm{G} 2<\mathrm{G} 4$ \\
\hline Forward passes accuracy & $70.4 \% \pm 18.3 \%$ & $69.6 \% \pm 18.5 \%$ & $70.2 \% \pm 18.0 \%$ & $70.9 \% \pm 18.5 \%$ & 0.400 & \\
\hline Shots (n) & $0.29 \pm 0.60$ & $0.39 \pm 0.67$ & $0.40 \pm 0.72$ & $0.28 \pm 0.61$ & $<0.001$ & $(\mathrm{G} 1=\mathrm{G} 4)<(\mathrm{G} 2=\mathrm{G} 3)$ \\
\hline Shots accuracy & $32.1 \% \pm 44.8 \%$ & $29.8 \% \pm 42.6 \%$ & $35.5 \% \pm 44.3 \%$ & $40.3 \% \pm 45.4 \%$ & 0.031 & \\
\hline Crosses (n) & $0.30 \pm 0.91$ & $0.18 \pm 0.56$ & $0.23 \pm 0.70$ & $0.22 \pm 0.60$ & $<0.001$ & $\mathrm{G} 2<\mathrm{G} 3=\mathrm{G} 1$ \\
\hline Crosses accuracy & $28.6 \% \pm 40.5 \%$ & $24.0 \% \pm 40.0 \%$ & $25.3 \% \pm 39.6 \%$ & $10.9 \% \pm 25.7 \%$ & 0.054 & \\
\hline \multicolumn{7}{|l|}{ Full-back } \\
\hline Passes (n) & $32.8 \pm 12.7$ & $34.2 \pm 12.4$ & $35.1 \pm 13.0$ & $46.8 \pm 17.9$ & $<0.001$ & $\mathrm{G} 1<\mathrm{G} 2=\mathrm{G} 3<\mathrm{G} 4$ \\
\hline Passes accuracy & $78.7 \% \pm 10.5 \%$ & $78.3 \% \pm 10.5 \%$ & $78.0 \% \pm 10.2 \%$ & $80.9 \% \pm 8.9 \%$ & 0.049 & \\
\hline Forward passes (n) & $13.3 \pm 5.9$ & $14.1 \pm 6.0$ & $15.0 \pm 6.1$ & $19.7 \pm 8.0$ & $<0.001$ & $\mathrm{G} 1<\mathrm{G} 2<\mathrm{G} 3<\mathrm{G} 4$ \\
\hline Forward passes accuracy & $64.8 \% \pm 18.2 \%$ & $64.8 \% \pm 16.8 \%$ & $64.6 \% \pm 16.6 \%$ & $68.2 \% \pm 14.5 \%$ & 0.303 & \\
\hline Shots (n) & $0.36 \pm 0.69$ & $0.45 \pm 0.76$ & $0.39 \pm 0.69$ & $0.55 \pm 0.82$ & 0.003 & $\mathrm{G} 1<\mathrm{G} 2$ \\
\hline Shots accuracy & $26.7 \% \pm 41.5 \%$ & $27.1 \% \pm 40.9 \%$ & $24.4 \% \pm 39.8 \%$ & $18.2 \% \pm 35.0 \%$ & 0.460 & \\
\hline Crosses (n) & $2.26 \pm 2.17$ & $2.47 \pm 2.27$ & $2.82 \pm 2.61$ & $4.56 \pm 2.65$ & $<0.001$ & $(\mathrm{G} 1=\mathrm{G} 2)<\mathrm{G} 3<\mathrm{G} 4$ \\
\hline Crosses accuracy & $23.9 \% \pm 30.4 \%$ & $23.4 \% \pm 30.4 \%$ & $24.1 \% \pm 30.9 \%$ & $23.9 \% \pm 25.8 \%$ & 0.911 & \\
\hline \multicolumn{7}{|l|}{ Central midfielder } \\
\hline Passes (n) & $43.5 \pm 16.9$ & $47.3 \pm 16.6$ & $49.3 \pm 17.0$ & $50.7 \pm 16.7$ & $<0.001$ & $\mathrm{G} 1<\mathrm{G} 2<(\mathrm{G} 3=\mathrm{G} 4)$ \\
\hline Passes accuracy & $81.0 \% \pm 10.4 \%$ & $81.2 \% \pm 9.1 \%$ & $80.7 \% \pm 8.9 \%$ & $80.0 \% \pm 9.5 \%$ & 0.086 & \\
\hline Forward passes (n) & $13.0 \pm 5.9$ & $14.4 \pm 6.2$ & $15.4 \pm 6.7$ & $16.1 \pm 7.4$ & $<0.001$ & $\mathrm{G} 1<\mathrm{G} 2<(\mathrm{G} 3=\mathrm{G} 4)$ \\
\hline Forward passes accuracy & $63.1 \% \pm 19.5 \%$ & $63.4 \% \pm 17.8 \%$ & $62.9 \% \pm 17.4 \%$ & $61.9 \% \pm 18.9 \%$ & 0.563 & \\
\hline Shots (n) & $0.88 \pm 1.25$ & $1.32 \pm 1.49$ & $1.49 \pm 1.58$ & $1.50 \pm 1.62$ & $<0.001$ & $\mathrm{G} 1<\mathrm{G} 2, \mathrm{G} 1<(\mathrm{G} 3=\mathrm{G} 4)$ \\
\hline Shots accuracy & $30.1 \% \pm 41.4 \%$ & $31.2 \% \pm 38.8 \%$ & $34.5 \% \pm 38.7 \%$ & $36.0 \% \pm 39.1 \%$ & 0.025 & $\mathrm{G} 2<\mathrm{G} 3$ \\
\hline Crosses (n) & $0.90 \pm 1.70$ & $1.87 \pm 2.77$ & $2.89 \pm 3.59$ & $1.61 \pm 2.78$ & $<0.001$ & $\mathrm{G} 1<\mathrm{G} 2<\mathrm{G} 3$ \\
\hline Crosses accuracy & $20.3 \% \pm 33.5 \%$ & $24.2 \% \pm 33.0 \%$ & $26.9 \% \pm 31.3 \%$ & $22.1 \% \pm 30.8 \%$ & 0.002 & $\mathrm{G} 1<\mathrm{G} 2<\mathrm{G} 3$ \\
\hline \multicolumn{7}{|l|}{ Wide midfielder } \\
\hline Passes (n) & $30.7 \pm 11.5$ & $33.6 \pm 12.2$ & $35.1 \pm 13.3$ & $30.0 \pm 9.7$ & $<0.001$ & $\mathrm{G} 1<\mathrm{G} 2<\mathrm{G} 3, \mathrm{G} 3>\mathrm{G} 4$ \\
\hline Passes accuracy & $75.1 \% \pm 12.2 \%$ & $76.4 \% \pm 10.8 \%$ & $75.5 \% \pm 10.8 \%$ & $72.4 \% \pm 11.7 \%$ & $<0.001$ & $(\mathrm{G} 1=\mathrm{G} 4)<\mathrm{G} 2$ \\
\hline Forward passes (n) & $7.7 \pm 4.4$ & $8.6 \pm 4.6$ & $9.9 \pm 5.3$ & $8.8 \pm 4.2$ & $<0.001$ & $\mathrm{G} 1<\mathrm{G} 2<\mathrm{G} 3$ \\
\hline Forward passes accuracy & $53.3 \% \pm 26.1 \%$ & $55.9 \% \pm 23.7 \%$ & $55.8 \% \pm 22.3 \%$ & $49.8 \% \pm 26.5 \%$ & 0.006 & $\mathrm{G} 1<\mathrm{G} 2$ \\
\hline Shots (n) & $1.61 \pm 1.63$ & $1.76 \pm 1.65$ & $1.88 \pm 1.75$ & $1.79 \pm 1.38$ & 0.005 & $\mathrm{G} 1<\mathrm{G} 3$ \\
\hline Shots accuracy & $35.3 \% \pm 38.7 \%$ & $38.9 \% \pm 39.2 \%$ & $39.5 \% \pm 39.1 \%$ & $42.7 \% \pm 39.2 \%$ & 0.142 & \\
\hline Crosses (n) & $2.41 \pm 2.47$ & $3.46 \pm 3.18$ & $4.20 \pm 3.89$ & $2.19 \pm 2.26$ & $<0.001$ & $(\mathrm{G} 1=\mathrm{G} 4)<\mathrm{G} 2<\mathrm{G} 3$ \\
\hline Crosses accuracy & $21.6 \% \pm 31.3 \%$ & $23.1 \% \pm 28.0 \%$ & $23.1 \% \pm 26.5 \%$ & $23.9 \% \pm 31.1 \%$ & 0.624 & \\
\hline \multicolumn{7}{|l|}{ Attacker } \\
\hline Passes (n) & $23.3 \pm 7.5$ & $26.2 \pm 9.4$ & $29.5 \pm 10.6$ & $30.6 \pm 9.3$ & $<0.001$ & $\mathrm{G} 1<\mathrm{G} 2<(\mathrm{G} 3=\mathrm{G} 4)$ \\
\hline Passes accuracy & $68.2 \% \pm 13.3 \%$ & $69.6 \% \pm 12.2 \%$ & $69.4 \% \pm 11.6 \%$ & $70.1 \% \pm 10.4 \%$ & 0.308 & \\
\hline Forward passes (n) & $5.0 \pm 3.1$ & $5.8 \pm 3.5$ & $7.3 \pm 4.8$ & $8.8 \pm 4.0$ & $<0.001$ & $\mathrm{G} 1<\mathrm{G} 2<\mathrm{G} 3<\mathrm{G} 4$ \\
\hline Forward passes accuracy & $40.4 \% \pm 29.4 \%$ & $43.6 \% \pm 27.8 \%$ & $44.4 \% \pm 25.8 \%$ & $47.0 \% \pm 22.3 \%$ & 0.112 & \\
\hline Shots (n) & $2.49 \pm 1.85$ & $2.69 \pm 1.96$ & $2.95 \pm 2.07$ & $2.55 \pm 2.01$ & $<0.001$ & $(\mathrm{G} 1=\mathrm{G} 2)<\mathrm{G} 3$ \\
\hline Shots accuracy & $38.0 \% \pm 36.8 \%$ & $44.6 \% \pm 35.3 \%$ & $45.1 \% \pm 34.7 \%$ & $48.3 \% \pm 36.4 \%$ & 0.026 & $\mathrm{G} 1<(\mathrm{G} 2=\mathrm{G} 3)$ \\
\hline Crosses (n) & $1.48 \pm 2.01$ & $1.55 \pm 2.09$ & $1.87 \pm 2.54$ & $1.49 \pm 1.64$ & $<0.001$ & $\mathrm{G} 2<\mathrm{G} 3$ \\
\hline Crosses accuracy & $23.3 \% \pm 36.4 \%$ & $23.3 \% \pm 34.4 \%$ & $22.0 \% \pm 32.0 \%$ & $21.4 \% \pm 31.4 \%$ & 0.796 & \\
\hline
\end{tabular}


Table 6.5 Character descriptions of confrontation-related technical performance variables according to each age group.

\begin{tabular}{|c|c|c|c|c|c|c|}
\hline Variables & Group 1 (17-22.9) & $\begin{array}{ll}\text { Group 2 } & (23-28.9) \\
\end{array}$ & Group 3 (29-34.9) & $\begin{array}{l}\text { Group 4 (35-40.9) } \\
\end{array}$ & 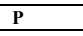 & Difference between Groups \\
\hline \multicolumn{7}{|l|}{ Central defender } \\
\hline Aerial Challenges (n) & $3.6 \pm 2.5$ & $3.9 \pm 2.7$ & $4.0 \pm 2.8$ & $3.1 \pm 2.3$ & $<0.001$ & $\mathrm{G} 4<\mathrm{G} 1<\mathrm{G} 3$ \\
\hline Aerial Challenges accuracy & $59.8 \% \pm 31.9 \%$ & $64.6 \% \pm 30.6 \%$ & $64.5 \% \pm 31.1 \%$ & $65.6 \% \pm 32.9 \%$ & 0.013 & $\mathrm{G} 1<(\mathrm{G} 2=\mathrm{G} 3)$ \\
\hline Ground Challenges (n) & $4.7 \pm 2.7$ & $4.9 \pm 2.9$ & $5.0 \pm 3.0$ & $4.7 \pm 2.8$ & 0.120 & \\
\hline Ground Challenges accuracy & $60.4 \% \pm 28.5 \%$ & $61.4 \% \pm 27.8 \%$ & $61.3 \% \pm 26.3 \%$ & $61.4 \% \pm 29.2 \%$ & 0.919 & \\
\hline Fouls committed (n) & $1.25 \pm 1.27$ & $1.29 \pm 1.23$ & $1.19 \pm 1.18$ & $1.35 \pm 1.21$ & 0.009 & $\mathrm{G} 2>\mathrm{G} 3$ \\
\hline Yellow Cards (n) & $0.17 \pm 0.40$ & $0.20 \pm 0.41$ & $0.16 \pm 0.38$ & $0.24 \pm 0.43$ & $<0.001$ & $\mathrm{G} 3<\mathrm{G} 2<\mathrm{G} 4$ \\
\hline \multicolumn{7}{|l|}{ Full-back } \\
\hline Aerial Challenges (n) & $2.3 \pm 1.9$ & $2.4 \pm 1.9$ & $2.3 \pm 1.8$ & $2.3 \pm 1.8$ & 0.292 & \\
\hline Aerial Challenges accuracy & $52.6 \% \pm 39.1 \%$ & $55.9 \% \pm 37.7 \%$ & $50.7 \% \pm 37.6 \%$ & $52.1 \% \pm 39.9 \%$ & 0.001 & $\mathrm{G} 2>\mathrm{G} 3$ \\
\hline Ground Challenges (n) & $6.3 \pm 3.4$ & $5.9 \pm 3.3$ & $5.9 \pm 3.3$ & $6.6 \pm 3.1$ & 0.017 & \\
\hline Ground Challenges accuracy & $58.1 \% \pm 25.3 \%$ & $57.2 \% \pm 25.5 \%$ & $56.3 \% \pm 25.7 \%$ & $55.3 \% \pm 25.7 \%$ & 0.430 & \\
\hline Fouls committed (n) & $1.62 \pm 1.42$ & $1.61 \pm 1.43$ & $1.49 \pm 1.30$ & $1.51 \pm 1.50$ & 0.048 & $\mathrm{G} 2>\mathrm{G} 3$ \\
\hline Yellow Cards (n) & $0.20 \pm 0.43$ & $0.20 \pm 0.42$ & $0.19 \pm 0.41$ & $0.32 \pm 0.52$ & 0.039 & $\mathrm{G} 3<\mathrm{G} 4$ \\
\hline \multicolumn{7}{|l|}{ Central midfielder } \\
\hline Aerial Challenges (n) & $2.7 \pm 2.6$ & $2.7 \pm 2.4$ & $2.6 \pm 2.6$ & $4.3 \pm 4.2$ & $<0.001$ & $(\mathrm{Gl}=\mathrm{G} 2=\mathrm{G} 3)<\mathrm{G} 4$ \\
\hline Aerial Challenges accuracy & $44.1 \% \pm 37.7 \%$ & $44.7 \% \pm 37.8 \%$ & $43.6 \% \pm 38.3 \%$ & $49.8 \% \pm 35.2 \%$ & 0.260 & \\
\hline Ground Challenges (n) & $7.3 \pm 4.0$ & $7.0 \pm 3.8$ & $6.5 \pm 3.7$ & $7.3 \pm 4.1$ & $<0.001$ & $(\mathrm{G} 1=\mathrm{G} 2)>\mathrm{G} 3$ \\
\hline Ground Challenges accuracy & $51.3 \% \pm 25.1 \%$ & $52.2 \% \pm 24.9 \%$ & $51.4 \% \pm 25.0 \%$ & $47.2 \% \pm 25.3 \%$ & 0.081 & \\
\hline Fouls committed (n) & $1.93 \pm 1.72$ & $1.85 \pm 1.55$ & $1.66 \pm 1.52$ & $2.16 \pm 1.72$ & $<0.001$ & $(\mathrm{G} 1=\mathrm{G} 2=\mathrm{G} 4)>\mathrm{G} 3$ \\
\hline Yellow Cards (n) & $0.21 \pm 0.47$ & $0.21 \pm 0.45$ & $0.20 \pm 0.43$ & $0.23 \pm 0.50$ & 0.826 & \\
\hline \multicolumn{7}{|l|}{ Wide midfielder } \\
\hline Aerial Challenges (n) & $2.8 \pm 2.6$ & $2.6 \pm 2.3$ & $2.7 \pm 2.5$ & $3.5 \pm 4.3$ & 0.001 & $(\mathrm{G} 2=\mathrm{G} 3)<\mathrm{G} 4$ \\
\hline Aerial Challenges accuracy & $31.9 \% \pm 34.5 \%$ & $34.7 \% \pm 35.9 \%$ & $33.4 \% \pm 34.7 \%$ & $35.9 \% \pm 35.9 \%$ & 0.274 & \\
\hline Ground Challenges (n) & $6.7 \pm 3.7$ & $6.5 \pm 3.7$ & $6.2 \pm 3.6$ & $6.6 \pm 4.0$ & 0.007 & $(\mathrm{G} 1=\mathrm{G} 2)>\mathrm{G} 3$ \\
\hline Ground Challenges accuracy & $48.3 \% \pm 25.9 \%$ & $47.9 \% \pm 25.4 \%$ & $46.7 \% \pm 26.1 \%$ & $53.5 \% \pm 25.9 \%$ & 0.122 & \\
\hline Fouls committed (n) & $1.63 \pm 1.50$ & $1.61 \pm 1.51$ & $1.58 \pm 1.48$ & $1.36 \pm 1.46$ & 0.453 & \\
\hline Yellow Cards (n) & $0.16 \pm 0.43$ & $0.15 \pm 0.40$ & $0.14 \pm 0.38$ & $0.16 \pm 0.42$ & 0.510 & \\
\hline \multicolumn{7}{|l|}{ Attacker } \\
\hline Aerial Challenges $(n)$ & $5.8 \pm 4.2$ & $5.8 \pm 4.1$ & $6.5 \pm 4.9$ & $7.8 \pm 6.3$ & $<0.001$ & $(\mathrm{G} 1=\mathrm{G} 2)<\mathrm{G} 4, \mathrm{G} 2<\mathrm{G} 3$ \\
\hline Aerial Challenges accuracy & $29.0 \% \pm 27.0 \%$ & $32.7 \% \pm 26.3 \%$ & $38.2 \% \pm 27.5 \%$ & $42.7 \% \pm 22.7 \%$ & $<0.001$ & $(\mathrm{G} 1=\mathrm{G} 2)<(\mathrm{G} 3=\mathrm{G} 4)$ \\
\hline Ground Challenges (n) & $6.3 \pm 3.5$ & $6.5 \pm 3.7$ & $6.0 \pm 3.3$ & $7.4 \pm 3.7$ & $<0.001$ & $(\mathrm{G} 2=\mathrm{G} 4)>\mathrm{G} 3$ \\
\hline Ground Challenges accuracy & $43.5 \% \pm 26.7 \%$ & $45.0 \% \pm 25.2 \%$ & $45.4 \% \pm 26.0 \%$ & $42.7 \% \pm 23.0 \%$ & 0.573 & \\
\hline Fouls committed (n) & $2.03 \pm 1.78$ & $1.97 \pm 1.72$ & $1.77 \pm 1.58$ & $2.39 \pm 1.79$ & $<0.001$ & $(\mathrm{G} 2=\mathrm{G} 4)>\mathrm{G} 3$ \\
\hline Yellow Cards (n) & $0.17 \pm 0.42$ & $0.16 \pm 0.41$ & $0.15 \pm 0.38$ & $0.25 \pm 0.45$ & 0.113 & \\
\hline
\end{tabular}

For central midfielders, players from group 1 performed more total distance (ES: 0.40-0.53; $p<.001$ ), high-intensity running distance (ES: $0.05-0.25 ; p<.001)$ and efforts (ES: $0.08-0.24$; $p<.001)$ than the other groups; the players from groups 1 and 2 performed more sprinting distance and efforts (ES: 0.11-0.24; $p<.001$ ), Group 2 made more sprinting percentage (ES: 
0.09-0.24; $p<.001$ ) than group 3 and 4 (Table 6.3). Central midfielders from groups 3 and 4 made more passes (ES: $0.12-0.42 ; p<.001$ ), and forward passes (ES: $0.16-0.50 ; p<.001$ ) than other two groups, while their passes accuracy had no differences; compared with the other groups, players from group 1 made significantly less shots (ES: $0.30-0.47 ; p<.001$ ), group 3 had higher successful shots percentage (ES: $0.08 ; p=.025$ ) than group 2; group 3 performed more crosses (ES: $0.32-0.60 ; p<.001)$ and higher cross accuracy (ES: $0.08-0.21 ; p=.002$ ) than groups 1 and 2 (Table 6.4). The central midfielders from group 4 made more aerial challenges (ES: $0.56-0.62 ; p<.001)$ than the other groups; the players from groups 1 and 2 made more ground challenge (ES: $0.11-0.20 ; p<.001)$ than group 3 ; the players aged in group 3 (29-34.9 years) made less fouls (ES: $0.13-0.32 ; p<.001)$ than the other groups (Table 6.5).

For wide midfielders, the players aged in groups 1 and 4 covered more total distance (ES: 0.37$0.50 ; p<.001$ ), more high-intensity running distance (ES: $0.18-0.32 ; p<.001$ ), and more highintensity running efforts (ES: $0.20-0.45 ; p<.001)$ than groups 2 and 3 ; The players from age group 1 had significantly (ES: $0.14-0.18 ; p<.001)$ more sprinting distance and sprinting efforts (ES: $0.16-0.21 ; p<.001$ ) than groups 2 and 3 (Table 6.3). Wide midfielders from group 3 had significantly more passes (ES: $0.12-0.39 ; p<.001)$ than the other groups, group 2 performed higher passes accuracy (ES: $0.12-0.37 ; p<.001$ ) than groups 1 and 4 ; group 3 made more forward passes than groups 1 and 2 (ES: 0.27-0.44; $p<.001$ ) and group 2 had higher forward passes accuracy than group 1 (ES: $0.11 ; p<.001)$; players from group 3 made more shots than group 1 (ES: $0.16 ; p<.001$ ), group 3 had more crosses than the other groups (ES: 0.22-0.54; $p<.001$ ) (Table 6.4). The players from group 4 made more aerial challenges than groups 2 and 3 (ES: $0.32-0.39 ; p=.001$ ), while group 3 performed fewer ground challenges than groups 1 and 2 (ES: $0.10-0.15 ; p=.007)$ (Table 6.5).

For attackers, the players aged in groups 1 and 4 covered more total distance than groups 2 and 3 (ES: $0.41-0.67 ; p<.001$ ), the players from group 1 covered more high-intensity running 
distance (ES: 0.28-0.55; $p<.001)$ and more high-intensity running efforts (ES: 0.29-0.53; $p<.001$ ); the players from group 1 performed more sprinting distance (ES: $0.25-0.68 ; p<.001$ ) and more sprinting efforts (ES: $0.25-0.63 ; p<.001)$ and more sprinting percentage than the other groups (ES: 0.22-0.72; $p<.001$ ) (Table 6.3). Players from group 3 and 4 made more passes (ES: $0.34-0.90 ; p<.001$ ) as well as forward passes (ES: $0.32-1.13 ; p<.001$ ) than groups 1 and 2 , while passes accuracy had no changes in the process of aging; group 3 made more shots (ES: 0.13$0.23 ; p<.001)$ than groups 1 and 2 , while groups 2 and 3 performed higher shots accuracy (ES: $0.19-0.21 ; p<.001)$ than group 1 ; group 3 made more crosses than group 2 (ES: $0.14 ; p<.001$ ) (Table 6.4). Group 4 performed more aerial challenges (ES: $0.41-0.48 ; p<.001$ ) than groups 1 and 2, and group 3 performed more aerial challenges than group 2 (ES: $0.17 ; p<.001$ ), the players from groups 3 and 4 had higher challenge success percentage than groups 1 and 2 (ES: 0.20-0.53; $p<.001)$; the attackers from group 3 (29-34.9 years) had fewer ground challenges (ES: $0.13-0.40 ; p<.001)$ and fouls commitment (ES: 0.12-0.39; $p<.001)$ (Table 6.5 ) than groups 2 and 4.

\subsection{Discussion}

This paper aims to study the technical-tactical and physical performance changes in elite soccer players according to their age and playing positions. The main findings of the present study support the hypothesis that players' match demands (physical capacity and technical ability) show different trends in the different age groups for the different playing positions. Players from different positions make up for their aging using different technical and physical behaviours (Sal de Rellan-Guerra et al., 2019).

\subsubsection{Defenders}

Central defenders and full-backs from older age groups covered less total distance (Figure 1). The older defenders (beyond 29 years) performed less high-intensity running distance, sprinting distance, sprinting distance, and sprinting percentage than younger players (Figure 1). These 
findings could be to a decrease in their physiological function (e.g., decrease VO2max beyond 30 years) (Botek, Krejci, McKune, \& Klimesova, 2016; Brooks, Fahey, \& White, 1996; Brown, Hughes, \& Tong, 2007; Gabbard, 1992). This fact may also be one of the reasons for that fewer older players play in the league as aging (group 4,6.0\%). The reduction in the physical variables could be makeup with the increase found in passes and forward passes, especially in defenders beyond 35 years (Figure 2). Older full-backs made more crosses than younger players did. The age-related decrease in physical capacity did not have a negative impact on their pass performance (pass accuracy).

The increase of passes could be attributed to the higher experience and training of players (game knowledge, anticipation, and tactical awareness). More forward passes and crosses indicate that experienced defenders could take more time to be focused on attacking. More experiences may lead to master technical performance skills, such as more forward pass distribution, more aerial challenges, higher aerial challenges accuracy, and fewer fouls (Figure 3).

Our findings are in accordance with previous research (Sal de Rellan-Guerra et al., 2019) which found that older central defenders ( $\geq 31$ years) performed lower physical performance in the first German league, while full-backs did not have less physical performance with aging which differs from this study. Probably, this divergence is because of different age groups distribution, different competition levels, and different playing styles in both studies.

The findings suggest that in order to have the ability to keep playing, players have to maintain high-intensity capacity (e.g., sprinting and power capacity) or increase their technical-tactical capacities (e.g., pass accuracy). In addition, except for defensive tasks, modern soccer requires the full-backs assist the attacking via more overlap sprints (Ade et al., 2016; Bush et al., 2015; Hughes et al., 2012), physical demands of full-backs are higher than central defenders. These could be the cause of the higher proportion of older players playing as central defenders. Coaches and managers need to consider the positive impact that players' experience can bring 
to the team and if this makeup for the possible decline in physical capacity caused by age (Sal de Rellan-Guerra et al., 2019).

\subsubsection{Midfielders}

Older midfielders covered less total distance, performed less high-intensity running, fewer high-intensity efforts, and less sprinting percentage than younger players, especially those under 35 years old (Figure 1). This tendency was also found by Sal de Rellan-Guerra et al. (2019). However, older midfielders made more passes, forward passes, crosses, and shots with similar accuracy than younger players (Figure 2). Wide midfielders reduce their pass accuracy when they are older (Figure 2). This reduction is consistent with previous studies (Sal de RellanGuerra et al., 2019). The midfielders' shooting accuracy increases when they are older. Experienced central midfielders seem to have a higher contribution to the attack (more passes, crosses, and shots). This information suggests that age may be a key factor in central midfielders' selection.

The wide midfielder role requires high physical capacity, especially during high-intensity actions (Ade et al., 2016). These physical demands could be behind the similar tendency that wide midfielders had with fullbacks. There are fewer wide midfielders as the age of the players increase. Previous studies have shown that the wide midfielder is a position that requires high physical capacities (e.g., high-intensity actions), higher speed of efforts, more repeated efforts, and driving inside the pitch at high-intensities (Ade et al., 2016). Midfielders cover significantly more total distance than other positions in a match (Bradley et al., 2009; Di Salvo et al., 2007; Di Salvo et al., 2009; Vigne, Gaudino, Rogowski, Alloatti, \& Hautier, 2010). This is related to their dual role in both offensive and defensive sequences of play (Mohr, Krustrup, \& Bangsbo, 2003). Midfielders also perform and complete more passes compared to other playing positions (Redwood-Brown, Bussell, \& Bharaj, 2012; Taylor et al., 2017).

Findings show how players of different ages can provide different approaches to midfield 
playing (central and wide positions). When recruiting players for this position, managers should consider aspects such as total distance, high-intensity efforts, passing and shooting accuracy to evaluate the midfielder's contribution to defence and offense.

\subsubsection{Attackers}

For attackers, high-intensity running, sprinting and their efforts decreased with age (Figure 1). These findings are in accordance with the trends of physiological development (Botek et al., 2016; Brooks et al., 1996; Brown et al., 2007; Gabbard, 1992). This reduction in the highintensity running distance affects their game strategy. Older players increased the total distance covered (players beyond 35 years), passes, and forward passes yet decreased their shots (Figure 2). This tendency could be related to the fact that they spend more time pressing the opponent and assisting attacks (e.g., backward running to receive the ball to assist the teammates to offense). Another possible explanation is that older attackers (beyond 35 years) that continue playing in the league maintain good physical capacity and have more experience which allows them to participate more in the game. Previous research has shown that sprints account for a higher proportion among attackers than among other positions (Vigne et al., 2010). In this playing position, the explosive/power elements of the game predominate over the endurance component (Bloomfield et al., 2007; Dendir, 2016).

Older attackers presented a higher percentage of successful shots, which is one of the most important factors for the success of the match (Lago-Ballesteros \& Lago-Peñas, 2010; Mao et al., 2017; Yue et al., 2014). This may be because their experience allows them to be able to choose a better position and find more space and time to shoot. With the increase in age and experience, the attackers participate more in the team's organization, through support and passing, and they had lower performance in their high-intensity activities (Sal de Rellan-Guerra et al., 2019). 


\subsection{Conclusion}

The findings show different trends for the different age groups according to playing position in physical and technical performance in CSL. For physical performance, the running performance of players decreased in the older age group, especially for high-intensity running. However, the older wide midfielders and attackers (beyond 30 years), who are still playing in the league, presented similar physical efforts. In possession-related technical performance, fullbacks and attackers performed more passes and forward passes, the older they got. Midfielders make more passes and crosses when they are near 30 years old. Midfielders and attackers have higher shooting ability when they are older. These tendencies show how players make up for their reduction in their physical performance. The results also indicate that maintaining the physical capacity is important to extend the sports career life of outfield soccer players, especially for fullbacks, wide midfielders, and attackers.

\subsection{Practical Application}

The study provides a normative profile for the different roles of elite professional players in technical and physical aspects in the Chinese Soccer Super League. These reference values could help coaches, especially those from Asian football teams, to monitor the training of players from different age groups. For players, they could acknowledge this information to understand how they could manage their playing strategy in advance or even consider the need to change their playing position. For soccer club managers, data could help in a player's recruitment and transfer campaigns and to establish technical and physical performance goals for a player's contract.

\subsection{Limitations}

This study did not consider the players' experience, training situation or competition conditions, team playing formation, or playing styles. The design of the study was observational and crosssectional. Future studies should consider the evolution of the players using longitudinal studies. 


\subsection{References}

Ade, J., Fitzpatrick, J., \& Bradley, P. S. (2016). High-intensity efforts in elite soccer matches and associated movement patterns, technical skills and tactical actions. Information for position-specific training drills. Journal of Sports Sciences, 34(24), 2205-2214. doi:10.1080/02640414.2016.1217343

Al Haddad, H., Simpson, B. M., Buchheit, M., Di Salvo, V., \& Mendez-Villanueva, A. (2015). Peak match speed and maximal sprinting speed in young soccer players: effect of age and playing position. International Journal of Sports Physiology and Performance, 10(7), 888-896. doi:10.1123/ijspp.2014-0539

Allen, S. V., \& Hopkins, W. G. (2015). Age of Peak Competitive Performance of Elite Athletes: A Systematic Review. Sports Medicine, 45(10), 1431-1441. doi:10.1007/s40279-0150354-3

Batterham, A. M., \& Hopkins, W. G. (2006). Making Meaningful Inferences About Magnitudes. International Journal of Sports Physiology and Performance, 1(1), 50-57. doi:10.1123/ijspp.1.1.50

Berthelot, G., Len, S., Hellard, P., Tafflet, M., Guillaume, M., Vollmer, J. C., . . T Toussaint, J. F. (2012). Exponential growth combined with exponential decline explains lifetime performance evolution in individual and human species. Age (Dordr), 34(4), 1001-1009. doi:10.1007/s11357-011-9274-9

Bloomfield, J., Polman, R., \& O'Donoghue, P. (2007). Physical demands of different positions in FA Premier League soccer. Journal of Sports Science \& Medicine, 6(1), 63-70.

Botek, M., Krejci, J., McKune, A. J., \& Klimesova, I. (2016). Somatic, Endurance Performance and Heart Rate Variability Profiles of Professional Soccer Players Grouped According to Age. J Hum Kinet, 54(1), 65-74. doi:10.1515/hukin-2016-0035

Bradley, P. S., Sheldon, W., Wooster, B., Olsen, P., Boanas, P., \& Krustrup, P. (2009). Highintensity running in English FA Premier League soccer matches. Journal of Sports Sciences, 27(2), 159-168. doi:10.1080/02640410802512775

Brooks, G. A., Fahey, T. D., \& White, T. P. (1996). Exercise physiology: Human bioenergetics and its applications: Mayfield publishing company.

Brown, P. I., Hughes, M. G., \& Tong, R. J. (2007). Relationship between $\mathrm{VO}^{\wedge}$ sub $2 \mathrm{max}^{\wedge}$ and repeated sprint ability using non-motorised treadmill ergometry. Journal of Sports Medicine and Physical Fitness, 47(2), 186.

Bush, M., Barnes, C., Archer, D. T., Hogg, B., \& Bradley, P. S. (2015). Evolution of match 
performance parameters for various playing positions in the English Premier League. Human Movement Science, 39, 1-11. doi:10.1016/j.humov.2014.10.003

Carling, C., Bloomfield, J., Nelsen, L., \& Reilly, T. (2008). The role of motion analysis in elite soccer: contemporary performance measurement techniques and work rate data. Sports Medicine, 38(10), 839-862. doi:10.2165/00007256-200838100-00004

Cohen, J. (2013). Statistical power analysis for the behavioral sciences: Routledge.

Dellal, A., Wong, D., Moalla, W., \& Chamari, K. (2010). Physical and technical activity of soccer players in the French First League - with special reference to their playing position. International Sportmed Journal, 11(2), 278-290.

Dendir, S. (2016). When do soccer players peak? A note. Journal of Sports Analytics, 2(2), 89105. doi:10.3233/jsa-160021

Di Salvo, V., Baron, R., Tschan, H., Calderon Montero, F. J., Bachl, N., \& Pigozzi, F. (2007). Performance characteristics according to playing position in elite soccer. International Journal of Sports Medicine, 28(3), 222-227. doi:10.1055/s-2006-924294

Di Salvo, V., Gregson, W., Atkinson, G., Tordoff, P., \& Drust, B. (2009). Analysis of high intensity activity in Premier League soccer. International Journal of Sports Medicine, 30(3), 205-212. doi:10.1055/s-0028-1105950

Gabbard, C. (1992). Lifelong motor development: Brown \& Benchmark Madison, WI.

Hughes, M., Caudrelier, T., James, N., Donnelly, I., Kirkbride, A., \& Duschesne, C. (2012). Moneyball and soccer - an analysis of the key performance indicators of elite male soccer players by position. Journal of Human Sport and Exercise, 7(2), 402-412. doi:10.4100/jhse.2012.72.06

Kalen, A., Rey, E., de Rellan-Guerra, A. S., \& Lago-Penas, C. (2019). Are Soccer Players Older Now Than Before? Aging Trends and Market Value in the Last Three Decades of the UEFA Champions League. Frontiers in Psychology, 10, 76. doi:10.3389/fpsyg.2019.00076

Lago-Ballesteros, J., \& Lago-Peñas, C. (2010). Performance in Team Sports: Identifying the Keys to Success in Soccer. Journal of Human Kinetics, 25(1), 85-91. doi:10.2478/v10078-010-0035-0

Mao, L., Peng, Z., Liu, H., \& Gómez, M.-A. (2017). Identifying keys to win in the Chinese professional soccer league. International Journal of Performance Analysis in Sport, 16(3), 935-947. doi:10.1080/24748668.2016.11868940

McCormack, W. P., Hoffman, J. R., Pruna, G. J., Scanlon, T. C., Bohner, J. D., Townsend, J. R., ... Fukuda, D. H. (2015). Reduced high-intensity-running rate in collegiate women's 
soccer when games are separated by 42 hours. International Journal of Sports Physiology and Performance, 10(4), 436-439. doi:10.1123/ijspp.2014-0336

Mendez-Villanueva, A., Buchheit, M., Kuitunen, S., Douglas, A., Peltola, E., \& Bourdon, P. (2011). Age-related differences in acceleration, maximum running speed, and repeatedsprint performance in young soccer players. Journal of Sports Sciences, 29(5), 477-484. doi:10.1080/02640414.2010.536248

Mohr, M., Krustrup, P., \& Bangsbo, J. (2003). Match performance of high-standard soccer players with special reference to development of fatigue. Journal of Sports Sciences, 21(7), 519-528. doi:10.1080/0264041031000071182

Redwood-Brown, A., Bussell, C., \& Bharaj, H. S. (2012). The impact of different standards of opponents on observed player performance in the English Premier League. Journal of Human Sport and Exercise, 7(2), 341-355. doi:10.4100/jhse.2012.72.01

Reilly, T. (2003). Motion analysis and physiological demands. In Science and soccer (pp. 6780): Routledge.

Rommers, N., Mostaert, M., Goossens, L., Vaeyens, R., Witvrouw, E., Lenoir, M., \& D'Hondt, E. (2019). Age and maturity related differences in motor coordination among male elite youth soccer players. Journal of Sports Sciences, 37(2), 196-203. doi:10.1080/02640414.2018.1488454

Sal de Rellan-Guerra, A., Rey, E., Kalen, A., \& Lago-Penas, C. (2019). Age-related physical and technical match performance changes in elite soccer players. Scandinavian Journal of Medicine and Science in Sports, 29(9), 1421-1427. doi:10.1111/sms.13463

Salinero, J. J., Gonzalez-Millan, C., Gutierrez, D., Abian-Vicen, J., Burillo, P., \& Coso, J. d. (2019). Age-related trends in anthropometry and jump and sprint performances in elite soccer players from 13 to 20 years of age: A cross-sectional study. Journal of Human Sport and Exercise, 14(4). doi:10.14198/jhse.2019.144.06

Sarmento, H., Marcelino, R., Anguera, M. T., CampaniCo, J., Matos, N., \& LeitAo, J. C. (2014). Match analysis in football: a systematic review. Journal of Sports Sciences, 32(20), 1831-1843. doi:10.1080/02640414.2014.898852

Saward, C., Morris, J. G., Nevill, M. E., Nevill, A. M., \& Sunderland, C. (2016). Longitudinal development of match-running performance in elite male youth soccer players. Scandinavian Journal of Medicine and Science in Sports, 26(8), 933-942. doi:10.1111/sms. 12534

Taylor, J. B., Mellalieu, S. D., \& James, N. (2017). Behavioural comparisons of positional demands in professional soccer. International Journal of Performance Analysis in Sport, 
4(1), 81-97. doi:10.1080/24748668.2004.11868294

Vigne, G., Gaudino, C., Rogowski, I., Alloatti, G., \& Hautier, C. (2010). Activity profile in elite Italian soccer team. International Journal of Sports Medicine, 31(5), 304-310. doi:10.1055/s-0030-1248320

Yue, Z., Broich, H., \& Mester, J. (2014). Statistical Analysis for the Soccer Matches of the First Bundesliga. International Journal of Sports Science \& Coaching, 9(3), 553-560. doi:10.1260/1747-9541.9.3.553

Zhou, C., Zhang, S., Lorenzo, A., \& Cui, Y. (2018). Chinese soccer association super league, 2012-2017: key performance indicators in balance games. International Journal of Performance Analysis in Sport, 18(4), 645-656. doi:10.1080/24748668.2018.1509254

Zubillaga, A., Gorospe, G., Mendo, A., \& Villaseñor, A. (2007). Match analysis of 2005-06 champions league final with Amisco system. Journal of Sports Science \& Medicine, 6(10), 20. 


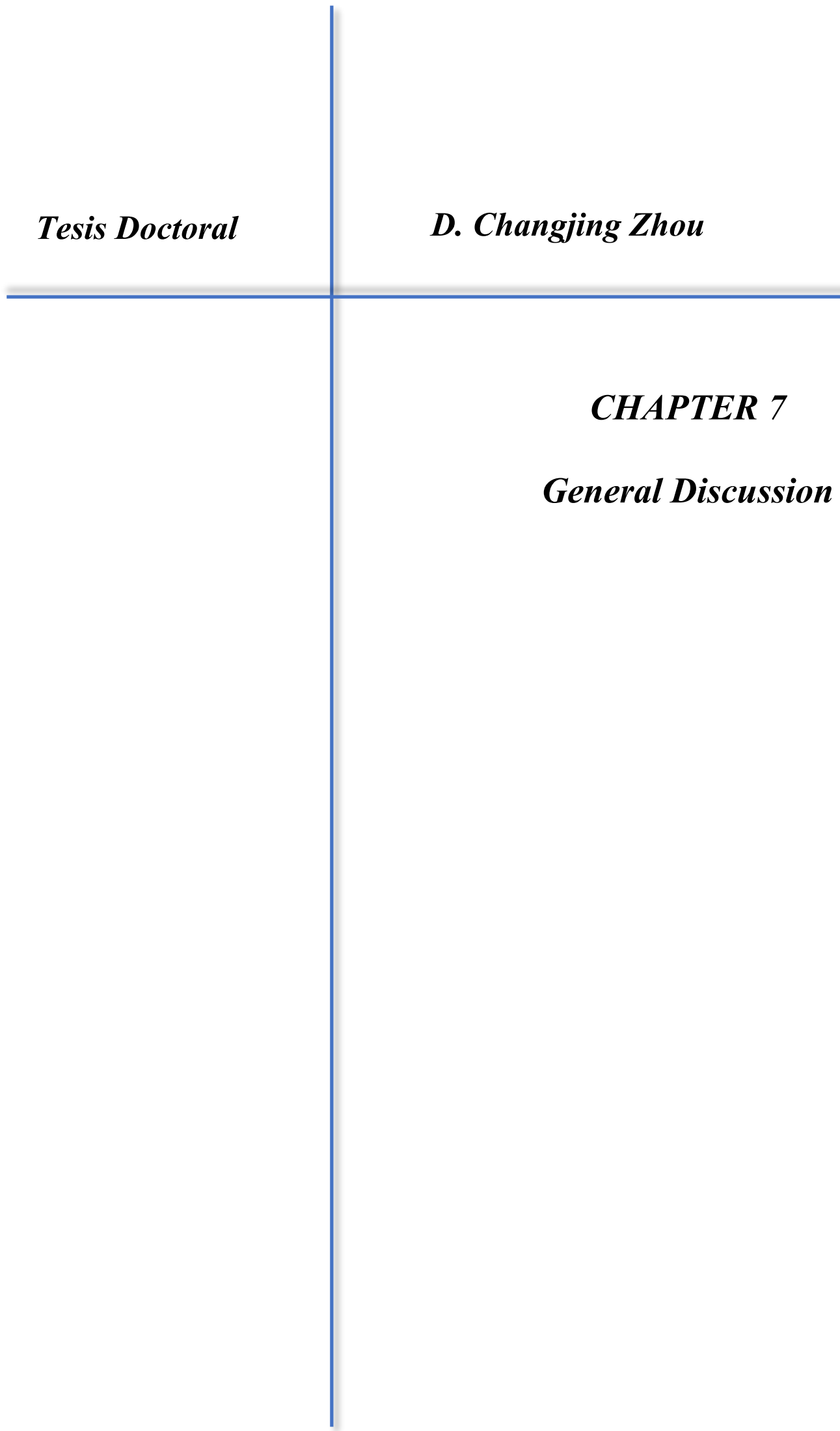




\section{Chapter 7 General discussion}

The general aim of this $\mathrm{PhD}$. thesis is to evaluate the match performance of soccer players and teams based on match-related statistics integrating with influencing factors (situational variables, environmental variables, player's age, player's playing position) in the CSL. The $\mathrm{PhD}$. thesis aimed to focus on the developing trends over a number of seasons and the potential causes. To achieve the aims of this research, this $\mathrm{PhD}$. thesis can be mainly summarized into the five interlinking Chapters from Chapter 2 to Chapter 6 and separated into three sections, each section focusing on a different aspect of the soccer performance analysis in Chinese soccer super league.

This Chapter of the thesis summarizes and links together the main findings from each section. Finally, the limitations and future directions of the studies in this $\mathrm{PhD}$. thesis are discussed in depth.

\subsection{Summary and discussion of Main Findings}

\subsubsection{Section 1 - The indicators discriminated match outcome (Chapter 2)}

From the team perspective, the performance indicators of teams that best discriminated match outcome in balance games were identified in Chapter 2. The results identified thirteen variables that differed between winning, drawing and losing teams, while in the subsequent discriminant analysis, only five variables were found to discriminate different match outcomes: shots on target, sprinting distance in ball possession, quality of opposition, passes and forward passes. It is worth to note that we standardized some ball possession-related variables with the percentage of ball possession in this study. We must admit that this approach will mask the authenticity of the data in some ways. On the other hand, we can see the density of each indicator in a match. This density can indicate how much the team has done in a unit of time (Leontijević, Janković, \& Tomić, 2019; Liu et al., 2015).

The increased popularity of counterattacking playing style has forced us to consider offensive 
efficiency. In the technical perspective, our findings are in line with the studies that showed that shots on target had the greatest discriminatory power to differentiate the match outcome (Castellano et al., 2012; Lago-Peñas et al., 2010; Mao et al., 2017; Rampinini et al., 2009; Szwarc, 2004). Both in total time and unit time, the number of shots on target have substantially positive affected the probability of winning. In the physical perspective, sprinting distance in possession of the ball can differentiate the match outcome. This means that, regardless of the percentage of the ball possession, more frequent, higher density sprints are more likely to improve the team's chances of winning. Especially during the counter-attacking process, more sprint runs by players in unit time can create opportunities for the team to score goals. This information shows that, especially in the balance game, improving offensive efficiency is the point we should pay more attention to.

Although the match location and the quality of opposition have a separate impact on the match outcome (Lago-Peñas et al., 2011), they also influence each other when they affect the match outcome (Lago-Penas \& Lago-Ballesteros, 2011; Mao et al., 2017). In this study, only the quality of opposition can discriminate the match outcome. It indicated that the quality of opposition is the more important index that affects the match outcome when both the home advantage and the opponent's quality are taken into account in the CSL. Home advantage can only bring about a match win if it can reinforce the various technical and tactical indicators that determine a match outcome. This conversion of home field advantage into game winning has to do with the quality of the team (Gómez, Mitrotasios, Armatas, \& Lago-Peñas, 2018). In this study, we explored key performance indicators and two-situational variables (match location and quality of opposition) that can determine the outcome of a match. However, we did not take into account the impact of situational factors on the performance indicators. 


\subsubsection{Section 2 - Influence of situational and environmental variables (Chapter 3)}

Existing performance analysis has provided preliminary information on the effects of situational variables (match location, match status, quality of the opponent and game period) on soccer match performance (Almeida et al., 2014; Aquino et al., 2017; Gómez et al., 2014; Gomez et al., 2013; Lago, 2009; Lago et al., 2010). Little research considered the effect of environmental-related variables (temperature, humidity, air pollution) on match performance (Chmura et al., 2017; Loxston, Lawson, \& Unnithan, 2019; Nassis et al., 2015; Rundell, 2012; Trewin et al., 2017). However, no study considered the influence of situational and environmental variables together, which leads identifying the influence of situational and environmental factors on the technical and physical performance of the CSL soccer teams. Our results show that situational variables (team and opponent's relative strength, match location) had major effects on the technical performance but trivial effects on the physical performance in the CSL; on the contrary, environmental factors affected mainly the physical performance but had only trivial or small effects on the technical performance. Specifically, increase in the rank difference (a better team vs a worse opponent) would increase shot, shot on target, possession, possession in opponent half, pass, pass accuracy, forward pass, forward pass accuracy, opponent $35 \mathrm{~m}$ entry, opponent penalty area entry, cross, corner, offside, and 50-50 challenge won to a small-to-moderate extent. Meanwhile, it would decrease foul committed, yellow card and red card at a small magnitude. This is in accordance with previous studies (Bradley et al., 2014; Lago-Penas \& Lago-Ballesteros, 2011; Trewin et al., 2017; Varley et al., 2017), when playing against weaker teams, the stronger team made more attacking related actions (possession, shots, shots on target, crosses, passes, passing accuracy) and fewer defensive actions (tackles, yellow cards). Match location (playing at home compared to playing away) had positive small effects on shot, shot on target, possession, possession in opponent half, pass, forward pass, opponent 35m entry, opponent penalty area entry, cross, and corner, 
and a negative small effect on yellow card. Several authors have also shown that, in soccer, home teams generally play better than the away teams, making more shots, shots on target, performing better in shot accuracy and other offensive performance measures that are closely related to match success, meanwhile achieving fewer match actions and events related to defending (Liu et al., 2017; Seckin \& Pollard, 2008). No meaningful differences were observed in high-intensity distance and total distance covered by teams in matches playing at home and playing away, this is consistent with the observation from Castellano et al. (2011). We could hence conclude that home advantage in the CSL only existed in the technical performance, but not physical aspects.

We found that an increase in humidity would decrease the physical performance-related parameters with a small magnitude. Due to the high moisture content in the high humidity, it was much harder for body heat to be lost by sweat evaporation (Brewer \& Warren, 2014; Chmura et al., 2017). This puts stress on the blood circulation system and the skeletal muscle system, which affects physical performance in the match. CSL teams achieved the most shot, forward pass, offside, foul committed, physical-related performance at temperatures varying from $10.6-22{ }^{\circ} \mathrm{C}$. This indicated that there may be a temperature comfort zone to promote soccer players' performance, especially in physical-related performance. Our findings are in accordance with exciting studies (Chmura et al., 2017; Link \& Weber, 2017). Too high or too low temperature will affect the normal physiological response during exercise, therefore decrease the physical performance of football players (Chmura et al., 2017; Doubt, 1991; Nassis et al., 2015; Nybo \& Secher, 2004; Sink et al., 1989).

Our results showed that an increase in AQI would likely bring a small increment in the physical performance-related parameters and would be most unlikely to bring a decrease of physical performance. This information is contrary to the previous findings (Boussetta et al., 2017), which demonstrated that air pollution would decrease the physical performance of soccer 
players. The current finding that the increment of physical performance in high AQI can be interpreted by the fact that the protection against the vascular dysfunction associated with particulate matter (PM) inhalation could potentially improve exercise performance in high-PM conditions (Rundell, 2012). Although temporary AQI did not affect the soccer players' acute physical performance, the long-term impact of environmental pollution on the athlete's wellbeing is still under caution.

In China, the climate and air pollution differ from region to region because of the country's extensive and complex topography, which raise higher requirement for coaching staff when preparing the match.

By combining the Chapters 2 and 3, it is worth noting that match performance was influenced by the situational and environmental variables, either independently or interactively. Consequently, this $\mathrm{PhD}$. thesis emphasised the need for coaches and performance analysts to consider the potential interactive effects of situational variables during the assessment of tactical, technical and physical performances in the future research.

Although Chapter 2 has combined data over consecutive seasons to provide sufficiently large sample sizes for analysis, combining data collected over a number of seasons may act as masking or confounding factors as both physical and technical performance evolves over time (Bush, 2017).

\subsubsection{Section 3 - The evolution of match performance parameters (Chapter 4,5} and 6)

The main aim of this section was to assess the evolution of technical and physical match performance in the CSL over six seasons, thus analysing whether the influence of key performance indictors on the match outcome changed over seasons. In accordance with previous studies (Barnes et al., 2014; Bush, 2017), the total distance covered during a match remained constant, while high-intensity running distances (sprinting and high-speed running) 
increased over six seasons in the CSL. These changes in physical performance may potentially be caused by some reasons: changes in the physical and physiological characteristics of soccer players (Haugen, Tonnessen, \& Seiler, 2013), stoppages increased in play (Wallace \& Norton, 2014), international transfers of players (Bush et al., 2016). Furthermore, we cannot ignore the influence of the findings of academic research that professional clubs are applying these results to improve teams' and players' performance (Bush, 2017). Regarding technical performance parameters, the number of shots on target increased over six seasons. This may result from better player recruitment, both in physical and technical terms, as well as improved tactics due to the influence of experienced coaches (e.g., team coaches, trainers, or managers). The number of opponent penalty area entries increased over six seasons in the CSL. This result may imply that once the team controlled the ball in the opponent's half (including recovering the ball in this area), they tried their best to pass the ball into the opponent's penalty area via more forward passes or crosses.

As the indicators evolve over seasons, the role of indicators in the competition is constantly changing. Chapter 4 pointed that key performance indicators in different seasons were not same. Specifically, there were six significant variables (Shots on target, possession, total distance in possession of the ball, total distance out of ball possession, match location and quality of opposition) that exerted a meaningful influence on winning the match in all the seasons and every variables plays a different role across six seasons. A possible explanation would be that the game styles of the team were constantly evolving over seasons as a result of players physical capacity improvement, recruitment of better players and coaches (Barnes et al., 2014; Bush et al., 2016; Bush et al., 2015).

As one of the most important key performance indicators, the number of shots on target has always been an important indicator to influence the match results (Lago-Ballesteros \& LagoPeñas, 2010; Lago-Peñas et al., 2010; Mao et al., 2017; Yang et al., 2018). Although the role 
of shots on target on winning the match has declined from 2012 to 2014 season, it has rebounded and stabilized in recent years. The advantage of these foreign attackers in offense, especially in shooting skills, may be the cause of the increased role of shots on target on winning the match in recent years (Gai et al., 2019). Different from results of Chapter 2, possession is a factor affecting the match outcome positively. It is arguable whether the possession is a key performance indicator in determining the match outcome (Collet, 2013; Kempe et al., 2014; Lago-Peñas \& Dellal, 2010; Lago, 2009; Lago \& Martin, 2007). Percentage of possession plays a more important role in the match during the recent seasons. This maybe related that the recruitment of more outstanding foreign players and coaches could contribute to the development of possession-based playing strategies (Bush et al., 2017). This finding indicates that obtain and use more possession is essential to win the match in the CSL. Chassy (2013) demonstrated that speed and precision of passes generated positive match outcomes rather than the percentage of possession. However, Kempe et al. (2014) showed that not only the percentage of ball possession but also the variables related to the possession have an impact on the match outcome. Combining the result of Chapter 2, possession is not a key performance indicator when we standardized the data by percentage of possession. The different influence of possession on the match outcome in these studies may be related to the differences of match samples used, different variables selected and different methods of analysis. Further research on CSL should pay more attention on the relationship between possessions, passing patterns and offensive efficiency.

The causes of the seasonal change observed in this section must be multifaceted. For the player perspective, players' age is a factor that affects their performance profiles (Carling, Bloomfield, Nelsen, \& Reilly, 2008). Years of training and experience also influence the players' physical, skill, or cognitive development and, therefore, their competitive performance (Allen and Hopkins, 2015). Then, the composition of a player's age in a certain season may affect overall 
team performance of a football league. Chapter 6 showed that players' match demands (physical capacity and technical ability) show different trends according to age for the different playing positions. Players from different positions make up for their aging using different technical and physical behaviours (Sal de Rellan-Guerra, et al., 2019). One of the possible reasons is that higher experience, mental and physical changes brought about by the age are intertwined, leading to these changes in physical and technical demands in the CSL. The players performed fewer total distance covered, fewer high-intensity running, less high-intensity efforts, and less sprinting percentage than younger players. One of the reasons is that older players learn how to make better use of their physical abilities due to the increased understanding of sports-related knowledge and football tactics that comes with age. The reduction in physical aspects shows different degrees of decline in different playing positions, this difference may be a result of physical characteristics and demands in different playing position. For players under 35 years old, more forward passes and crosses taken by older players indicated that experienced fullbacks, midfielders and attackers could take more time to be focused on attacking. More experience may lead to master technical performance skills, such as more forward pass distribution, higher aerial challenges accuracy, and fewer fouls. The decrease in physical performance with age did not have a negative impact on their pass performance. The reduction in the physical variables could be makeup with the increase found in passes and forward passes, especially in defenders beyond 35 years. Coaches and managers need to consider the positive impact that players' experience can bring to the team and if this make up for the possible decline in physical performance (Sal de Rellan-Guerra et al., 2019). 


\subsection{Limitations}

Throughout this $\mathrm{PhD}$. thesis, there were a number of limitations associated with the studies as follows:

The first limitation is that balanced games (final score differences equal to or less than 2 goals) were selected as the research sample in the Chapter 2 because this filtering criterion can represent the highest level of competitiveness to the utmost extent in the CSL. Hence, the research results fail to provide evidence to underpin previous studies in the unbalanced game. Another limitation of this $\mathrm{PhD}$. thesis is that we have not considered the influence of different acclimatization (physiological adaptations) and fitness status of individual players, neither have we investigated the interactive effects of contextual and environmental factors. The air quality index values of our study were collected from the air quality monitoring stations nearest to the stadium, which might be not the most accurate real air quality index of the playing condition inside the stadium.

Final limitation of this $\mathrm{PhD}$ thesis is that when we evaluate the age influence on the match performance, it did not consider the players' experience, their training situation or competition condition, team playing formation, and playing styles.

\subsection{Future Directions}

Future research and applied practitioners need to be aware of the different methods that is used to analyse performance.

Given the fact that both physical and technical indicators have an impact on the match outcome, future research should focus on the interaction between physical and technical variables. Further research is needed into the causes (rule changed, foreign players' recruitment, playing style, etc.) of the seasonal increases observed in this $\mathrm{PhD}$. thesis.

It would be worthy to continue the work begun within this $\mathrm{PhD}$ thesis to investigate whether these increases in performance are continuing to be observed in the following seasons and 
whether continued exposure to high-intensity and high-quality coaching continues to help develop player's capabilities. Alternatively, does performance reach a plateau where players cannot increase physical and/or technical performance any further irrespective of the amount of coaching received or increased players' physical capacities?

Hence, further study could employ more accurate and direct measures to investigate the effects of long-term environmental conditions on the soccer match performance.

It is vital that future studies would be recommended to continue to further expand situational variables and to refine the interactive influences of these contextual variables on technical and physical performances according to playing position. 


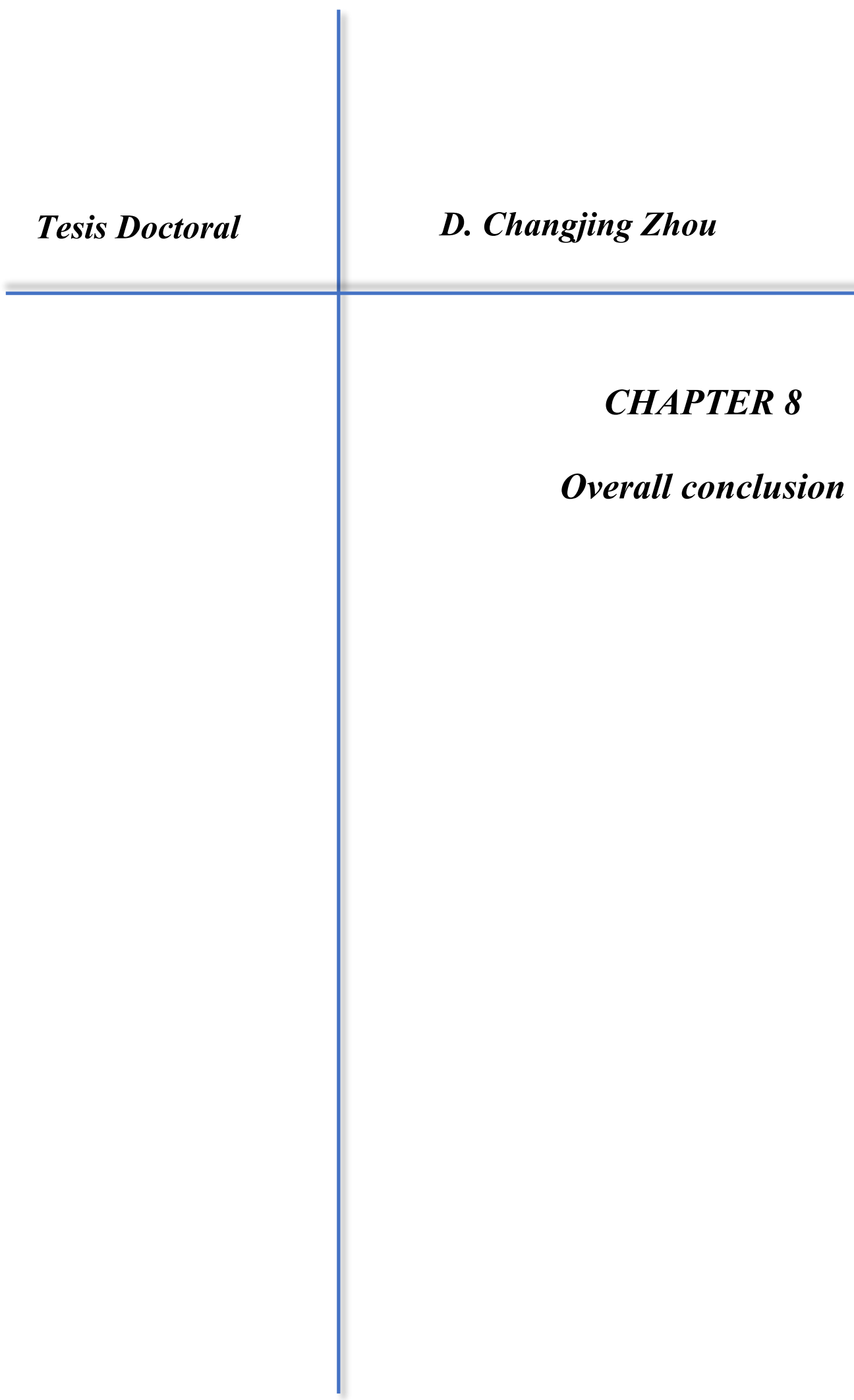




\section{Chapter 8 Overall conclusion}

\subsection{Overall conclusion}

The general aim of the $\mathrm{PhD}$. thesis is to evaluate the technical and physical performances from team and player perspectives in CSL, and the efficiency of situational variables (Match location, quality of opponent and match outcome), environmental variables (Air quality index, temperature and humidity), players' age also was taken into deep account. Combining the key findings from the entire $\mathrm{PhD}$. thesis chapters, theoretical recommendations and overall conclusions were established as follows:

The performance factors that best discriminate among winning, drawing and losing teams in the balance games of the CSL were the following: shots on target, sprinting distance in ball possession, quality of opposition, passes and forward passes. Winning teams have more shots on targets and more sprinting distance in ball possession than drawing and losing teams, winning and drawing teams have less passes and forward passes than drawing losing teams. Increase in the rank difference (a better team vs a worse opponent) would substantially increases shot, shot on target, possession, possession in opponent half, pass, pass accuracy, forward pass, forward pass accuracy, opponent 35m entry, opponent penalty area entry, cross, corner, offside, and 50-50 challenge won to a small-to-moderate extent. Meanwhile, it would decrease foul committed, yellow card and red card at a small magnitude. Match location (playing at home compared to playing away) had positive small effects on shot, shot on target, possession, possession in opponent half, pass, forward pass, opponent $35 \mathrm{~m}$ entry, opponent penalty area entry, cross, and corner, and a negative small effect on yellow card. There may be an ambient temperature comfort zone $\left(10.6-22{ }^{\circ} \mathrm{C}\right)$ to promote soccer performance (shots, forward pass, outside, foul committed, total distance, sprinting distance, sprinting effort, high-speed-running distance, high-speed-running effort, high-intensity-running distance and high-intensity-running effort), and higher or lower temperature may impair soccer match performance. An increase in 
humidity would decrease the physical performance-related parameters (total distance, sprinting distance, sprinting effort, high-speed-running distance, high-speed-running effort, highintensity-running distance and high-intensity-running effort) with a small magnitude. Interestingly, an increase in AQI would likely bring a small increment in the physical performance-related parameters (total distance, sprinting distance, sprinting effort, high-speedrunning distance, high-speed-running effort, high-intensity-running distance and highintensity-running effort) and would most unlikely cause a decrease.

Physical performance, especially high-intensity running distances, together with technical performance parameters, such as crosses, shots on target, and opponent penalty area entries, have increased over six seasons in the CSL. The influence of various factors exerts on match outcome change over six seasons. Shots on target, possession, total distance in ball possession, total distance out of ball possession, and match location exerted a decreased influence on winning the game from 2012 to 2014 season. However, these variables have a more powerful role when winning the match from 2014 to 2017 season. Lastly, the quality of opposition has a continuously increased negative influence on the match outcome.

There are different trends with aging according to playing position in physical and technical performance. In physical performance, the running performance of players decreased with advancing age, especially for high-intensity running. However, the older wide midfielders and attackers (beyond 30 years) who are still playing in the league presented similar physical efforts. In possession-related technical performance, full-backs and attackers performed more passes and forward passes, as advancing age. Midfielders take more passes and crosses when they are near 30 years old. Midfielders and attackers have higher number of shots and shot accuracy when they are older.

\subsection{Practical application}

These results have important applications in some aspects: the results can be used to set 
performance normative profiles, both within a team and players, thus identifying the weakness of them in specific performance. In addition, this information is valuable for medical staff at clubs, identifying when a player is able to perform to the standard required to fit back into training and/or matches following injury. Knowledge regarding evolutionary patterns can help club managers in talent identification and recruitment perspectives, identifying players who perform within the expected boundaries of a team, and should therefore be able to perform to the coach's desire. The current results could also be used to compare the current situation in Chinese soccer with that in developed soccer leagues internationally.

To win the match, teams should find ways to get more possession, for example, running more to regain possession quickly when the opponent is in ball possession. When the team is in ball possession, more shots on target should be taken through fewer passes as well as forward passes to get the ball into the goal area, combined with more sprint runs. With the increased physical demands of the match on players, coaches should set up physical training to specifically improve the running ability of players, especially in high intensity running. Considering match location and quality of opposition have a huge influence on the match outcome and match performance of players. The coaching staff should set up some targeted training (e.g., psychological skill) in order to improve the stability of player's performance in home and away and analyse the playing patterns of the opponent, formulating the corresponding match strategy and practice in advance. 


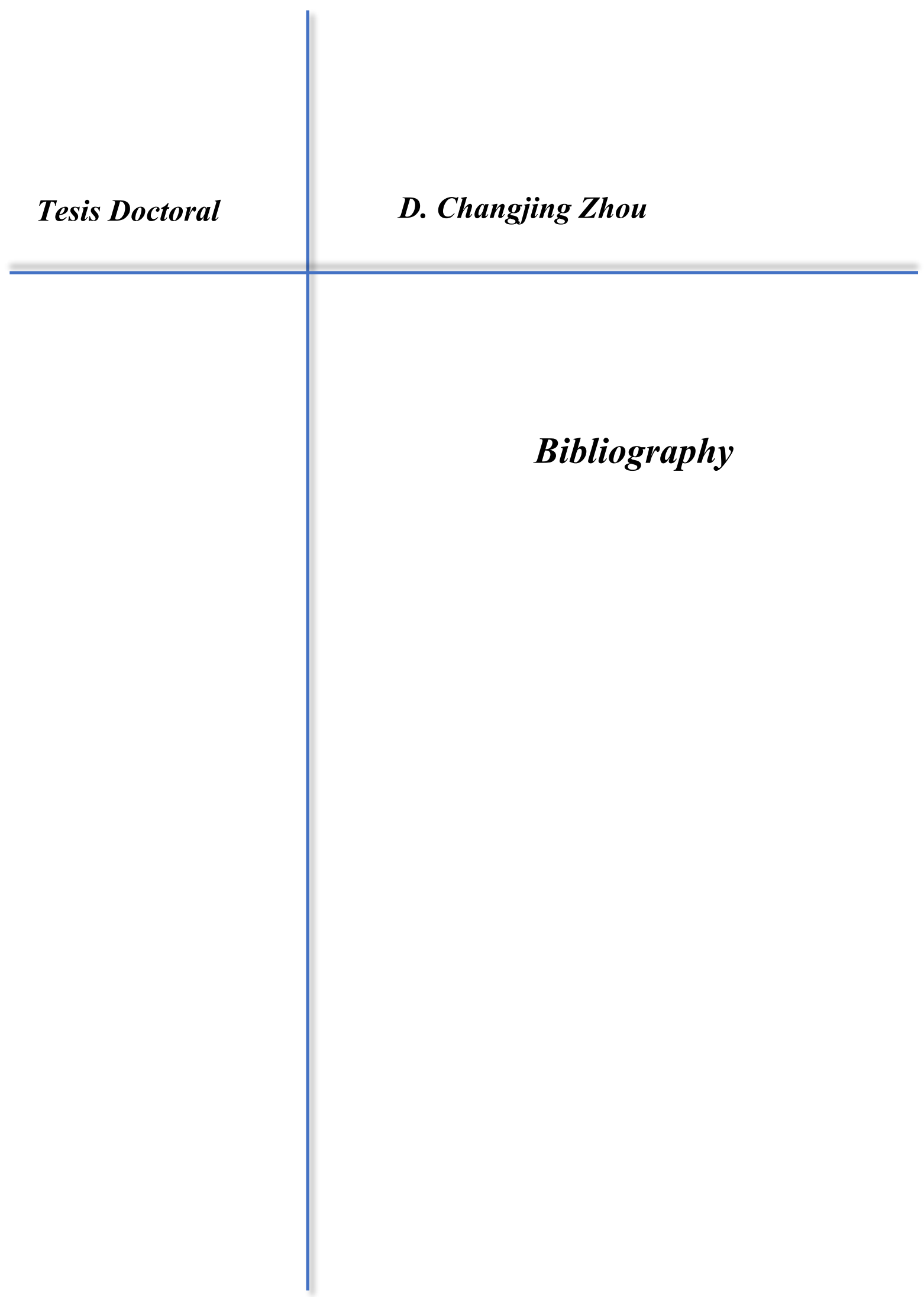




\section{Bibliography}

Al Haddad, H., Simpson, B. M., Buchheit, M., Di Salvo, V., \& Mendez-Villanueva, A. (2015). Peak match speed and maximal sprinting speed in young soccer players: effect of age and playing position. International Journal of Sports Physiology and Performance, 10(7), 888-896. doi:10.1123/ijspp.2014-0539

Allen, S. V., \& Hopkins, W. G. (2015). Age of Peak Competitive Performance of Elite Athletes: A Systematic Review. Sports Medicine, 45(10), 1431-1441. doi:10.1007/s40279-0150354-3

Almeida, C. H., Ferreira, A. P., \& Volossovitch, A. (2014). Effects of Match Location, Match Status and Quality of Opposition on Regaining Possession in UEFA Champions League. J Hum Kinet, 41(1), 203-214. doi:10.2478/hukin-2014-0048

Aquino, R., Munhoz Martins, G. H., Palucci Vieira, L. H., \& Menezes, R. P. (2017). Influence of Match Location, Quality of Opponents, and Match Status on Movement Patterns in Brazilian Professional Football Players. Journal of Strength and Conditioning Research, 31(8), 2155-2161. doi:10.1519/JSC.0000000000001674

Barnes, C., Archer, D. T., Hogg, B., Bush, M., \& Bradley, P. S. (2014). The evolution of physical and technical performance parameters in the English Premier League. International Journal of Sports Medicine, 35(13), 1095-1100. doi:10.1055/s-00341375695

Berthelot, G., Len, S., Hellard, P., Tafflet, M., Guillaume, M., Vollmer, J. C., . . Toussaint, J. F. (2012). Exponential growth combined with exponential decline explains lifetime performance evolution in individual and human species. Age (Dordr), 34(4), 1001-1009. doi:10.1007/s11357-011-9274-9

Boussetta, N., Abedelmalek, S., Aloui, K., \& Souissi, N. (2017). The effect of air pollution on diurnal variation of performance in anaerobic tests, cardiovascular and hematological parameters, and blood gases on soccer players following the Yo-Yo Intermittent Recovery Test Level-1. Chronobiology International, 1-18.

Bradley, P. S., Archer, D. T., Hogg, B., Schuth, G., Bush, M., Carling, C., \& Barnes, C. (2016). Tier-specific evolution of match performance characteristics in the English Premier League: it's getting tougher at the top. Journal of Sports Sciences, 34(10), 980-987. doi:10.1080/02640414.2015.1082614

Bradley, P. S., Lago-Penas, C., Rey, E., \& Sampaio, J. (2014). The influence of situational variables on ball possession in the English Premier League. Journal of Sports Sciences, 
32(20), 1867-1873. doi:10.1080/02640414.2014.887850

Brewer, J., \& Warren, L. (2014). Review of the potential implications of hot and humid environmental conditions on soccer match-play performance. Int J Sci: Basic Appl Res, 15(1), 584-589.

Bush, M. (2017). Contemporary Factors Impacting Match Performances Of Elite Soccer Players: The Development And Evolution Of Performance In The English Premier League. University of Sunderland,

Bush, M., Archer, D. T., Barnes, C., Hogg, B., \& Bradley, P. S. (2016). Longitudinal match performance characteristics of UK and non-UK players in the English Premier League. Science and Medicine in Football, 1(1), 2-9. doi:10.1080/02640414.2016.1233347

Bush, M., Archer, D. T., Barnes, C., Hogg, B., \& Bradley, P. S. (2017). Longitudinal match performance characteristics of UK and non-UK players in the English Premier League. Science and Medicine in Football, 1(1), 2-9.

Bush, M., Barnes, C., Archer, D. T., Hogg, B., \& Bradley, P. S. (2015). Evolution of match performance parameters for various playing positions in the English Premier League. Human Movement Science, 39, 1-11. doi:10.1016/j.humov.2014.10.003

Carling, C., Bloomfield, J., Nelsen, L., \& Reilly, T. (2008). The role of motion analysis in elite soccer: contemporary performance measurement techniques and work rate data. Sports Medicine, 38(10), 839-862. doi:10.2165/00007256-200838100-00004

Carling, C., Williams, A. M., \& Reilly, T. (2005). Handbook of soccer match analysis: A systematic approach to improving performance: Psychology Press.

Castellano, J., Blanco-Villasenor, A., \& Alvarez, D. (2011). Contextual variables and timemotion analysis in soccer. International Journal of Sports Medicine, 32(6), 415-421. doi:10.1055/s-0031-1271771

Castellano, J., Casamichana, D., \& Lago, C. (2012). The Use of Match Statistics that Discriminate Between Successful and Unsuccessful Soccer Teams. J Hum Kinet, 31, 139-147. doi:10.2478/v10078-012-0015-7

Chassy, P. (2013). Team Play in Football: How Science Supports F. C. Barcelona's Training Strategy. Psychology, 04(09), 7-12. doi:10.4236/psych.2013.49A2002

Chmura, P., Konefal, M., Andrzejewski, M., Kosowski, J., Rokita, A., \& Chmura, J. (2017). Physical activity profile of 2014 FIFA World Cup players, with regard to different ranges of air temperature and relative humidity. International Journal of Biometeorology, 61(4), 677-684. doi:10.1007/s00484-016-1245-5

Collet, C. (2013). The possession game? A comparative analysis of ball retention and team 
success in European and international football, 2007-2010. Journal of Sports Sciences, 31(2), 123-136. doi:10.1080/02640414.2012.727455

Dendir, S. (2016). When do soccer players peak? A note. Journal of Sports Analytics, 2(2), 89105. doi:10.3233/jsa-160021

Di Salvo, V., Gregson, W., Atkinson, G., Tordoff, P., \& Drust, B. (2009). Analysis of high intensity activity in Premier League soccer. International Journal of Sports Medicine, 30(3), 205-212. doi:10.1055/s-0028-1105950

Doubt, T. J. (1991). Physiology of exercise in the cold. Sports Medicine, 11(6), 367-381. doi:10.2165/00007256-199111060-00003

Drust, B. (2010). Performance analysis research: Meeting the challenge. In: Taylor \& Francis.

Gai, Y., Leicht, A. S., Lago, C., \& Gomez, M. A. (2019). Physical and technical differences between domestic and foreign soccer players according to playing positions in the China Super League. Research in Sports Medicine, 27(3), 314-325. doi:10.1080/15438627.2018.1540005

Gómez, M.-Á., DelaSerna, A., Lupo, C., \& Sampaio, J. (2014). Effects of Situational Variables and Starting Quarter Score in the outcome of elite women's water polo game quarters. International Journal of Performance Analysis in Sport, 14(1), 73-83.

Gómez, M.-Á., Mitrotasios, M., Armatas, V., \& Lago-Peñas, C. (2018). Analysis of playing styles according to team quality and match location in Greek professional soccer. International Journal of Performance Analysis in Sport, 18(6), 986-997. doi:10.1080/24748668.2018.1539382

Gomez, M. A., Lago-Penas, C., \& Pollard, R. (2013). Situational Variables. In T. MCGARRY, P. O'DONOGHUE, \& J. SAMPAIO (Eds.), Routledge Handbook of sports performance analysis (pp. 259-269). London: Routledge.

Harrop, K., \& Nevill, A. (2017). Performance indicators that predict success in an English professional League One soccer team. International Journal of Performance Analysis in Sport, 14(3), 907-920. doi:10.1080/24748668.2014.11868767

Haugen, T. A., Tonnessen, E., \& Seiler, S. (2013). Anaerobic performance testing of professional soccer players 1995-2010. International Journal of Sports Physiology and Performance, 8(2), 148-156. doi:10.1123/ijspp.8.2.148

Hughes, M., \& Franks, I. (2005). Analysis of passing sequences, shots and goals in soccer. Journal of Sports Sciences, 23(5), 509-514.

Hughes, M., \& Franks, I. M. (2004). Notational analysis of sport: Systems for better coaching and performance in sport: Psychology Press. 
Hughes, M. D., \& Bartlett, R. M. (2002). The use of performance indicators in performance analysis. Journal of Sports Sciences, 20(10), 739-754.

Kalen, A., Rey, E., de Rellan-Guerra, A. S., \& Lago-Penas, C. (2019). Are Soccer Players Older Now Than Before? Aging Trends and Market Value in the Last Three Decades of the UEFA Champions League. Frontiers in Psychology, 10, 76. doi:10.3389/fpsyg.2019.00076

Kempe, M., Vogelbein, M., Memmert, D., \& Nopp, S. (2014). Possession vs. direct play: evaluating tactical behavior in elite soccer. International journal of sports science, 4(6A), 35-41. doi:10.5923/s.sports.201401.05

Lago-Ballesteros, J., \& Lago-Peñas, C. (2010). Performance in Team Sports: Identifying the Keys to Success in Soccer. Journal of Human Kinetics, 25(1), 85-91. doi:10.2478/v10078-010-0035-0

Lago-Peñas, C., \& Dellal, A. (2010). Ball Possession Strategies in Elite Soccer According to the Evolution of the Match-Score: the Influence of Situational Variables. Journal of Human Kinetics, 25(1), 93-100. doi:10.2478/v10078-010-0036-z

Lago-Penas, C., \& Lago-Ballesteros, J. (2011). Game location and team quality effects on performance profiles in professional soccer. Journal of Sports Science \& Medicine, $10(3), 465-471$.

Lago-Peñas, C., Lago-Ballesteros, J., Dellal, A., \& Gómez, M. (2010). Game-related statistics that discriminated winning, drawing and losing teams from the Spanish soccer league. Journal of Sports Science \& Medicine, 9(2), 288.

Lago-Peñas, C., Lago-Ballesteros, J., \& Rey, E. (2011). Differences in performance indicators between winning and losing teams in the UEFA Champions League. Journal of Human Kinetics, 27(1), 137-148. doi:10.2478/v10078-011-0011-3

Lago, C. (2009). The influence of match location, quality of opposition, and match status on possession strategies in professional association football. Journal of Sports Sciences, 27(13), 1463-1469. doi:10.1080/02640410903131681

Lago, C., Casais, L., Dominguez, E., \& Sampaio, J. (2010). The effects of situational variables on distance covered at various speeds in elite soccer. European Journal of Sport Science, 10(2), 103-109. doi:10.1080/17461390903273994

Lago, C., \& Martin, R. (2007). Determinants of possession of the ball in soccer. Journal of Sports Sciences, 25(9), 969-974. doi:10.1080/02640410600944626

Leontijević, B., Janković, A., \& Tomić, L. (2019). Attacking Performance Profile of Football Teams in Different National Leagues According to Uefa Rankings for Club 
Competitions. Facta Universitatis, Series: Physical Education and Sport, 697-708. doi:10.22190/fupes1804040621

Lichter, A., Pestel, N., \& Sommer, E. (2017). Productivity effects of air pollution: Evidence from professional soccer. Labour Economics, 48, 54-66.

Link, D., \& Weber, H. (2017). Effect of Ambient Temperature on Pacing in Soccer Depends on Skill Level. Journal of Strength and Conditioning Research, 31(7), 1766-1770. doi:10.1519/JSC.0000000000001013

Liu, H., Gomez, M. A., Lago-Penas, C., \& Sampaio, J. (2015). Match statistics related to winning in the group stage of 2014 Brazil FIFA World Cup. Journal of Sports Sciences, 33(12), 1205-1213. doi:10.1080/02640414.2015.1022578

Liu, H., Hopkins, W. G., \& Gomez, M. A. (2016). Modelling relationships between match events and match outcome in elite football. European Journal of Sport Science, 16(5), 516-525. doi:10.1080/17461391.2015.1042527

Liu, H., Yi, Q., Giménez, J.-V., Gómez, M.-A., \& Lago-Peñas, C. (2017). Performance profiles of football teams in the UEFA Champions League considering situational efficiency. International Journal of Performance Analysis in Sport, 15(1), 371-390. doi:10.1080/24748668.2015.11868799

Loxston, C., Lawson, M., \& Unnithan, V. (2019). Does environmental heat stress impact physical and technical match-play characteristics in football? Science and Medicine in Football, 1-7. doi:10.1080/24733938.2019.1566763

Mao, L., Peng, Z., Liu, H., \& Gómez, M.-A. (2017). Identifying keys to win in the Chinese professional soccer league. International Journal of Performance Analysis in Sport, 16(3), 935-947. doi:10.1080/24748668.2016.11868940

Mendez-Villanueva, A., Buchheit, M., Kuitunen, S., Douglas, A., Peltola, E., \& Bourdon, P. (2011). Age-related differences in acceleration, maximum running speed, and repeatedsprint performance in young soccer players. Journal of Sports Sciences, 29(5), 477-484. doi:10.1080/02640414.2010.536248

Nassis, G. P., Brito, J., Dvorak, J., Chalabi, H., \& Racinais, S. (2015). The association of environmental heat stress with performance: analysis of the 2014 FIFA World Cup Brazil. British Journal of Sports Medicine, 49(9), 609-613. doi:10.1136/bjsports-2014094449

Nybo, L., \& Secher, N. H. (2004). Cerebral perturbations provoked by prolonged exercise. Progress in Neurobiology, 72(4), 223-261. doi:10.1016/j.pneurobio.2004.03.005

O’Donoghue, P. (2005). Normative profiles of sports performance. International Journal of 
Performance Analysis in Sport, 5(1), 104-119.

Rampinini, E., Impellizzeri, F. M., Castagna, C., Coutts, A. J., \& Wisloff, U. (2009). Technical performance during soccer matches of the Italian Serie A league: effect of fatigue and competitive level. Journal of Science and Medicine in Sport, 12(1), 227-233. doi:10.1016/j.jsams.2007.10.002

Rommers, N., Mostaert, M., Goossens, L., Vaeyens, R., Witvrouw, E., Lenoir, M., \& D'Hondt, E. (2019). Age and maturity related differences in motor coordination among male elite youth soccer players. Journal of Sports Sciences, 37(2), 196-203. doi:10.1080/02640414.2018.1488454

Rundell, K. W. (2012). Effect of air pollution on athlete health and performance. British Journal of Sports Medicine, 46(6), 407-412. doi:10.1136/bjsports-2011-090823

Sal de Rellan-Guerra, A., Rey, E., Kalen, A., \& Lago-Penas, C. (2019). Age-related physical and technical match performance changes in elite soccer players. Scandinavian Journal of Medicine and Science in Sports, 29(9), 1421-1427. doi:10.1111/sms.13463

Salinero, J. J., Gonzalez-Millan, C., Gutierrez, D., Abian-Vicen, J., Burillo, P., \& Coso, J. d. (2019). Age-related trends in anthropometry and jump and sprint performances in elite soccer players from 13 to 20 years of age: A cross-sectional study. Journal of Human Sport and Exercise, 14(4). doi:10.14198/jhse.2019.144.06

Sarmento, H., Marcelino, R., Anguera, M. T., CampaniCo, J., Matos, N., \& LeitAo, J. C. (2014). Match analysis in football: a systematic review. Journal of Sports Sciences, 32(20), 1831-1843. doi:10.1080/02640414.2014.898852

Saward, C., Morris, J. G., Nevill, M. E., Nevill, A. M., \& Sunderland, C. (2016). Longitudinal development of match-running performance in elite male youth soccer players. Scandinavian Journal of Medicine and Science in Sports, 26(8), 933-942. doi:10.1111/sms.12534

Seckin, A., \& Pollard, R. (2008). Home advantage in Turkish professional soccer. Perceptual and Motor Skills, 107(1), 51-54. doi:10.2466/pms.107.1.51-54

Sink, K. R., Thomas, T. R., Araujo, J., \& Hill, S. F. (1989). Fat energy use and plasma lipid changes associated with exercise intensity and temperature. European Journal of Applied Physiology and Occupational Physiology, 58(5), 508-513.

Szwarc, A. (2004). EFFECTIVENESS OF BRAZILIAN AND GERMAN TEAMS AND THE TEAMS DEFEATED BY THEM DURING THE 17TH FIFA WORLD CUP. Kinesiology, 36(1).

Taylor, J. B., Mellalieu, S. D., James, N., \& Barter, P. (2010). Situation variable effects and 
tactical performance in professional association football. International Journal of Performance Analysis in Sport, 10(3), 255-269.

Taylor, J. B., Mellalieu, S. D., James, N., \& Shearer, D. A. (2008). The influence of match location, quality of opposition, and match status on technical performance in professional association football. Journal of Sports Sciences, 26(9), 885-895. doi:10.1080/02640410701836887

Trewin, J., Meylan, C., Varley, M. C., \& Cronin, J. (2017). The influence of situational and environmental factors on match-running in soccer: a systematic review. Science and Medicine in Football, 1(2), 183-194. doi:10.1080/24733938.2017.1329589

Tucker, W., Mellalieu, D. S., James, N., \& Taylor, B. J. (2005). Game location effects in professional soccer: A case study. International Journal of Performance Analysis in Sport, 5(2), 23-35.

Varley, M. C., Gregson, W., McMillan, K., Bonanno, D., Stafford, K., Modonutti, M., \& Di Salvo, V. (2017). Physical and technical performance of elite youth soccer players during international tournaments: influence of playing position and team success and opponent quality. Science and Medicine in Football, 1(1), 18-29.

Wallace, J. L., \& Norton, K. I. (2014). Evolution of World Cup soccer final games 1966-2010: game structure, speed and play patterns. Journal of Science and Medicine in Sport, 17(2), 223-228. doi:10.1016/j.jsams.2013.03.016

Yang, G., Leicht, A. S., Lago, C., \& Gomez, M. A. (2018). Key team physical and technical performance indicators indicative of team quality in the soccer Chinese super league. Research in Sports Medicine, 26(2), 158-167. doi:10.1080/15438627.2018.1431539

Zhang, S., Lorenzo, A., Gómez, M.-A., Mateus, N., Gonçalves, B., \& Sampaio, J. (2018). Clustering performances in the NBA according to players' anthropometric attributes and playing experience. Journal of Sports Sciences, 36(22), 2511-2520. doi:10.1080/02640414.2018.1466493

Zhou, C., Zhang, S., Lorenzo, A., \& Cui, Y. (2018). Chinese soccer association super league, 2012-2017: key performance indicators in balance games. International Journal of Performance Analysis in Sport, 18(4), 645-656. doi:10.1080/24748668.2018.1509254 


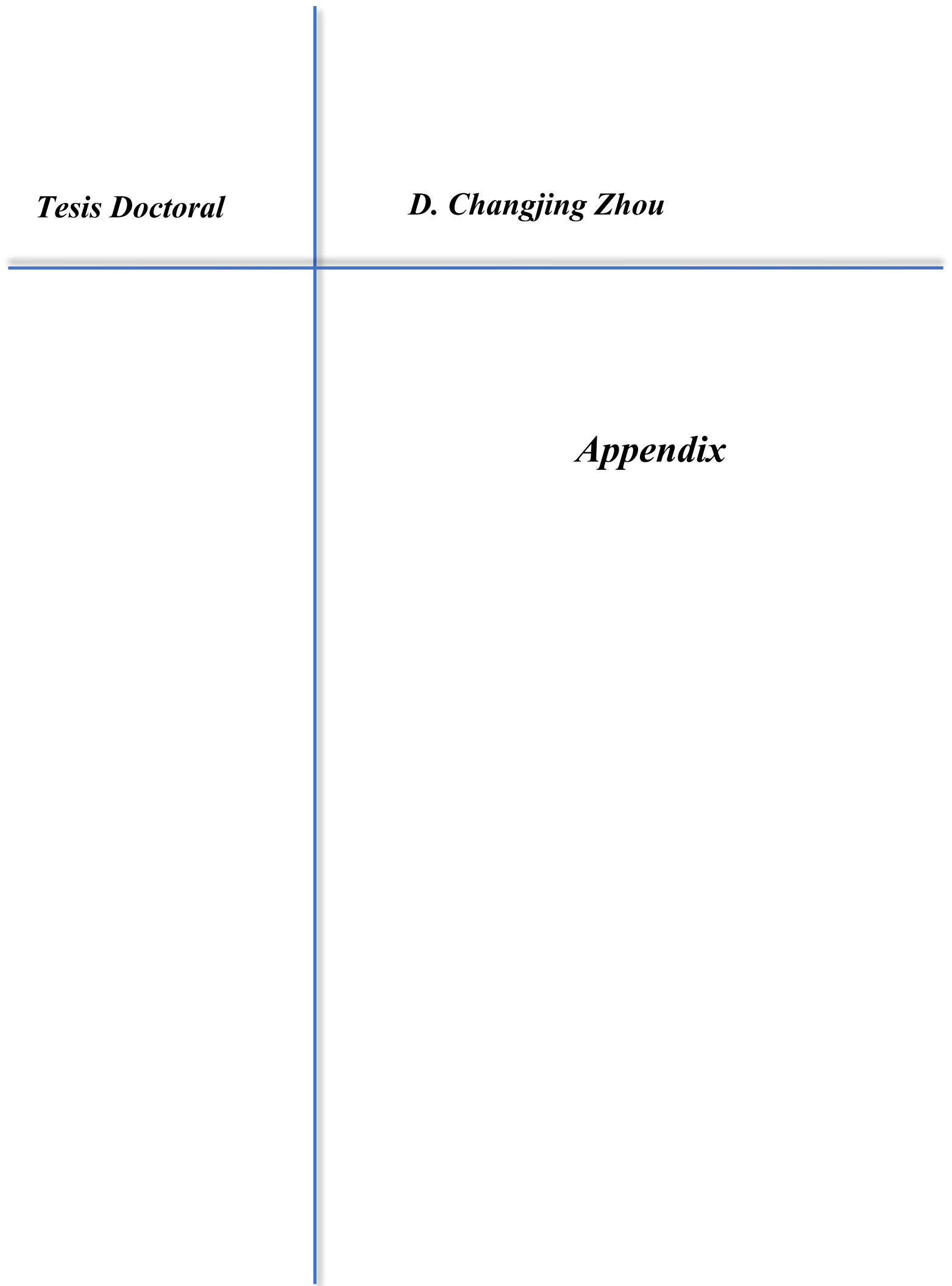




\section{Appendix}

- Publications and Conference Presentations

\section{Publications in scientific journals}

Zhou, C., Gómez, M. A, Lorenzo, A. (2020). The evolution of physical and technical performance parameters in Chinese Soccer Super League, Biology of sports. DOI: 10.5114/biolsport.2020.93039 (Published)

Zhou, C., Hopkins, W. G., Mao, W., Lorenzo, A., \& Liu, H. (2019). Match Performance of Soccer Teams in the Chinese Super League-Effects of Situational and Environmental Factors. International Journal of Environmental Research and Public Health, 16(21), 4238. doi:10.3390/ijerph16214238 (Published)

Zhou, C., Zhang, S., Lorenzo, A., \& Cui, Y. (2018). Chinese soccer association super league, 2012-2017: key performance indicators in balance games. International Journal of Performance Analysis in Sport, 18(4), 645-656. doi:10.1080/24748668.2018.1509254 (Published)

Zhou, C., Lorenzo, A., Gómez, M. A., \& Jose M, P. (2019). Players' match demands according to age and playing position in professional male soccer players, International Journal of Performance Analysis in Sport. doi:10.1080/24748668.2020.1753979 (Published)

Zhang, S., Lorenzo, A., Zhou, C., Cui, Y., Gonçalves, B., \& Gómez, M. A. (2019). Performance profiles and opposition interaction during game-play in elite basketball: evidences from National Basketball Association. International Journal of Performance Analysis in Sport, 19(1), 28-48. doi:10.1080/24748668.2018.1555738 (Published)

Zhou, C., Lorenzo, A., \& Gómez, M. A. (2020). Long-term trend analysis of playing styles in the Chinese Soccer Super League. Journal in human kinetics. (Under review)

Zhou, C., Lorenzo, A., Robertson, S., \& Gómez, M. A. (2020). Long-term influence of technical, physical performance indicators and situational variables on match outcome in male 
professional Chinese soccer, Journal of sports science. (Under review)

\section{Presentations in International Conferences}

Zhou, C., Lorenzo, A., Gómez, M.-A., Cui, Y., \& Shaoliang, Z. (2017). Physical Performance in Match of Teams in the Chinese Football Association Super League: Effects of Match Location, Period and Ball Possession Status. Complex Systems in Sport, International Congress Linking Theory and Practice. (Oral)

Zhou, C., Lorenzo, A., Gómez, M.-Á., \& Zhang, S. (2018). Match Performance profiles of strong teams and weak teams In Chinese Soccer Super League. $23^{\text {rd }}$ Annual Congress of the European College of Sport Science. (Mini Oral)

Zhou, C., Hopkins, W. G., Mao, W., \& Liu, H. (2019). Match Performance of Soccer Teams in the Chinese Super League-Effects of Situational and Environmental Factors. The Ninth World Congress on Science and Football. (Oral)

Gong, B., Gómez, M.-Á., Zhou, C. \&Cui, Y (2018). The variation in teams' match performance profiles according to league ranking in the Chinese Football Association Super League. XII World Congress of Performance Analysis of Sport. (Poster) 